Rolf Weder (Hrsg.)

\title{
Parallelimporte und der Schweizer Pharmamarkt
}


$\mathrm{D}$ as Europainstitut der Universität Basel ist ein rechts-, politik- und wirtschaftswissenschaftliches Zentrum für interdisziplinäre Lehre und Forschung zu europäischen Fragen. Neben einem einjährigen, praxisbezogenen und interdisziplinären Nachdiplomstudium zum Master of Advanced European Studies und dem Vertiefungsstudium Major in Conflict and Development werden spezielle Weiterbildungskurse angeboten. In der Forschung werden in Zusammenarbeit mit benachbarten Instituten sowohl fachspezifische wie multidisziplinäre Themen bearbeitet. Das Europainstitut ist als Ansprechpartner für Politik, Wirtschaft und Verwaltung beratend tätig.

Prof. Dr. Rolf Weder ist ordentlicher Professor für Ökonomie und europäische Integration an der Universität Basel, Leiter der Abteilung Aussenwirtschaft \& Europäische Integration am Wirtschaftswissenschaftlichen Zentrum (WWZ) und Dozent für Ökonomie am Europainstitut der Universität Basel.

Der vorliegende Band ist ein Druck der überarbeiteten Referate an der Tagung „Parallelimporte und der Schweizer Pharmamarkt“, die vom Europainstitut und dem WWZ-Forum organisiert und am 22. November 2004 in Basel durchgeführt wurde.

\section{Inhaltsverzeichnis}

Vorwort

BEGRÜSSUNG UND EINFÜHRUNG AUS

AUSSENWIRTSCHAFTLICHER SICHT

Von Prof. Dr. Rolf Weder

RECHTSLAGE UND HANDLUNGSSPIELRAUM

Von Dr. Felix Addor

PREISTREIBEND?

Von Rudolph H. Strahm

DIE SCHWEIZ UND DAS AUSLAND - KONZEPTIONELLE

ÜBERLEGUNGEN

Von Guido Barsuglia

PARALLELIMPORTE IN DIE SCHWEIZ

EMPIRISCHE RESULTATE

Von Dr. Stephan Vaterlaus

PHARMAINDUSTRIE SCHWEIZ

Von Thomas Cuen

DIE SPEZIALITÄTENLISTE

Von Dr. Reinhard Kämpf

AUS DEUTSCHLAND

ÖSTERREICHISCHE KLEINSTAAT-ERFAHRUNGEN

MIT PARALLELIMPORTEN 


\section{Vorwort}

„Soll die Schweiz am Parallelimportverbot für patentierte Güter und damit am Prinzip der nationalen Erschöpfung im Patentrecht festhalten?" Diese Frage wurde, bezogen auf den Schweizer Pharmamarkt, an einer gemeinsam vom Europainstitut und WWZ-Forum der Universität Basel durchgeführten Tagung im November 2004 diskutiert. Die Referate verschiedener Experten aus Beratung, Verwaltung, Wirtschaft und Wissenschaft im In- und Ausland sind in dieser Publikation in überarbeiter Form abgedruckt.

Die Fragestellung ist komplex, die Diskussion war und ist kontrovers, und eine Antwort bleibt mit einigen Unsicherheiten behaftet. Dies liegt daran, dass die Alternativen (regionale und internationale Erschöpfung des Patentrechtes) bezüglich ihrer wirtschaftlichen Auswirkungen und politischen Machbarkeit unterschiedlich beurteilt werden. Das unterschiedliche Urteil ergibt sich insbesondere daraus, dass die Mechanismen im Pharmamarkt durch die Koexistenz von zahlreichen (zum Teil intransparenten) Regulierungen im In- und Ausland in ihrer Gesamtwirkung momentan kaum wirklich erfasst werden können.

Der Bundesrat hat im Dezember 2004 aufgrund eines erneuten Berichtes, der sich speziell mit der Einführung der regionalen Erschöpfung auseinandersetzt, entschieden, am Parallelimportverbot für patentierte Güter festzuhalten. ${ }^{1}$ Damit wird die Diskussion aber kaum verstummen. Vor diesem Hintergrund dürften die Beiträge in diesem Band wertvoll bleiben. Dies vor allem deshalb, weil sie in kurzer Form die unterschiedlichen Standpunkte, jeweils betonten Problembereiche und individuellen Folgerungen aufzeigen.

Der Preisüberwacher, Rudolf Strahm, fasst die Situation zusammen mit „in unserem Land regulieren alle immer mit bestem Wissen und Gewis- 
sen im Sinne der Sicherheit (...), alle tun ihr Bestes, doch niemand denkt an den Preis", während der Generalsekretär der Interpharma, Thomas Cueni, umgekehrt bemängelt, dass man in der ganzen Diskussion um das Gesundheits- und Pharmawesen zu stark auf die Kosten und zu wenig auf den Nutzen hinweise. Die in diesem Band publizierten Beiträge geben weiter einen Einblick in eine Vielzahl von Aspekten, von denen hier einige aufgezählt werden sollen: Problematik der regionalen Erschöpfung (Felix Addor), Preisfestsetzung durch den Preisregulator (Reinhard Kämpf), Nutzen und Erfahrungen des Parallelimporteurs (Jörg Geller), Abschätzung der gesamtwirtschaftlichen Effekte einer Handelsliberalisierung für Pharmaprodukte (Guido Barsuglia, Stefan Vaterlaus), Behandlung von Parallelimporten in Österreich (Gernot Spanninger).

Ob Parallelimporte ein Zaubermittel gegen hohe Preise, für mehr Wettbewerb und mehr Wohlstand in der Schweiz sind, kann mit dieser Publikation (noch) nicht abschliessend beantwortet werden. Es gibt hier noch zu viele „Iose Enden“. ${ }^{2}$ Dazu gehört insbesondere auch die Frage, wie die regulierten Preise im In- und Ausland genau zustande kommen und ob bzw. wie diese Preise im Ausland durch eine Aufhebung des Parallelimportverbotes der Schweiz beeinflusst würden. Meines Erachtens ist die Beantwortung dieser Frage entscheidend für die Bewertung der sich aus einer Liberalisierung ergebenden Wohlfahrtseffekte auf die Schweiz. Und hier tragen m. E. die im Laufe der Tagung erwähnten Studien wenig zur Klärung bei.

Nicht unterschätzt werden darf der Informationsgehalt der hier veröffentlichten Beiträge hinsichtlich einer "grösseren Reform des Pharmamarktes“: eine Reform, die sich nicht „nur" der Frage widmet, welche Auswirkungen die Liberalisierung des internationalen Handels mit patentierten Pharmazeutika auf die Schweiz bei bestehenden Regulierungen hätte, sondern eine Reform, die sich mit der Optimierung und allenfalls Abschaffung von gewissen Produkt- und Preisregulierungen im In- und Ausland befasst. Dazu finden sich in mehreren Beiträgen Ideen und konkrete Vorschläge.

Ich danke den Referenten für ihr Engagement und ihre Bereitschaft, aktiv an der Tagung mitzuwirken und ihre Referatstexte für diese Publikation zu überarbeiten. Dank gebührt auch meinen Assistenten, Guido Barsuglia und Ulf Lewrick, für die inhaltliche und organisatorische Mitbetreuung der Tagung, sowie Ariane Schnueriger für das Erstellen der Textentwürfe auf der Basis von Tonbandaufnahmen und Didier Plaschy für die redaktionelle Begleitung bis zur Drucklegung.

Im April 2005

Rolf Weder

\section{Fussnoten:}

1 „Parallelimporte und Patentrecht: Regionale Erschöpfung“. Bericht des Bundesrates vom 3. Dezember 2004 in Beantwortung des Postulats der WAK-N (03.3423) sowie der Postulate 04.3164 und 04.3197.

2 Zweifel sind meines Erachtens berechtigt, wie ich dies im folgenden Artikel aufzuzeigen versuchte: „Parallelimporte - Ein Zaubermittel?“, Basler Zeitung, 28.2.2005, S. 19 . 


\section{BEGRÜSSUNG UND EINFÜHRUNG AUS AUSSENWIRTSCHAFTLICHER SICHT}

Prof. Dr. Rolf Weder, Wirtschaftswissenschaftliches Zentrum und Europainstitut, Universität Basel

Meine Damen und Herren,

ich möchte Sie kurz in die Thematik einführen, etwas übers Programm sagen und dann einige Überlegungen aus aussenwirtschaftstheoretischer und -politischer Sicht anstellen.

\section{Inhalt und Motivation dieser Tagung}

Wie Sie wissen hat der Inhaber eines patentgeschützten Produktes das exklusive Recht zu bestimmen, wann, wo und zu welchem Preis er sein Produkt zum ersten Mal in den Markt einbringen will. Sobald diese Einführung stattgefunden hat, dann sind die Schutzrechte verbraucht bzw. dann ist das Schutzrecht erschöpft. Das Produkt kann dann von Dritten weiter gehandelt werden. Bei einer internationalen Erschöpfung ist dieses Recht bereits dann erschöpft, wenn der Patentinhaber das Produkt in irgendeinem Land lanciert hat. Es kann dann durch Dritte in sämtliche Länder eingeführt werden. Man nennt dies Parallelimporte. Besteht hingegen eine nationale Erschöpfung, wie dies in der Schweiz für patentgeschützte Güter der Fall ist, dann hat der Patentinhaber das Exklusivrecht, das Produkt in diesem Land zu vertreiben. Der internationale Handel wird auf diese Weise beschränkt. Es besteht ein Parallelimportverbot. Es ist also nicht mehr möglich, ein Produkt, das vom Hersteller im Ausland ebenfalls verkauft wird, durch Dritte (Konsumenten, Parallelimporteure) in die Schweiz zu importieren.

Das Thema hat deshalb eine Bedeutung erhalten, weil ein Bundesgerichtsentscheid im Jahre 1999 das Parallelimportverbot für patentierte Güter etablierte, was eine Gegenreaktion provozierte. Und zwar reichte Frau Simonette Sommaruga eine Interpellation im Nationalrat ein unter 
dem Titel „mehr Wettbewerb dank Parallelimporten». Der Bundesrat hat dann sofort reagiert und gesagt, in gewöhnlichen Märkten stimme dies zwar schon; aus "wirtschaftstheoretischer" Sicht wäre ein Systemwechsel sinnvoll und die Zulassung von Parallelimporten wäre sachgerecht. ${ }^{1}$ Allerdings bezweifelte er, ob dies auch für preisregulierte Märkte gilt. Er setzte deshalb verschiedene Arbeitsgruppen zur Analyse dieser Fragestellung ein. Im Jahre 2002 kam der Bundesrat dann zum Schluss, dass am Parallelimportverbot festgehalten werden solle, und zwar aufgrund „politischer Erwägungen“. In den Argumenten kamen folgende Stichworte vor: „geringer Zusatznutzen“, „,negative Signale“, „die Schweiz als Trittbrettfahrerin“, „Abwanderung der forschungsintensiven Industrie“, „die Schweiz auf einer US Watch Liste“ und „Preisgabe eines Verhandlungstrumpfes in der WTO".

Es stellt sich heute die Frage, ob dieser Entscheid nach wie vor richtig ist oder ob das Parallelimportverbot allenfalls aufgehoben werden sollte. Warum eigentlich nicht? Wir lehren unsere Studierenden im ersten Semester des Studiums der Wirtschaftswissenschaften, dass der internationale Handel gut ist, und zwar für alle. In höheren Semestern wird diese Aussage etwas relativiert. Aber für die Volkswirtschaft als Ganzes wird dieser positive Zusammenhang zwischen Handel und Wohlfahrt in der Regel weiter betont.

Die Brisanz ist gross, das wissen Sie alle. Ich möchte dazu fünf Punkte in Erinnerung rufen:

(1) Die EU-Mitgliedländer kennen eine regionale Erschöpfung, das heisst, unsere Nachbarländer kennen kein Parallelimportverbot. Die Frage stellt sich, warum der Parallelimport für uns (die Schweiz) nicht gut ist, wenn er unter den Mitgliedländer der EU angewendet wird.

(2) In vielen Branchen nehmen Handelsbeschränkungen tendenziell ab (Beispiele: Textilhandel, Agrarhandel und Telekommunikation). Zwar verläuft diese Liberalisierung nicht reibungslos, doch wird sie Schritt für
Schritt angestrebt. Warum also nicht auch für patentierte Pharmaprodukte oder generell für patentierte Güter? Was macht diese Produkte so speziell - oder ist dieses Vorgehen rein politisch motiviert, indem man gewisse Branchen eben liberalisiert und andere nicht?

(3) Kostenexplosion auf der Baustelle des Gesundheitswesens. Wie Sie wissen, sind die Kosten stark gestiegen. In der Schweiz und den USA machen die Gesundheitsausgaben 10 bis $15 \%$ des BIP aus. Obwohl die Medikamente nicht einen so grossen Anteil an diesen Kosten einnehmen, steht die Frage im Raum, ob denn die Hersteller von Medikamenten nicht eine gewisse Mitverantwortung wahrnehmen sollten, indem sie nicht zu hohe Preise verlangen, zumal in den Hochpreisländern wie den USA und der Schweiz die Gesundheitsausgaben relativ hoch sind.

(4) Man weiss sehr wohl, dass in der Schweiz die Pharmaindustrie eine hohe Wertschöpfung erarbeitet. Die Branche generiert also viele gut bezahlte Arbeitsplätze, gerade im Forschungs- und Entwicklungsbereich, was auch ganz speziell für die Region Basel wichtig ist. Dies ist bei der Überlegung zur allfälligen Aufgabe des Parallelimportverbotes nicht zu vergessen. Würde dadurch der Forschungsstandort Schweiz gefährdet?

(5) Schliesslich die regionale Erschöpfung zwischen USA und Kanada: es ist interessant, dass dort zumindest laut nachgedacht wird, ob man eine regionale oder allenfalls sogar eine internationale Erschöpfung einführen soll. Sie können sich vorstellen, dass, wenn die zwei Länder das tun würden, dies natürlich grosse Auswirkungen hätte. In diesem Zusammenhang muss auch die Entwicklungsländer-Problematik erwähnt werden, gewissermassen die andere Seite der Medaille. Die Entwicklungsländer wären an sich auf Medikamente zu tiefen Preisen angewiesen, und eine internationale Erschöpfung würde dieses Be- 
streben wohl nicht begünstigen.

\section{Struktur der Tagung}

Es freut mich nun ausserordentlich, dass wir namhafte Vertreter und Exponenten insbesondere aus der Praxis für diese Tagung gewinnen konnten. Exponenten und Vertreter, die sich sehr stark mit diesem Thema beschäftigen und die sich bereit erklärt haben, ihre Erfahrungen und Sichtweisen mit uns zu teilen. Ich werde sie dann vorstellen, wenn wir durch das Programm gehen. Ziel ist es aber nicht nur, dass wir diese Stellungnahmen anhören, sondern es ist ganz wichtig, dass wir auch Fragen an diese Personen stellen können. Ebenfalls ist es mir ein Anliegen, dass wir auch Ihre Erfahrungen, die Erfahrungen aus dem Publikum, hier einbringen. Für beides ist an dieser Tagung gesorgt. Wir haben jeweils nach einzelnen Blöcken kurze Zeiträume reserviert, während derer Sie Fragen stellen können an die Referenten. Gleichzeitig ist für den Schluss eine Abschlussdiskussion geplant, in der wir das Thema integral nochmals diskutieren können.

Zur Struktur der Tagung. In einem ersten Block wollen wir grundlegende Überlegungen anstellen, indem aus Sicht des Patentgebers und aus Sicht des Preisüberwachers das Fundament gelegt wird. In einem zweiten Block werden wir konzeptionell und empirisch das Ganze vertiefen. Am Nachmittag haben wir dann einen dritten Block, in dem wir die Position der forschenden Pharmaindustrie und die Position des Schweizer Preisregulators betrachten. Die Idee ist, dass letztlich die Konsumentensicht am Morgen schon einbezogen wird aus Sicht des Preisüberwachers. Aber natürlich muss der Preisregulator unter anderem auch diese Position berücksichtigen. Im vierten Block kommen dann die Erfahrungen aus dem Ausland ins Gespräch, die Erfahrungen eines Parallelimporteurs aus Deutschland, dann aber auch die Erfahrungen aus Österreich.

\section{Inhaltliche Punkte aus aussenwirtschaftlicher Sicht ${ }^{2}$}

Lassen Sie mich nun ein paar Grundbemerkungen aus aussenwirtschaftlicher Sicht machen. Ich habe Ihnen ein paar Fragen notiert, die meines Erachtens immer im Hintergrund sein werden.

- Warum wirkt eine Handelsliberalisierung gesamtwirtschaftlich grundsätzlich positiv?

Im Prinzip sind es immer zwei Punkte. Der erste Punkt ist, dass Importe letztlich eine Preisreduktion implizieren, was dazu führt, dass einerseits die Konsumenten gewinnen, aber andererseits die Produzenten verlieren. Wir können aber davon ausgehen, dass „im Normalfall“ eine Steigerung der gesamtwirtschaftlichen Wohlfahrt stattfindet, weil der Gewinn der Konsumenten im Falle des importierenden Landes grösser als der Verlust der Produzenten ist. Freigesetzte Ressourcen auf der Produzentenseite können anderweitig optimaler genutzt werden. Die Effizienz der Ressourcenallokation nimmt zu. Der zweite Punkt ist wichtig, wenn im Inland der Wettbewerb nicht allzu hoch ist, wenn also eine monopolistische Marktstruktur besteht. In diesem Fall führt die Importliberalisierung zu mehr Wettbewerb, was die inländischen Firmen wiederum dazu bewegt, ihre Preise zu senken und vermehrt Anstrengungen zur Kostensenkung zu unternehmen. In beiden Fällen haben wir eine Umverteilung von Produzenten zu Konsumenten. Gesamtwirtschaftlich erfolgt aber eine Verbesserung der Allokation der beschränkten Ressourcen. Die Wohlfahrt steigt.

- Was gibt es hier an sich noch zu diskutieren - wann ist diese positive Wirkung unsicher?

Können wir aufgrund dieser Überlegungen nicht nach Hause gehen? Die Antwort ist "nein“. Es gibt nämlich bestimmte Gründe, warum wir uns nicht immer auf diese zwei positiven Effekte verlassen können. Die 
Aussenwirtschaftstheorie lehrt ganz allgemein, dass, wenn in einem Markt verschiedene Marktverzerrungen bestehen, nicht unbedingt eine Wohlfahrtsverbesserung eintritt, falls nur eine Marktverzerrung beseitigt wird. Dies geht zurück auf die so genannte Theorie des Zweitbesten („Theory of the second best"). Lassen Sie mich ein Beispiel geben. Nehmen Sie an, wir haben eine Firma, die bei der Produktion relativ viele Umweltschäden verursacht. Nun öffnen wir den internationalen Handel. Wir nehmen an, dass die Firma ihr Produkt infolge der Öffnung nun auch exportiere. Dies führt zu zwei Effekten. Einerseits generiert die Firma mehr Einkommen, gleichzeitig nimmt aber die Umweltverschmutzung noch mehr zu. Wenn in der Ausgangssituation ohne Handel die Umweltregulierung nicht optimal war, dann sind wir im neuen Gleichgewicht noch weiter weg vom Optimum. Die Kosten aus der Umweltverschmutzung dürften mehr steigen als der Gewinn und das Einkommen aus der zunehmenden Produktion. Die Wohlfahrt verschlechtert sich durch die Öffnung des Handels. Allgemein hatten wir in der Ausgangssituation ohne Handel zwei Verzerrungen: eine Verzerrung des Preisgefüges aufgrund der Handelsbeschränkung und eine Verzerrung von privaten und gesamtwirtschaftlichen Kosten aufgrund der ungenügenden Umweltregulierung. Wenn eine Verzerrung beseitigt wird (die Handelsbeschränkung), dann muss bei weiterem Bestehen der anderen Verzerrung (nicht optimale Umweltregulierung) die Wohlfahrt nicht steigen.

\section{- Was macht den Pharmamarkt speziell?}

Diese Erkenntnis („Theorie des Zweitbesten“) lässt sich auf verschiedene Fälle anwenden. Aber man muss jeweils untersuchen, ob eine Anwendung notwendig ist oder ob man es mit einem „einfachen“ Fall der Handelsliberalisierung zu tun hat. Könnte es sein, dass der Pharmamarkt irgendwie in diese Richtung analysiert werden müsste? Es gibt verschiedene Aspekte, die inn in der Tat speziell machen. Erstens wird den Firmen vom Staat durch das Verleihen eines Patentes praktisch ein Monopol für ein bestimmtes Produkt gegeben. Zweitens haben die Firmen hohe Forschungs- und Entwicklungsfixkosten bei gleichzeitig sehr tiefen Grenzkosten. Drittens bestehen Preisregulierungen in verschiedenen Märkten. Viertens bestehen komplexe Nachfragestrukturen im Gesundheitswesen, die die Frage aufwerfen, ob überhaupt jemand ein Interesse hat, Produkte zu tiefen Preisen zu kaufen. Diese verschiedenen Aspekte wirken zusammen. Es stellt sich auf dieser Basis die Frage, ob im Pharmamarkt nicht verschiedene Marktverzerrungen dergestalt bestehen, dass die Elimination einer Verzerrung gar nicht zu einer Wohlfahrtsverbesserung führt. Dies muss die Sicht des Aussenwirtschaftstheoretikers sein, der diesen Sachverhalt untersuchen will. Es ist also nicht so, wie der Bundesrat 1999 erwähnte, dass aus wirtschaftstheoretischer Sicht eine Liberalisierung sinnvoll wäre, während aus politischer Sicht davon Abstand genommen werden sollte. Im Gegenteil: es ist möglich, dass aus wirtschaftstheoretischer Sicht eine Liberalisierung problematisch ist. Dies ist aber sorgfältig zu untersuchen.

\section{Wichtigste Fragen und Schlüsselgrössen zur Beantwortung}

Was sind meines Erachtens die wichtigsten Fragen, die beantwortet werden müssten? Es sind im Prinzip zwei Fragen. Erstens, inwiefern führt die Liberalisierung des Aussenhandels zu einer Veränderung der Forschungs- und Entwicklungsausgaben und damit zum Innovationsverhalten? Zweitens, werden die Konsumenten in Tiefpreisländern durch die Liberalisierung starke Verluste erleiden? Ich kann Ihnen zwei Extrembeispiele geben, die die Problematik verdeutlichen.

Zum ersten Punkt: nehmen Sie mal an, dass die regulierten Preise im Ausland praktisch den Grenzkosten der forschenden Firmen entsprechen würden. Wenn Sie jetzt öffnen, dann würden in dieser Branche keine Profite mehr erwirtschaftet werden. Da diese Profite aber letztlich die Forschung und Entwicklung finanzieren, gäbe es auch 
keine neuen Pharmaprodukte mehr. Die Wohlfahrt würde in diesem Extrembeispiel sinken.

Zum zweiten Punkt: Es könnte sein, dass durch die Handelsliberalisierung einzelne Pharmaprodukte in gewisse Länder überhaupt nicht mehr geliefert werden. Dies hätte dort einen erheblichen Wohlfahrtsverlust zur Folge, da Produkte nicht mehr angeboten werden, deren marginale Herstellkosten unter der Zahlungsbereitschaft der dortigen Konsumenten liegen. Dieser Wohlfahrtsverlust wäre so gross, dass er den Wohlfahrtsgewinn im Inland leicht überkompensieren könnte.

Das sind zwei wichtige Punkte. Wenn wir da nicht genau wissen, was passiert, dann ist es schwierig, a priori zu sagen, was die Wohlfahrtseffekte der Liberalisierung sind und ob die Wohlfahrt in der Schweiz und in der Weltwirtschaft durch die Zulassung von Parallelimporten steigt.

Somit kommen wir zu Schlüsselgrössen, die für die Beantwortung der Fragen analysiert werden müssen.

Erstens muss untersucht werden, wie sich die Zulassung von Parallelimporten auf die Preise und Preisregulierungen im Ausland auswirken. Eine Möglichkeit ist, dass die Preise im Ausland konstant bleiben, da der schweizerische Markt im Vergleich zum Gesamtmarkt relativ klein ist. Es könnte aber auch sein, dass die Preise im Ausland steigen, weil die Firmen sich dann vermehrt einsetzen werden, über den Preisregulator im Ausland die Preise zu erhöhen. Alternativ wird immer wieder erwähnt, dass die Preise im Ausland sinken könnten, da der Preis in der Schweiz als Referenzpreis für die Preisfestsetzung im Ausland dient. Wie der ausländische Preis auf die Liberalisierung reagiert, ist also ganz entscheidend für die Eruierung der Effekte.

Zweitens ist zu untersuchen, wie sich mit dem Einstieg von Parallelimporteuren die Parallelimporte auf das Preisniveau im Inland auswirken. Es wird manchmal kritisch erwähnt, dass Parallelimporteure einfach eine Rente absorbieren aus der Preisdifferenz zwischen dem In- und
Ausland. Dieses Geld steht dann nicht mehr für die Forschung zur Verfügung, gleichzeitig profitieren in diesem Fall auch die Konsumenten nicht oder nur wenig von tieferen Preisen. Allerdings scheint es, dass dies nur eine kurzfristige Möglichkeit darstellt, da die Konkurrenz unter den Parallelimporteuren und zwischen den Parallelimporteuren und den Herstellern langfristig zu einer Preissenkung führen sollte.

Drittens stellt sich die Frage, ob es überhaupt einen engen Zusammenhang zwischen dem Profit der Hersteller - das heisst der Monopolrente -, den Forschungs- und Entwicklungsausgaben sowie der Innovation gibt. Wie stark ist dieser Zusammenhang? Wenn also die Profite etwas sinken infolge der Liberalisierung des Handels, wird dies auch die Innovation reduzieren? Und falls dies der Fall ist, ist diese Reduktion der Innovation gesamtwirtschaftlich negativ zu beurteilen - wird heute vielleicht nicht sogar zuviel geforscht? Dies sind schwierige Fragen, da sie letztlich auf die optimale Höhe von Forschung und Entwicklung im Pharmamarkt (inklusive optimale Patentdauer) verweisen, die nur sehr schwierig zu bestimmen ist.

Das sind aus meiner Sicht die wichtigen Fragen und Schlüsselgrössen, die es zu behandeln gilt. Wir sind nun gespannt, welche Antworten die Referate hierzu geben und auf welche weiteren Fragen und Problembereiche die Referenten hinweisen werden.

\section{Fussnoten:}

' Vergleiche zu diesem und zum folgenden „Parallelimporte und Patentrecht. Bericht des Bundesrates in Beantwortung des Postulats (00.3612) WAK-N und zu den verschiedenen Regulierungen im Markt für Humanarzneimittel“, November 2002.

2 Die grundsätzliche Problematik, wie sie hier und im nächsten Abschnitt kurz geschildert wird, ist detaillierter in folgendem Artikel entwickelt: Weder, Rolf und Guido Barsuglia (2003), „Erhöhen Parallelimporte die Wohlfahrt in regulierten Märkten?", Die Volkswirtschaft, No. 10, 2003, S. 21-25. 


\section{RECHTSLAGE UND HANDLUNGSSPIELRAUM}

Dr. Felix Addor, Leiter Recht \& Internationales, Mitglied der Direktion des Eidgenössischen Instituts für Geistiges Eigentum, Bern

Das Eidgenössische Institut für Geistiges Eigentum ist das Kompetenzzentrum des Bundes für alle Fragen im Immaterialgüterrecht und damit aus immaterialgüterrechtlicher Seite mit dieser Fragestellung befasst. Zunächst einmal:

\section{Was sind Parallelimporte?}

Unter Parallelimport im hier verwendeten Sinne ${ }^{1}$ versteht man den Import einer immaterialgüterrechtlich (z.B. durch ein Patent) geschützten Ware, die vom Schutzrechtsinhaber selber oder mit dessen Zustimmung in einem Drittland in Verkehr gebracht wurde. Parallelimporte sind nur bei einer internationalen (= weltweiten) oder einer regionalen (= innerhalb eines Wirtschaftsraums) Erschöpfung des Schutzrechts möglich. Sie treten vor allem dann auf, wenn die Preise im Drittland signifikant tiefer sind als im Importland.

Die Frage der Zulässigkeit von Parallelimporten betrifft die Ausgestaltung und den Umfang der dem Patentinhaber eingeräumten Ausschliesslichkeitsrechte bzw. die Frage, aufgrund welcher Handlungen des Patentinhabers sich seine Rechte erschöpfen. Die Zulassung von Parallelimporten bedeutet eine Einschränkung der Ausschliesslichkeitsrechte, welche letztlich die Refinanzierungsmöglichkeiten der gemachten Erfindung und somit die Verkaufsstrategien und die Preispolitik des Patentinhabers (auch im Ausland) beeinflusst.

Parallelimporte marken- und urheberrechtlich geschützter Produkte sind in der Schweiz nach geltendem Recht zulässig ...

Im Markenrecht gilt in der Schweiz das Prinzip der internationalen Erschöpfung. Somit sind Parallelimporte von Markenartikeln (z.B. 
Kleider, Parfums, Lebensmittel) aus der ganzen Welt zulässig. Dies hat das Bundesgericht zuletzt in seinem Entscheid "Chanel“ (BGE 122 III 469) bestätigt. Ebenso entschied es für das Urheberrecht im Urteil „Nintendo“" (BGE 124 III 321).

Allerdings hat das Parlament im Rahmen der Revision des Filmgesetzes eine Sonderregelung für die Erschöpfung der Urheberrechte an audiovisuellen Werken geschaffen. Diese Bestimmung, welche für diese Werkkategorie generell die nationale Erschöpfung vorsah, wurde per 1. April 2004 dahingehend modifiziert, dass das Recht, $\mathrm{Pa}$ rallelimporte von Videokassetten und DVDs zu verbieten, nur so lange besteht, als die erste Kinoverwertung des Werks nicht abgeschlossen ist. Sobald die primäre Kinoverwertung beendet ist, ist der Parallelimport aus der ganzen Welt erlaubt. ${ }^{2}$ Die Erstaufführung von Kinofilmen wird somit geschützt, ohne dass der Wettbewerb in Bezug auf den Vertrieb von Videokassetten und DVDs durch ein Parallelimportverbot eingeschränkt würde.

\section{... und der Grundsatz der nationalen Erschöpfung im Patent-} recht gilt nicht uneingeschränkt

Im „Kodak“-Urteil (BGE 126 III 129) hat das Bundesgericht die im Patentgesetz nicht explizit geregelte Frage der Erschöpfung zugunsten der nationalen Erschöpfung entschieden. Das Bundesgericht schloss sich damit der weltweit überwiegend geltenden Rechtslage an.

\section{Es besteht eine kartellrechtliche Eingriffsmöglichkeit ...}

Das Bundesgericht hat aber in seinem „Kodak"-Urteil das Prinzip der nationalen Erschöpfung dadurch eingeschränkt, als es festhält, dass sich der Patentinhaber Parallelimporten patentierter Güter in die Schweiz nur so weit widersetzen kann, als damit nicht eine kartellrechtswidrige Wettbewerbsbeschränkung verbunden ist. Diese Feststellungen des Bundesgerichts wurden anlässlich der Revision des Kartellgesetzes durch eine Ergänzung von Art. 3 Abs. 2 KG gesetzlich verankert. Darin wurde klargestellt, dass die Ausübung der geistigen
Eigentumsrechte dann nicht vom Anwendungsbereich des Kartellgesetzes ausgeschlossen ist, wenn es um Einfuhrbeschränkungen gestützt auf diese Rechte geht. ${ }^{3}$ Dem Kartellgesetz kommt somit die Rolle des Korrektivs gegenüber Preismissbräuchen zu, welche auf der nationalen Erschöpfung basieren.

\section{... und eine Regelung zur Verhinderung des Missbrauchs des \\ Mehrfachschutzes ist in Vorbereitung}

Während in der Schweiz der Parallelimport von marken- und urheberrechtlich geschützten Produkten aufgrund des dort geltenden Grundsatzes der internationalen Erschöpfung überwiegend zulässig ist, gilt im Patentrecht die nationale Erschöpfung. Um zu verhindern, dass über einen „nebensächlichen“ patentierten Bestandteil Parallelimporte von marken- und/oder urheberrechtlich geschützten Waren missbräuchlich unterbunden werden, wird in der laufenden Patentgesetzrevision eine Regelung dieser sog. Mehrfachschutzproblematik vorgeschlagen. Demnach ist im Einzelfall abzuwägen, welches Schutzrecht aufgrund seines spezifischen Zwecks einer mehrfach geschützten Ware die Charakteristik verleiht. Parallelimporte mehrfach geschützter Waren könnten somit dann nicht unterbunden werden, wenn die durch das Patent geschützte technische Innovation die Charakteristik der Ware insgesamt nicht entscheidend prägt. ${ }^{4}$

So wird zum Beispiel im Fall eines Markenparfums, dessen Flacon mit einem patentierten Zerstäuber versehen ist, in aller Regel die mit der Marke verbundene Kennzeichnungsfunktion des Produkts im Vordergrund stehen und nicht die technische Innovation des Zerstäubers. Anders zu beurteilen wäre dagegen ein Pflaster mit einem patentgeschützten transdermalen Wirkstoff, der zudem noch ein für Kinder ansprechendes Design hat oder ein Personenfahrzeug mit einer patentierten Ventilsteuerung des Motors, welche den innovativen Charakter dieses Autos ausmacht. Bei diesen Beispielen führt die Abwägung nach dem spezifischen Schutzzweck zum Ergebnis, dass die technische Innovation im Verhältnis zum Zweck des Mar- 
ken- und Urheberrechtsschutzes massgebend und nicht bloss von untergeordneter Bedeutung ist.

\section{Wie regelt die EU die Frage der Parallelimporte?}

Im Markenrecht gilt sowohl nach dem Recht der Mitgliedstaaten (Art. 7 Erste Richtlinie 89/104/EWG zur Angleichung der Rechtsvorschriften der Mitgliedstaaten über die Marken; ABI. L 40 vom 11.02.1989, S. 1) als auch für die Gemeinschaftsmarken (Art. 13 Verordnung $(E G) \mathrm{Nr}$. 40/94 über die Gemeinschaftsmarke; ABI. L 11 vom 14.01.1994, S. 1) die regionale Erschöpfung. Es ist den EU-Mitgliedstaaten insbesondere auch untersagt, nationalrechtlich weiterhin das Prinzip der internationalen Erschöpfung anzuwenden (EuGH, Rs. C-355/96, Silhouette International Schmied/Hartlauer Handelsgesellschaft, Slg. 1998, I4799). Anders interpretierte der EFTA-Gerichtshof die Bestimmung hinsichtlich deren Tragweite für Norwegen, Island und Liechtenstein, indem er befand, dass es den EWR-Staaten auch unter Richtlinie 89/104/EWG unbenommen bleibe, die Doktrin der internationalen Erschöpfung des Markenrechts anzuwenden (EFTA-Gerichtshof, Rs. E-2/97, Mag Instrument Inc./California Trading Company Norway). Diese Entscheidung ist jedoch wegen Art. 2 des EWR-Protokolls 28 nicht mehr anwendbar; auch der EFTA-Gerichtshof muss das EU-Recht (wie es vom EuGH interpretiert wurde) befolgen.

Im Urheberrecht gilt ebenfalls die regionale Erschöpfung. Dies ergibt sich aus der Rechtsprechung des EuGH (Rs. 78/70, Deutsche Grammophon Gesellschaft/Metro-SB-Grossmärkte, Slg. 1971, 487) sowie aus dem relevanten Richtlinienrecht, welches namentlich auch eine nationalrechtliche internationale Erschöpfung im Recht der Mitgliedstaaten ausschliesst. ${ }^{5}$

Bezüglich Patenten hat der EuGH bereits früh auf die regionale Erschöpfung der Rechte und damit die freie Zirkulation patentgeschützter Waren innerhalb der Gemeinschaft erkannt (EuGH, Rs. 15/74, Centrafarm/Sterling Drug, Slg. 1974, 1147). In seiner Rechtsprechung stellte der Gerichtshof zudem klar, dass die regionale Erschöpfung auch im Falle von staatlichen Preiskontrollen gelte (EuGH, verb. Rs. C-267/95 u. C-268/95, Merck/Primecrown, Slg. 1996, 6371). Auch die Richtlinie 98/44/EG über den rechtlichen Schutz biotechnologischer Erfindungen (ABI. L 213 vom 30.7.1998, S. 13) und der Vorschlag für eine Verordnung über das Gemeinschaftspatent ${ }^{6}$ sehen das Prinzip der regionalen Erschöpfung vor.

In Bezug auf pharmazeutische Produkte hat die Europäische Kommission vor kurzem eine Mitteilung über Paralleleinfuhren von Arzneimitteln, deren Inverkehrbringen bereits genehmigt ist, veröffentlicht. ${ }^{7}$ Darin stellt die Kommission klar, wie der Grundsatz des freien Warenverkehrs in der EU bei Paralleleinfuhren von Arzneimitteln anzuwenden ist. Die zuständigen Behörden der Mitgliedstaaten sollen für ein parallel eingeführtes Arzneimittel auf der Basis eines vereinfachten Verfahrens eine Zulassungsgenehmigung erteilen, wenn sie bereits über die zum Schutz der öffentlichen Gesundheit erforderlichen Informationen verfügen. Dieses Vorgehen steht in Einklang mit der Praxis des EuGH, wonach der Gebrauch des Markenrechts nicht zur künstlichen Abschottung des Binnenmarktes führen darf (EuGH, Rs. C-443/99, Merck, Sharp \& Dohme/Paranova Pharmazeutika Handels GmbH, Sgl. 2002, I-03703). Parallel eingeführte Originalarzneimittel dürfen also umgepackt, umetikettiert und mit der Marke des Bestimmungslandes versehen werden, solange dadurch der Originalzustand der Ware nicht beeinträchtigt oder der Ruf der Marke bzw. ihres Inhabers geschädigt wird. Weiter ist auf der neuen Verpackung anzugeben, von wem das Erzeugnis umgepackt und hergestellt wurde, und der Markeninhaber ist zu unterrichten, bevor das umgepackte Erzeugnis zum Kauf angeboten wird.

In Bezug auf die wettbewerbsrechtlichen Aspekte von Parallelimporten von Arzneimitteln hat der EuGH unlängst bestätigt, dass Produzenten aus dem EU/EWR-Raum die Möglichkeit haben, die Lieferung ihrer Produkte auf die zur Versorgung der Mitgliedstaaten notwendige Menge zu begrenzen und so Parallelimporte zu vermeiden (EuGH, 
verb. Rs. C-2/01 P und C-3/01, Bundesverband der Arzneimittel-Importeure \& EG-Kommission/Bayer AG, Slg. 2004). Eine solche Begrenzung der Versorgung gilt nicht als verbotene wettbewerbshindernde Vereinbarung zwischen Unternehmen nach Art. 81 EG-Vertrag. Die Schlussfolgerungen von Generalstaatsanwalt Jacobs im vor dem EuGH hängigen Fall GlaxoSmithKline ${ }^{8}$, in dem er dieselbe Frage unter dem Aspekt des Missbrauchs einer marktbeherrschenden Stellung prüft, gehen in dieselbe Richtung (Rs C-53/03, Syfait/GlaxoSmithKline): Da Preisunterschiede zwischen den Mitgliedstaaten im Arzneimittelmarkt die Folge staatlicher Regelung seien, würde eine Verpflichtung zur Versorgung nicht zwingend den freien Warenverkehr begünstigen; zudem könnte es der Innovation abträglich sein. Gemäss Generalstaatsanwalt Jacobs liegt der Parallelhandel nicht immer im Interesse der Konsumentinnen und Konsumenten, sondern vor allem im Interesse der Zwischenhändlerler. Die Beschränkung von Parallelimporten von Arzneimitteln seien deshalb nicht als Missbrauch einer marktbeherrschenden Stellung zu betrachten. ${ }^{9}$

\section{Warum hat der Bundesrat die Einführung der internationalen Erschöpfung im Patentrecht bisher abgelehnt?}

Der Bundesrat hat in seinen verschiedenen, seit dem Kodak-Urteil ergangenen Stellungnahmen zur Frage eines Systemwechsels im Patentrecht von der nationalen zur internationalen Erschöpfung immer am Grundsatz der nationalen Erschöpfung festgehalten. Der Grund dafür liegt insbesondere in den als gering veranschlagten gesamtwirtschaftlichen Auswirkungen eines Systemwechsels, welcher gemäss einer externen Studie lediglich zu einem BIP-Wachstum zwischen 0,0 und $0,1 \%$ führen würde. ${ }^{10}$ Zudem sind auch die möglichen negativen Konsequenzen eines Systemwechsels genauer zu beachten.

Zunächst ist den möglichen Folgen im Kontext des Welthandels Rechnung zu tragen: Als Reaktion auf die Einführung der internationalen Erschöpfung in Hochpreisländern ist zu befürchten, dass in
Niedrigpreisländern die Preise an das höhere Preisniveau angeglichen oder diese Märkte nicht mehr oder erst viel später beliefert würden. In Entwicklungsländern könnte dies ernsthafte Konsequenzen auf die Versorgung haben, so vor allem im auf internationaler Ebene heftig debattierten Bereich der Medikamente.

Zudem besteht das Risiko, dass Medikamente zur Behandlung verbreiteter epidemischer Krankheiten wie etwa HIVIAIDS, Tuberkulose oder Malaria, die von der Industrie stark verbilligt an bedürftige Entwicklungsländer abgegeben werden, nicht den eigentlich Bedürftigen zugute kommen, sondern letztlich als parallelimportierte Produkte wieder auf den Märkten der Industrieländer auftauchen. Ohne Gewähr, dass ihre patentgeschützten Produkte nicht über Parallelimporte in die Industriestaaten gelangen können, zeigen sich die Hersteller nicht bereit, ihre Preise der Kaufkraft der Entwicklungsländer anzupassen. Die Möglichkeit, Parallelimporte aus Entwicklungsländern gestützt auf das Patentrecht zu verhindern, bringt dabei klar die grösste Sicherheit.

Weiter ist auch zu bedenken, dass forschungsintensive Unternehmen in der Schweiz einen Regimewechsel als Signal interpretieren könnten, dass der politische Wille abnimmt, Immaterialgüterrechte angemessen zu schützen und der slippery slope der Patentrechtserosion eingeschlagen würde. Dies könnte sich letztlich zum Nachteil der Standortattraktivität der Schweiz für Forschung und Entwicklung aus der Sicht dieser Unternehmen auswirken, selbst wenn bei einer auf den vergleichsweise kleinen schweizerischen Markt beschränkten Einführung der internationalen Erschöpfung keine gravierenden Konsequenzen auf die Refinanzierungsmöglichkeiten für die kostenintensive Forschung und Entwicklung zu erwarten wären und somit die objektiven Standortfaktoren weitgehend unverändert blieben.

Zumindest die beiden erstgenannten Nachteile würden wegfallen, wenn die Schweiz den Systemwechsel lediglich mit Bezug auf die EU-Länder vollziehen und eine sog. regionale Erschöpfung einführen würde. Der Bundesrat hat deshalb auch diese Alternative eingehend 
geprüft.

Was hat der Bundesrat bisher im Hinblick auf die Einführung einer regionalen Erschöpfung mit der EU unternommen?

Der Versuch, im Rahmen des Freihandelsabkommens Schweiz-EG eine Ausdehnung der regionalen Erschöpfung der EU auf die Schweiz auf der Grundlage der Gegenseitigkeit zu diskutieren bzw. zu erreichen, scheiterte bisher am fehlenden Interesse der EU-Kommission (vgl. Bericht des Bundesrats vom Mai 2000, S. 19).

Die Frage der regionalen Erschöpfung wurde im Rahmen der Vorbereitungsarbeiten zu den bilateralen Verhandlungen II verwaltungsintern diskutiert. Angesichts der schweizerischen Interessenlage und der Schwierigkeiten in den verschiedenen Verhandlungsdossiers - insbesondere bezüglich der Abkommen Schengen/Dublin - wurde damals darauf verzichtet, dieses Thema ins Verhandlungsmandat aufzunehmen.

Eine interdepartementale Arbeitsgruppe erarbeitet dieses Jahr einen (dritten!) Bericht zu Handen des Bundesrates, in welchem in Beantwortung eines Postulats der Kommission für Wirtschaft und Abgaben des Nationalrats (Postulat 03.3423) die Aufnahme von Verhandlungen mit der EU geprüft wird, welche die Einführung einer gegenseitigen regionaleuropäischen Erschöpfung im Patentrecht zum Ziel haben. Der Bericht soll vom Bundesrat im Dezember 2004 behandelt und danach veröffentlicht werden.

\section{Abklärung der Auswirkungen ...}

Der Bericht klärt die Möglichkeit der Einführung der gegenseitigen regionaleuropäischen Erschöpfung im Patentrecht ab. Er untersucht, welche positiven und negativen Auswirkungen die Vereinbarung der regionalen Erschöpfung für die Schweizer Wirtschaft hätte, wobei sämtliche Betroffenen, also nebst Konsumentinnen und Konsumenten auch Rechtsinhaberinnen und Rechtsinhaber sowie Verkaufs- und
Detailhandelskreise zu berücksichtigen sind.

$\mathrm{Zu}$ beachten ist auch, dass die EU einer Vereinbarung der regionalen Erschöpfung wohl nur zustimmen würde, wenn sie sämtliche Immaterialgüterrechte, also auch das Marken- und Urheberrecht umfasst. Da sich nach bisherigem Recht Marken- und Urheberrechte in der Schweiz international erschöpfen, besteht das Risiko einer Einschränkung des freien Warenverkehrs: Parallelimporte marken- oder urheberrechtlich geschützter Güter aus Tiefpreisländern ausserhalb der EU wären diesfalls nicht mehr zulässig.

... insbesondere auch des Preissenkungspotentials einer Einführung der regionalen Erschöpfung im Patentrecht im Allgemeinen ...

Der zweite Bericht des Bundesrats zu Parallelimporten und Patentrecht hat aufgezeigt, dass bereits das Wachstumspotential, das aus der Einführung der internationalen Erschöpfung im Patentrecht resultieren würde, bescheiden ist (BIP-Wachstum von 0.0\% - 0.1\%). Entsprechend sind aufgrund des höheren Preisniveaus in der EU die zu erwartenden Effekte der Einführung einer regionalen Erschöpfung noch geringer.

Auch eine Analyse der in der Economic Survey der OECD über die Schweiz für 2003 aufgeführten Preisunterschiede gegenüber der EU im Konsumentenbereich ergibt, dass von den aufgeführten Waren und Dienstleistungssektoren Patentschutz einzig bei Arzneimitteln und allenfalls bei Fahrzeugen eine Rolle spielt. Gerade im Arzneimittelmarkt gelten aber aufgrund der Preisregulierungen besondere Regeln. Wichtig ist auch die Feststellung, dass bezüglich markenrechtlich geschützter Güter trotz der internationalen Erschöpfung und der damit verbundenen Zulässigkeit von Parallelimporte in der Schweiz bisher keine Angleichung des Preisniveaus an das umliegende Ausland stattfand. 


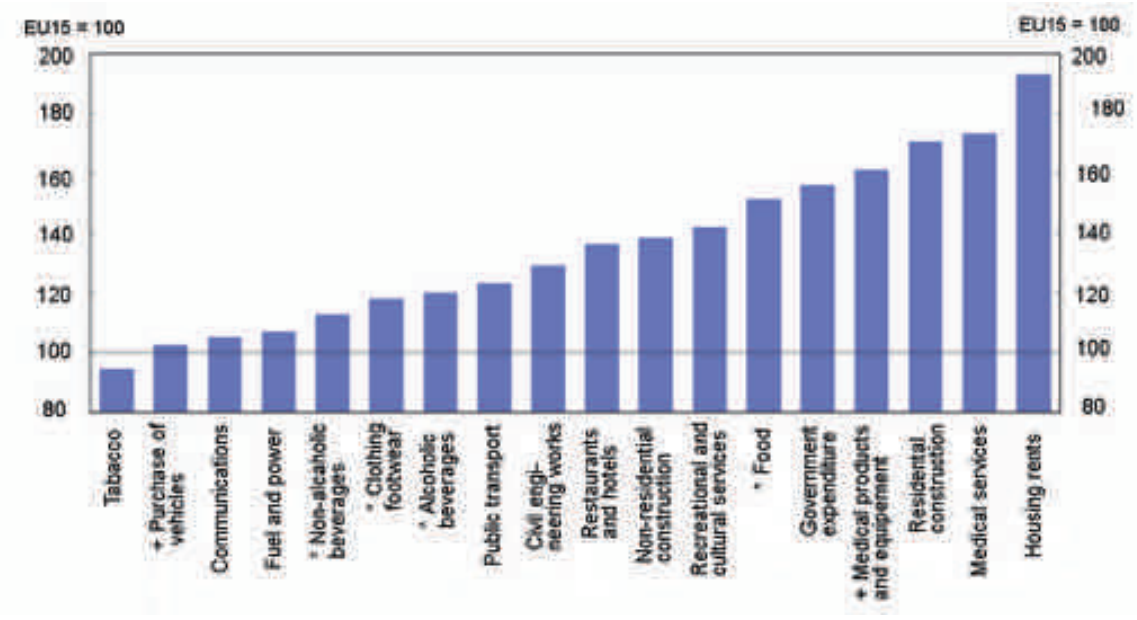

keine immaterialgüterrechtlich geschützte Güter * primär markenrechtlich geschützte Güter + patentrechtlich geschützte Güter

Mögliche Auswirkungen der regionalen Erschöpfung des Patentrechts auf das Preisniveau in der Schweiz

(Quelle des Diagramms: OECD Economic Survey Switzerland 2003, S. 94)

... und bei preisregulierten Märkten wie dem Arzneimittelmarkt im Besonderen

Während sich die Produktepreise in gewöhnlichen Märkten nach Angebot und Nachfrage bilden, bestimmt in preisregulierten Märkten der Staat im Wesentlichen die Preise, indem er entweder direkt den Preis selbst, ein Preisband oder einen Höchstpreis für die entsprechenden Produkte festlegt. Im preisregulierten Arzneimittelmarkt führt die Zulassung von Parallelimporten somit nicht zum Preiswettbewerb, sondern zum Wettbewerb zwischen den unterschiedlichen Regulierungen. Die Folge ist nicht eine Aufhebung der Preisverzerrungen, sondern eine Unterwanderung der politischen Entscheide eines Landes in Bezug auf seine Gesundheitspolitik. Die Legitimität eines solchen Wettbewerbs der Regulierungen ist deshalb fragwürdig.

\section{Machbarkeit eines Systemwechsels zur gegenseitigen regiona- len Erschöpfung}

Der 3. Bericht setzt sich auch mit der rechtlichen und politischen Machbarkeit einer Vereinbarung mit der EU auseinander. Der Übergang von der nationalen zur regionalen Erschöpfung im Patentrecht wäre im Rahmen der internationalen Verpflichtungen der Schweiz und der EU unproblematisch. Anders im Marken- und Urheberrecht: Ein Übergang von der internationalen auf die regionale Erschöpfung könnte als Errichtung eines neuen Handelshemmnisses für Güter von ausserhalb der EU qualifiziert werden, was den Bestimmungen des WTO-Rechts zuwiderlaufen würde.

Wichtig für den Entscheid über die Aufnahme von Verhandlungen mit der EU sind auch die potentiellen Gegenforderungen, welche von Seiten der EU zu erwarten wären. Die Erfahrungen mit den bilateralen Verhandlungen II haben gezeigt, dass die EU den Verhandlungsvorschlägen der Schweiz jeweils mit umfangreichen Gegenforderungen zur Wahrung von Gemeinschaftsinteressen gegenübertritt. Deren mögliche Auswirkungen für die Schweiz sind bei der Entscheidung über die Aufnahme von Verhandlungen über die regionale Erschöpfung mitzuberücksichtigen.

\section{Weshalb kann die regionale Erschöpfung von der Schweiz nicht einseitig eingeführt werden?}

Die regionale Erschöpfung kann nur aufgrund eines bilateralen Abkommens mit der EU oder den EWR-Staaten abgeschlossen werden. Eine einseitige Einführung der regionalen Erschöpfung würde das Diskriminierungsverbot nach WTO/GATT, WTO/TRIPS-Abkommen sowie der Pariser Verbandsübereinkunft zum Schutz des gewerblichen Eigentums verletzen. Zudem erschiene es ohne Gegenrecht integrationspolitisch 
wenig sinnvoll, Vorleistungen gegenüber der EU (im Sinne der Zulassung von Parallelimporten aus dem EU-Raum) zu erbringen.

\section{Fussnoten:}

${ }^{1}$ Zu Begriff und Hintergründen s. <http://www.evd.admin.ch/evd/dossiers/ parallelimporte/index.html?lang=de $>$.

${ }^{2}$ Art. 12 Abs. 1bis URG (in Kraft seit 1. April 2004): „Exemplare von audiovisuellen Werken dürfen so lange nicht weiterveräussert oder vermietet werden, als der Urheber oder die Urheberin dadurch in der Ausübung des Aufführungsrechts (Art. 10 Abs. 2 Bst. c) beeinträchtigt wird."

${ }^{3}$ Art. 3 Abs. 2 KG (in Kraft seit 1. April 2004): „Nicht unter das Gesetz fallen Wettbewerbswirkungen, die sich ausschliesslich aus der Gesetzgebung über das geistige Eigentum ergeben. Hingegen unterliegen Einfuhrbeschränkungen, die sich auf Rechte des geistigen Eigentums stützen, der Beurteilung nach diesem Gesetz."

${ }^{4}$ Art. $9 b$ Abs. 2 E-PatG (Bestandteil der Ende Oktober 2004 abgelaufenen Vernehmlassung zur Patentgesetzrevision): „Die Zustimmung des Patentinhabers zum Inverkehrbringen im Inland ist nicht erforderlich für eine patentgeschützte Ware, an der weitere Rechte des geistigen Eigentums bestehen und für deren Charakter der Patentschutz im Vergleich zu diesen Rechten untergeordnete Bedeutung hat."
${ }^{5}$ Vgl. Art. 4 Abs. 2 Richtlinie 2001/29/EG zur Harmonisierung bestimmter Aspekte des Urheberrechts und der verwandten Schutzrechte in der Informationsgesellschaft (ABI. L 167 vom 22.06.2001, S. 10); Art. 9 Abs. 2 Richtlinie 92/100/EWG zum Vermiet- und Verleihrecht sowie zu bestimmten dem Urheberrecht verwandten Schutzrechten im Bereich des geistigen Eigentums (ABI. L 346 vom 27.11.1992, S. 61) sowie Art. 4 Bst. c zweiter Satz der Richtlinie 91/250/EWG über den Rechtsschutz von Computerprogrammen (ABI. L 122 vom 17.05.1991 S. 42).

${ }^{6} \mathrm{Vgl}$. Rat der Europäischen Union, Vorschlag für eine Verordnung des Rates über das Gemeinschaftspatent vom 8. März 2004 (Dok.-Nr. 7114/04), abrufbar unter <http://register.consilium.eu.int/pdf/de/04/st07/st07119.de04.pdf>.

${ }^{7}$ Mitteilung der Kommission über Paralleleinfuhren von Arzneispezialitäten, deren Inverkehrbringen bereits genehmigt ist, KOM(2003) 839 endg. <http:// europa.eu.int/comm/internal market/en/goods/docs/com-893_de.pdf>.

$8<$ curia.eu.int/jurisp/cgi-bin/form.pl?lang=de\&Submit=Suchen $\&$ docrequire= alldocs $\&$ numaff $=C-53 \% 2 F 03 \&$ datefs $=\&$ datefe $=\&$ nomusuel $=\&$ domaine $=\& \mathrm{~m}$ ots $=\&$ resmax $=100>$

9 Zum Verbot des Verkaufs von rezeptpflichtigen Medikamenten. 


\section{WIRKT DIE SCHWEIZER MARKTORDNUNG PREISTREIBEND?}

Von Rudolf Strahm, Preisüberwacher, Eidgenössisches Volkswirtschaftsdepartement, Bern ${ }^{1}$

Die Medikamente gehören bei der Preisüberwachung zu den häufigsten Preisbeschwerden aus dem Publikum sowie von Medizinalpersonen und Institutionen des Gesundheitswesens. Die Leute können heute reisen, die Arzneimittelpreise mit dem Ausland vergleichen, der Euro erleichtert die Preisvergleiche mit der Schweiz. Die Pharma-Preise sind zu einem emotionalen Thema und zum Ärgernis von Patienten, Touristen und Leistungserbringern geworden.

Innert sechs Jahren, von 1996 bis 2002 sind die Arzneimittelkosten zu Lasten der Krankenversicherung, der Sozialversicherungen und der Haushalte von 3.8 auf 4.9 Mia Franken gestiegen, also um +1.1 Mia Franken. Pro Haushalt betragen die Arzneimittelkosten Fr. 1'630.-.

\section{Entwicklung der Medikamentenpreise}

Die Preisüberwachung verfolgt laufend die Medikamentenpreise und erfasst ein sehr repräsentatives Sample von kassenpflichtigen Medikamenten der Spezialitätenliste (SL-Liste). Im Dezember 2004 wurden 2'242 Präparate der SL-Liste mit entsprechenden Präparaten in Deutschland verglichen.

- Wenn alle 2'242 Präparate verglichen werden, liegen die Fabrikabgabepreise (Ex Factory; ohne MWSt) in der Schweiz 18.9 Prozent über dem gleichen Sample in Deutschland.

- Bei den vor 1990 in Verkehr gesetzten und aufgenommenen Präparaten betrug die Preisdifferenz +26.0 Prozent.

- Bei den Medikamenten, die zwischen 1990 und1995 in die SL-Liste aufgenommen wurden, war die Schweiz 38.4 Prozent teurer als Deutschland. 
- Bei den Präparaten nach 1996 betrug die Preisdifferenz der Schweiz gegenüber Deutschland noch +7.6 Prozent. $^{2}$

Dieser Preisvergleich kann als repräsentativ betrachtet werden, denn die erfassten 2'242 Medikamente umfassen grössenordnungsmässig mehr als die Hälfte des gesamten Medikamentenkonsums. Wir können jedoch jenen Preisvergleichen nichts abgewinnen, die sehr selektiv nur eine kleine Zahl von Präparaten herausnehmen. Beispielsweise der Preisvergleich der zehn umsatzstärksten Präparate umfasst grössenordnungsmässig nur zehn Prozent des Pharmamarktes. Durch eine derart selektive Auswahl sind Manipulationen und Fehlaussagen am Platz. [Immerhin hat die Vips/Interpharmastudie vom Herbst 2004 die 100 umsatzstärksten Präparate betroffen und sollte daher doch als relativ repräsentativ gelten können. Die Resultate entsprechen denn auch weitgehend unseren eigen, wenigstens was die Vergleiche auf FAP-Niveau betrifft.]

Verschiedene Interessenskreise haben auch Preisvergleiche zwischen der Schweiz und dem Ausland publiziert, die auf Kaufkraft-bereinigten Wechselkursen beruhen (PPP). Es wird dem zu Folge implizit mit einem anderen Wechselkurs gerechnet als mit dem kommerziellen Umrechnungskurs der Finanzmärkte (1Euro $=1.55 \mathrm{SFr}$ ). Bei Importpreisvergleichen ist die Kaufkraftbereinigung nach unserer Auffassung nicht zulässig.

Bei Vergleichen auf Publikumspreisniveau sind auch die Apothekertaxen (Leistungsorientierte Abgeltung) zu berücksichtigen. Bei den von der Preisüberwachung durchgeführten Ex Factory-Preisen sind die Vertriebskosten nicht einbezogen.

\section{Wo sind die Preistreiber im Medikamentensektor?}

Seit etwa 1999 ist die Entwicklung der Medikamentenkosten von der Entwicklung der Kosten der Sozialen Krankenversicherung (Grundversicherung) ausgebrochen und überproportional gestiegen. Gleichzeitig ist aber der offizielle Preisindex für Medikamente leicht gesunken. In erster, grober Näherung müssten man den Schluss ziehen, dass bei sinkenden Preisen und steigenden Kosten ein starker Mengeneffekt im Spiel ist.

Der Schluss einer Mengenausdehnung im Arzneimittelkonsum ist eine falsche Folgerung. Die Zahl der verkauften Packungen ist in etwa stabil geblieben. Was steckt hinter diesem Paradoxon?

Der preistreibende Faktor ist weder die Einzelpreis-Entwicklung noch die Mengenausdehnung, sondern es sind die ständigen Mutationen mit der begleitenden „Umsteigeteuerung“, die den Motor der ArzneimittelKostenexplosion darstellen.

Die Mutationen auf der Spezialitätenliste waren zahlenmässig enorm. Von 1995 bis 2003 wurden auf der SL-Liste von 5'336 Präparaten (Jahr 1995)

1 '798 Präparate gestrichen,

3'061 neue Präparate zugelassen,

unter Einbezug aller gemeldeten Änderungen und neuer Wirkstoffkombinationen

insgesamt 6'890 Mutationen vorgenommen!

Die Preisvergleiche zwischen 1995 und 2003 zeigten Folgendes:

- Bei den Präparaten, die keine Änderung erfahren haben, gab es eine Preissenkung von -13.7 Prozent (Publikumspreise, 3'526 Präparate).

- Bei den neu zugelassenen Medikamenten, inbegriffen alle Präparate mit einer Mutation, stiegen dem gegenüber die Fabrikabgabepreise von 1995 bis 2003 um +151 Prozent, die Publikumspreise um +101 Prozent! ${ }^{3}$

Dieser Vergleich zeigt deutlich: Weder die Entwicklung der Einheitspreise noch die Mengenausdehnung sind die Preistreiber, sondern die ständigen Mutationen. Ständig werden neue Kombinationen bekannter Wirkstoffe auf den Markt gebracht, ständig wird die Galenik gewechselt oder erweitert, ständig wird ein „Patent-Evergreening“ praktiziert. 
Unzählige Neuerungen sind Scheininnovationen und dienen rein kommerziellen Zwecken der Marktbearbeitung. Man spricht sogar auch von Verhinderungspatenten, die ebenfalls der Markt-Sortimentspolitik dienen. Das Resultat dieser Mutationen ist jedoch klar: Es resultiert ein ständig höherer Preis. Diese „Umsteigeteuerung“ ist der eigentliche Motor der Kostenexplosion im Arzneimittelbereich.

Ist diese Preiserhöhung der Innovationen oder Scheininnovationen gerechtfertigt? Wir stellen fest, dass die Wirkungsverbesserung der neu zugelassenen Medikamente nicht erfasst und geprüft wird. Es gibt im Zulassungsverfahren nach Heilmittelgesetz keine Nachweispflicht oder Kontrolle des therapeutischen Mehrwerts. Eine Cost/Benefit-Analyse der Innovation im Pharmabereich ist in der Schweiz nicht möglich. (Der Nachweis des therapeutischen Mehrwerts beim MedikamentenZulassungsverfahren ist seinerzeit auf Druck der Pharmainteressen aus dem Heilmittelgesetz im Vorverfahren gestrichen worden.).

\section{Marktordnung und Preisstrategien im Pharmabereich}

Die Sortimentspolitik der Pharma-Anbieter ist also die entscheidende strategische Variable in der Beherrschung des Arzneimittelmarkts. Die Kosten der Pharmakonzerne für die Marktbearbeitung und Werbung betragen heute in etwa das Doppelte der effektiven Forschungsaufwendungen.

Rund 70 Prozent des Arzneimittel-Konsums in der Schweiz besteht aus Importen, knapp ein Drittel der Pharmazeutika wird bei Schweizer Firmen produziert. Von den grossen industriellen Schweizer Pharmaherstellern werden indessen nur 2 Prozent der Gesamtproduktion auf dem schweizerischen Markt abgesetzt.

Die Pharmakonzerne praktizieren in der Schweiz und weltweit eine Marketingstrategie, welche im Business-Lehrbuch als "Market Segmentation" bezeichnet wird. Darunter versteht man eine länderweise Marktaufteilung mit einer länderbezogenen Preisdifferenzierung, welche sich am Kaufkraftpotential der einzelnen Absatzmärkte richtet.
Märkte mit hoher Kaufkraft und hohem Preisniveau werden mit höheren Fabrikabgabe- und Lieferpreisen ausgereizt, wogegen Märkte mit tiefem Preisniveau auch tiefere Lieferpreise festgesetzt erhalten.

Ökonomisch betrachtet sind also Preisdiskriminierungen von der Schweiz aus gesehen ein "Geschenk" ans Ausland, indem ausländische Lieferanten (bei 70 Prozent des Arzneimittelkonsums, der auf Importen basiert) von der Schweiz aus höher entschädigt werden. Die Wertschöpfung liegt im Ausland, die Schweizer zahlen mehr, weil sie reicher sind. Dies führt logischerweise zum Ruf nach der Ermöglichung von Parallelimporten, um dieser Marktsegmentierungsstrategie der Konzerne entgegenzuwirken.

Auf Grund dieser Marktordnung sind verschiedene Preisstrategien abzuleiten, die wir im Folgenden einzeln skizzieren.

\section{Preisstrategie 1: Medikamenten-Zulassungspraxis}

Die Zulassungspraxis gemäss Heilmittelgesetz muss überprüft werden. Der Gesetzgeber wollte ausdrücklich im Artikel 14 Absatz 2 des HMG eine erleichterte Zulassung für Medikamente, deren Patent abgelaufen ist. Dies betrifft immerhin 40 Prozent des Arzneimittelmarktes. Unter erleichterter Zulassung wurde eine rasche, unbürokratische Ermöglichung von Parallelimporten gleicher oder gleichwertiger Medikamente aus dem (europäischen) Ausland verstanden. Bislang ist allerdings nach dreijähriger Inkraftsetzung des HMG noch kein einziges Importbewilligungsverfahren für Parallelimporte zustande gekommen und es sind noch keine Parallelimporte zugelassen worden.

Mittelfristig ist die Medikamentenzulassung der europäischen Pharmabehörde (EMEA) zu anerkennen. Es ist auf Dauer ineffizient und schwer verständlich zu machen, weshalb die gleichen multinationalen Pharmakonzerne ihre gleichen Arzneimittel in der Schweiz Swissmedic mit den genau gleichen wissenschaftlichen Unterlagen und Dokumentationen wie der EMEA zur Zulassung unterbreiten. Dies dient einzig der Marktabschottung aber gewiss nicht der Medikamentensicherheit. 
Ob diese Anerkennung ein bilaterales Abkommen mit den europäischen Behörden erfordert oder ob eine solche Anerkennung einseitig möglich ist, ist zu prüfen.

Der „Swiss Finish“ bei der Pharmazulassung muss beseitigt werden. Heute bestehen zum Heilmittelgesetz sage und schreibe 20 Verordnungen, die von Bundesrat, von Departement und vom Institutsrat von Swissmedic erlassen worden sind. ${ }^{4}$ Beispielsweise wurde auf Institutsebene (sicher nicht im Sinne des Gesetzgebers!) eine Namensidentität für zuzulassende Produkte gefordert, welche in der Folge zu Importschwierigkeiten wegen des Markenrechts führt: Swissmedic fordert, dass das Parallelimportpräparat mit dem in der Schweiz bereits zugelassenen Präparat Namensidentität habe. Unter den Top-10 haben aber 2 vollständig andere Namen (Selipran = Pravasin; Seretide = Viani), wären also bereits aus diesem Grund vom Parallelimportmarkt ausgeschlossen.

Da darüber hinaus auch das Parallelimportpräparat unter dem Originalnamen in der Schweiz in den Handel gebracht werden muss, ergibt sich die zusätzliche Konfliktquelle bzw. ein zusätzliches Prozessrisiko im Bereich des Markenrechts. Weil Swissmedic Namensidentität bei Importprodukten fordert, muss der ausländische Markenname verwendet werden, dies wiederum erfordert die Benützung des Layouts und Logos und mithin der Originalverpackung des Markenherstellers. Dies ist jedoch für Medizinalpersonen und Professionelle (z.B. für Spitalapotheken) völlig überflüssig und bloss kostentreibend.

Zur Zulassungspraxis gehört in Zukunft auch der Nachweis der Wirkungsverbesserung, damit der therapeutische Mehrwert auch bei der Preisfestsetzung berücksichtigt werden kann. Dem BAG schwebt eine Beteiligung an einem internationalen Netzwerk zur Wirkungsanalyse und zum Informationsaustausch vor (sogenanntes Health Technology Assessment). Im Übrigen ist der Ausbau der firmenunabhängigen Pharmakologie mit einem firmenunabhängigen, neutralen Ärzteinformationssystem für Fachpersonen sehr bedeutsam.

\section{Preisstrategie 2: Parallelimporte}

Es muss das Ziel sein, in Zukunft Parallelimporte von Arzneimitteln zu ermöglichen.

Bei Medikamenten mit abgelaufenem Patent ist die Ermöglichung von Parallelimporten bereits durch die Änderung der Zulassungspraxis möglich.

Für Zulassungsgesuche von Spitälern ist eine Gebührenordnung nötig, welche den Marktzutritt möglichst wenig behindert. Ferner sind die Detailvorschriften bezüglich Namensidentität, Dokumentation, „Swiss Finish“ zu korrigieren und zu revidieren. Es ist nicht einzusehen, weshalb zumindest Professionelle und Medizinalpersonen, z.B. Spitalapotheker, Medikamente nicht im Ausland beziehen können. Was nützt Spitalapotheken eine Anschreibepflicht für Verpackungen in drei Sprachen und was nützen Detailvorschriften für den Verpackungszettel? Diese werden ohnehin im Spital weggeworfen und dem Patienten wird das Produkt mit einer eigenen Anschrift ans Bett gebracht.

Höhere Gesetzesschranken und massive Interessenwiderstände gibt es bei Parallelimporten jener Medikamente, die unter Patentschutz stehen. Wir plädieren für eine regional-europäische Patenterschöpfung anstelle der nationalen Erschöpfung. Wir widersetzen uns vehement einer gesetzlichen Festschreibung der nationalen Erschöpfung, übrigens im Einvernehmen mit der Wettbewerbskommission WEKO, die sogar eine internationale Patenterschöpfung forderte. Die nationale Erschöpfung bedeutet, dass ein Alleinvertreiber oder Alleinimporteur die allein ihm zustehende „überschiessende Rechtsmacht“ - sprich: das Marktmonopol - für den gesamten schweizerischen Arzneimittelmarkt erhält, was inm (in den Schranken der Preisfestsetzung bei SLMedikamenten) die Möglichkeit zu jeder Monopolrente verleiht. Eine regional-europäische Erschöpfung bedeutet, dass auch patentierte Produkte direkt aus dem Ausland importiert werden dürfen. Dies heisst aber nicht etwa ein Unterlaufen des Innovationsschutzes oder des $\mathrm{Pa}$ tentrechts. Vielmehr wird in diesem Fall einfach die Lizenzgebühr für 
die Patentnutzung dem ausländischen Hersteller oder Patentinhaber bezahlt, statt dem schweizerischen.

Es wurde ins Feld geführt, die Pharmaindustrie sei auf die Finanzierung der hohen Forschungsaufwendungen angewiesen. Darauf ist zu antworten: Wenn nur 2 Prozent der Produktion der grossen Pharmakonzerne auf den schweizerischen Markt gehen, ist es abwegig, vom schweizerischen Markt einen massiv überproportionalen Forschungskostenanteil zu verlangen. Diese „Heimatschutz-Argumentation“ kann im Zeichen der Globalisierung, die ja die Konzerne für sich beanspruchen, nicht mehr aufrecht erhalten werden.

Wir akzeptieren auch nicht das Argument, ein protektionistisch abgeschotteter Heimmarkt diene dazu, höhere Referenzpreise für Pharmazeutika festzulegen, um dann im Ausland bei der Anlehnung der dortigen administrierten Preise an die schweizerischen Referenzpreise eine Zusatzrente herauszuholen. Auch diese Argumentation widerspricht gerade dem von den multinationalen Konzernen aufrechterhaltenen und gepflegten Dogma der Globalisierungsvorteile.

\section{Preisstrategie 3: Preisfestsetzungsverfahren}

Die Medikamentenpreise bei der SL-Liste sind administrierte Preise. Sie werden vom BAG auf Grund einer Empfehlung der Eidgenössischen Arzneimittelkommission und der Preisüberwachung festgesetzt. Der Kreis der Vergleichsländer wurde zwar von drei auf vier erhöht (Deutschland, Holland, Dänemark + England; + «subsidiär» F, I, A), muss aber noch stärker erweitert werden. Wir plädieren mindestens für den vollen Einbezug aller vier Nachbarländer der Schweiz in den Preisvergleich.

Zudem müssen alle Altmedikamente nun sehr rasch überprüft werden. Neuerdings können auch die neu zugelassenen Medikamente nach zwei Jahren nochmals hinsichtlich der Preisfixierung überprüft werden. Alle diese bestehenden Möglichkeiten der Preisfixierung sind voll auszuschöpfen. Bei den Generica wurde bisher die Referenzländer- methode bei der Preisfestsetzung nicht angewandt (man hatte sich mit der Forderung nach einem 30-prozentigen Preisabschlag gegenüber dem Originalpräparat zufrieden gegeben); diese Methode muss angesichts der Preisüberhöhung in dieser Kategorie nun ebenfalls nachgeholt werden. Ein gewisser Erfolg bei der schärferen Preisfixierung ist bereits in der Statistik feststellbar, indem die neueren Medikamente kleinere Differenzen gegenüber Deutschland aufweisen. Die Generation 1990-1995 wurde noch nie nach den neuen KVG-Regeln überprüft. Dies soll nun nachgeholt werden, so dass die «Altlastenbereinigung» abgeschlossen werden kann.

\section{Preisstrategie 4: Anreizsysteme}

Krankenkassen müssen auch importierte Medikamente, die auf Grund eines Rezepts im Ausland beschafft worden sind, entschädigen können. Dies erfordert eine KVG-Revision, denn nach heutigem Recht wäre korrekterweise eine Entschädigung von Import-Arzneimitteln nur in Ausnahmefällen möglich.

Im Weiteren muss im Krankenversicherungsgesetz festgelegt werden, dass nur das preisgünstige (resp. preisgünstigste) Medikament der gleichen Klasse entschädigt wird.

Es sind auch Anreizsysteme in dem Sinne denkbar, dass der Patient oder Kunde die Hälfte der eingesparten Kosten bei der Beschaffung im Ausland vergütet erhält . Ebenso müssten Ärzte und Spitalapotheker, die Medikamente im Ausland beschaffen, einen pekuniären Sparanreiz erhalten.

Wir plädieren dafür, dass Swissmedic oder eine schweizerische Amtsstelle Adressen von vertrauenswürdigen Bezugsapotheken im nahen Ausland zugänglich macht und damit die Beschaffungssicherheit im Ausland erhöht.

\section{Preisstrategie 5: Anreize für Spitäler}

Für den Spitalbedarf ist die vereinfachte Zulassung und Importmöglich- 
keit vordringlich. Spitalapotheken, die ja einen professionellen Standard vorweisen, müssten sich mit Pharmaprodukten direkt im Ausland eindecken können. Für den Spitalbedarf sind die Importmöglichkeiten bezüglich Anschreibepflicht, Formula officinalis usw. zu erleichtern. Im Weiteren müsste das Rabattsystem für Spitäler nochmals überprüft werden, wobei natürlich mindestens die Hälfte der Rabatte weitergegeben werden müssen.

\section{Zum Schluss}

Wenn wir die preispolitischen Strategien in der aussenhandelspolitischen Optik auflisten, kommen wir zu folgenden vier Punkten:

1. Es braucht einen Beitritt zur EMEA, der europäischen Zulassungsbehörde, oder mindestens die einseitige Zulassungsanerkennung durch die Schweiz.

2. Es braucht eine regional-europäische Patenterschöpfung.

3. Um weitere Probleme anderweitiger nicht tarifarischer Handelshemmnisse auszumerzen, braucht es die Anwendung des Cassis de Dijon-Prinzips auch im Medikamentenbereich.

4. Eine Vergütung von Medikamenten-Direktlieferungen aus dem Ausland an den Patienten (basierend auf einem schweizerischen Rezept) durch die Krankenkasse ist ein längst fälliger Schritt.

Ohne eine systematisch konzipierte und koordinierte Strategie bringen wir die Hochpreispolitik auf dem Schweizer Pharmamarkt nicht zum verschwinden. Die ins Feld geführte Möglichkeit, dass die WEKO neuerdings Vertikalbindungen beseitigen kann (Kartellgesetz Artikel 5 Absatz 4), ist allein gesehen ungenügend. Die WEKO kann zwar in Zukunft Liefer- und Preisbindungen pönalisieren, aber sie kann stets nur Einzelfallweise eingreifen und ihre Entscheide unterliegen erst noch den langwierigen Rekursverfahren bis zum Bundesgericht.

In unserem Land regulieren alle immer mit bestem Wissen und Gewissen im Sinne der Sicherheit: Produktesicherheit, Medikamen- tensicherheit, Versorgungssicherheit usw., alle tun ihr Bestes, aber niemand denkt an den Preis! Für den „Swiss Finish“, den schweizerischen Perfektionismus, zahlen wir einen zu hohen Preis. Wir stehen bei der Beseitigung der Marktabschottungsmechanismen etwa in der gleichen Phase wie vor einem Jahrzehnt bei der Verschärfung des Kartellgesetzes: Mit unzähligen Studien, Interventionen und Abwanderungsdrohungen wurde damals die Verschärfung des Kartellrechts bekämpft. Nun braucht es ebensoviel Energie, um das Hochpreisland Schweiz gegenüber dem Ausland durch Parallelimporte anzugleichen. In zehn Jahren wird man rückblickend die Argumente gegen die Marktöffnung mit Häme belächeln, wie wir dies heute gegenüber den Rechtfertigungstheorien der alten Horizontalkartelle tun.

\section{Preisvergleich Medikamente}

Soviel sind Medikamente in $\mathrm{CH}$ teurer als in D (Jan. 04) (Mehrwertsteuer-korrigiert, $1 €=1.555 \mathrm{Fr}$.), Fabrikabgabepreise (ex factory)

\begin{tabular}{lccl}
$\begin{array}{l}\text { Alle } \\
\text { Medikamente }\end{array}$ & $\begin{array}{c}\text { Aufnahme } \\
\text { bis 1988 }\end{array}$ & $\begin{array}{c}\text { Aufnahme } \\
1989-95\end{array}$ & $\begin{array}{l}\text { Aufnahme } \\
\text { ab 1996 }\end{array}$ \\
\hline Anzahl 2494 & Anzahl 937 & Anzahl 467 & Anzahl 1090
\end{tabular}

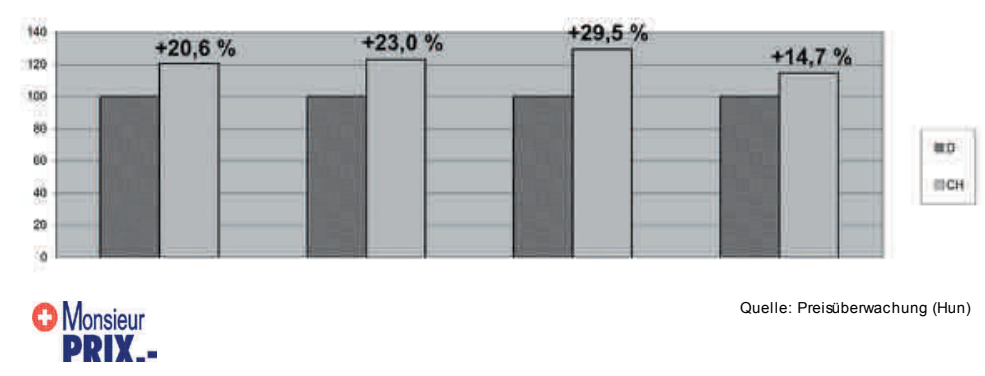




\section{Steigende Medikamentenkosten - \\ sinkende Medikamentenpreise:}

\section{Ein statistisches Paradox?}

Gesundheits- und Medikamentenkosten

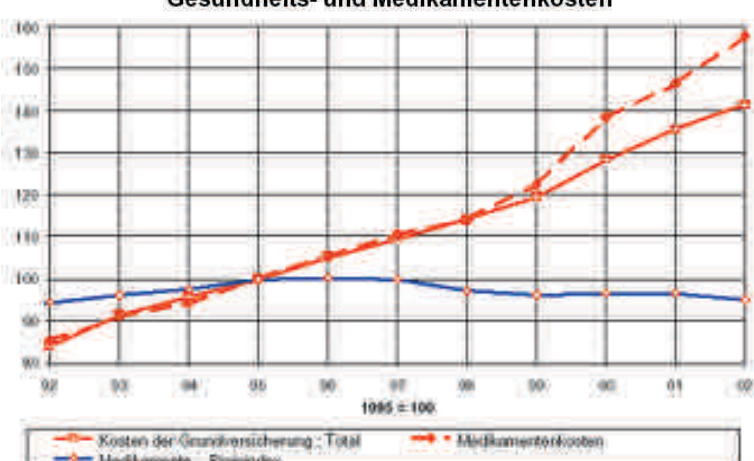

PMonsieur

Quelle: Jahresbericht Preisiberwachung 2003

PRIX.-

\section{Fussnoten:}

Dr. Josef Hunkeler, Mitarbeiter und Pharmaspezialist bei der Preisüberwachung, hat zu diesem Artikel die Daten und Statistiken geliefert.

2 Jahresbericht 2004, in „Recht und Politik des Wettbewerbs“ Nr. 5/2004, Seite 1352 Tabelle I

3 Jahresbericht des Preisüberwachers 2003 in: "Recht und Politik des Wettbewerbs" Nr 5/2003 Seite 1021, Tab 2.,

${ }^{4}$ Siehe Website www.swissmedic.ch, Rubriken „Fachpersonen“, „Recht und Normen“ 


\section{DIE SCHWEIZ UND DAS AUSLAND - KONZEPTIONELLE ÜBERLEGUNGEN}

Guido Barsuglia, Wissenschaftlicher Mitarbeiter, Europainstitut der Universität Basel

Die Frage, ob Parallelimporte von pharmazeutischen Produkten zugelassen werden sollen oder nicht, ist nicht so einfach mit einem Ja oder einem Nein zu beantworten. Zwar lassen sich Befürworter und Gegner von Parallelimporten schnell ausfindig machen: Gesundheitsbudgets, Krankenkassen und Konsumenten werden für Parallelimporte sein, da sie vom tieferen ausländischen Preis profitieren wollen. - Pharmaproduzenten sind klar gegen Parallelimporte, da sie Verluste befürchten. Doch wo liegt die volkswirtschaftliche Optimallösung? Wie viel gewinnen Konsumenten, wie viel verlieren Produzenten tatsächlich? Und wie vergleiche ich volkswirtschaftlich unterschiedliche Erschöpfungsregime?

Genau die Beantwortung dieser Fragen sehe ich als meine Aufgabe an der heutigen Tagung an. Darum lautet auch der Untertitel meines Referats: Wie finde ich konzeptionell volkswirtschaftliche Optimalität. Herr Vaterlaus von Plaut Economics wird dann in seinem nachfolgenden Referat empirische Schätzungen präsentieren, die auf ähnlichen Überlegungen beruhen und mit welchen er bereits den Bundesrat bei seinen Entscheidungen unterstützt hat und auch weiterhin unterstützen wird.

Zur Struktur meines Vortrags. Eine Antwort auf meine eingangs gestellten Fragen basiert auf dem Konzept der Maximierung der Gesamtwohlfahrt. Wir suchen nun diese Gesamtwohlfahrt, genauer gesagt ihre Zusammensetzung in zwei Grundszenarien: Einerseits am gewöhnlichen Wettbewerbsmarkt und andererseits am regulierten Pharmamarkt. In beiden Grundszenarien werde ich Ihnen zeigen, was passiert, wenn Sie die Grenzen zum Ausland öffnen, sprich Importe 
zulassen. Wir werden sehen, dass sich der Pharmamarkt klar vom gewöhnlichen Wettbewerbsmarkt unterscheidet. Ich schliesse mit Folgerungen und einigen Fragen als Stoff für die Diskussion.

Bevor wir uns in die Welt der Wohlfahrtsdreiecke begeben, möchte ich noch zwei Punkte vorausschicken: Erstens, ich werde Ihnen ein Modell vorstellen. Dieses Modell versucht nicht die Realität als Ganzes abzubilden, denn dann könnte ich gar nichts aussagen. Darum arbeite ich mit einer Teilrealität um Ihnen mögliche Entwicklungen aufzeigen zu können. - Vereinfachungen und Annahmen helfen uns dabei. Zum Zweiten möchte ich meine Ausführungen auch für Nichtökonomen verständlich machen und werde daher versuchen eine einfache Sprache zu wählen. Dies, da mir gerade der Weg zu meinen Schlussfolgerungen sehr wichtig ist. - Doch genug der einführenden Worte. Lassen Sie uns einsteigen in eine Welt der Modelle und Konzepte.

\section{Der Käsemarkt - ein Wettbewerbsmarkt}

Ich beginne meine Überlegungen auf einem gewöhnlichen Wettbewerbsmarkt. Sagen wir, es sei der Schweizer Markt für Käse, vielleicht noch spezifischer, der Schweizer Markt für Lochkäse.

Ökonomen beschreiben einen Markt grundsätzlich über Angebot und Nachfrage und stellen diesen wie in Abbildung 1 für den isolierten Schweizer Käsemarkt dar: Die Nachfragekurve repräsentiert die Konsumenten und gibt an, wie viel Käse Konsumenten bereit sind, zu einem bestimmten Preis zu kaufen. Umgekehrt steht die Angebotskurve für die Produzenten und gibt an, wie viel Käse Produzenten bereit sind, zu einem bestimmten Preis anzubieten. - Was grundsätzlich von ihren Herstellungskosten abhängig ist.

Der Marktpreis bringt schlussendlich Angebot und Nachfrage in ein Gleichgewicht. Das Schöne bei der Geschichte ist, dieser Marktpreis findet sich am Käsemarkt durch Feilschen der Akteure vollkommen von selbst. Grafisch endet dieses Feilschens genau im Schnittpunkt der beiden Geraden mit dem Gleichgewichtspreis $\mathrm{P}_{\mathrm{AUT}}$ und der Gleichgewichts- menge $Q_{A U T}$ Zudem ist dieses Gleichgewicht aus volkswirtschaftlicher Sicht optimal. - Wie lässt sich nun diese volkswirtschaftliche Optimalität zwischen Konsumenten und Produzenten als Grösse darstellen? Ich sagte einleitend, ich brauche diese Grösse, um Szenarien geschlossener und offener Grenzen miteinander vergleichen zu können.

\section{Der Wettbewerbsmarkt in Autarkie}

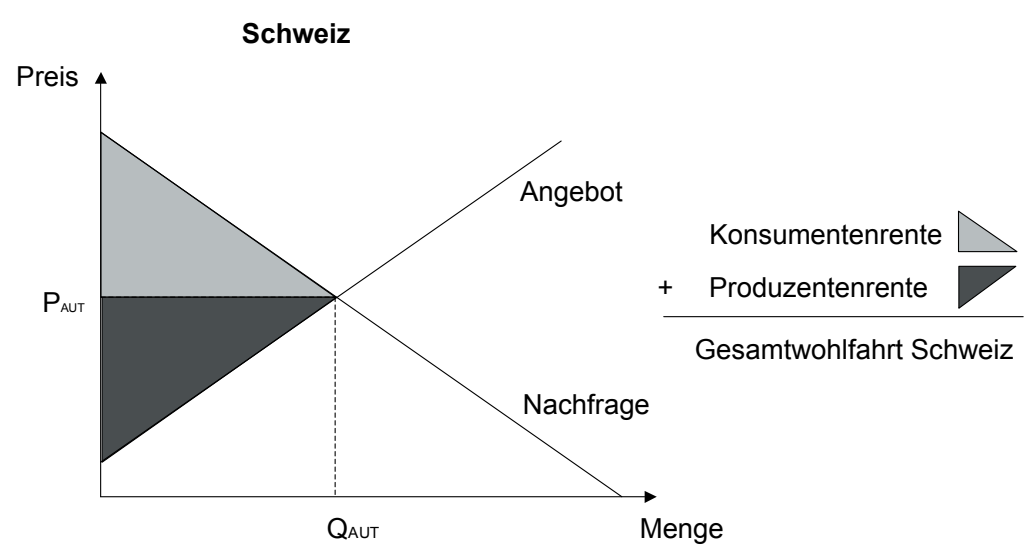

Abbildung 1

Beginnen wir mit einem realistischen Beispiel und den Konsumenten. Stellen Sie sich vor, Sie beschliessen einen Kilo Käse mit Löchern zu kaufen, und Sie sind bereit, dafür 30 Franken auszugeben. Im Geschäft stellen Sie fest, dass ein Kilo Käse nur 20 Franken kostet. Sie gewinnen also theoretisch 10 Franken mit welchen Sie entweder mehr Käse oder andere Güter kaufen können. Diesen theoretischen Gewinn von 10 
Franken nennen wir ökonomisch Konsumentenrente und können diese in Abbildung 1 für alle Schweizer als hellgraues Dreieck einzeichnen. Wichtig ist für meine weiteren Ausführungen, dass Sie sich merken: Konsumentenrente ist die hellgraue Fläche oberhalb des Preises und unterhalb der Nachfragekurve.

Die gleiche Überlegung können wir auch für die Produzenten anstellen, indem wir fragen, wie viel gewinnen die Produzenten wenn sie am Käsemarkt teilnehmen? Nachdem unternehmerischer Gewinn nichts anderes ist als Erlöse minus Kosten, muss die Fläche zwischen Angebotskurve und Preis den Gewinn der Produzenten angeben. Ich nenne diesen Gewinn Produzentenrente und färbe ihn hier und in Folge schwarz ein.

Zusammen ergeben Konsumenten- und Produzentenrente die Gesamtwohlfahrt eines Landes aus einem bestimmten Markt. Wie Sie richtig vermuten, muss es das Ziel sein diese Gesamtwohlfahrt zu maximieren. Und wie wir hier sehen, ist sie am Wettbewerbsmarkt von alleine so gross als möglich.

\section{Offene Grenzen am Wettbewerbsmarkt}

Soweit der Schweizer Lochkäsemarkt in der Autarkie. Ich habe mir absichtlich etwas mehr Zeit für diesen Teil gelassen um im Folgenden auf diesen Grundkonzepten aufbauen zu können: Konsumentenrente, Produzentenrente und Gesamtwohlfahrt. - Jetzt fragen wir uns was passiert, wenn wir unsere Grenzen öffnen, und zwar für identischen, aber weit billigeren ausländischen Lochkäse. Dieses tiefere ausländische Preisniveau erkennen Sie in Abbildung 2 durch den fett gezeichneten Weltmarktpreis. Ich habe den ausländischen Preis absichtlich so gewählt, dass kein einziger Schweizer Käseproduzent aufgrund seiner hohen Kosten mit dem Ausland mithalten kann. Das Ausland ist schlicht effizienter in der Produktion. Die Schweiz wird schlussendlich keinen Käse mehr selbst herstellen, sondern nur noch importieren.

\section{Der Wettbewerbsmarkt bei offenen Grenzen}

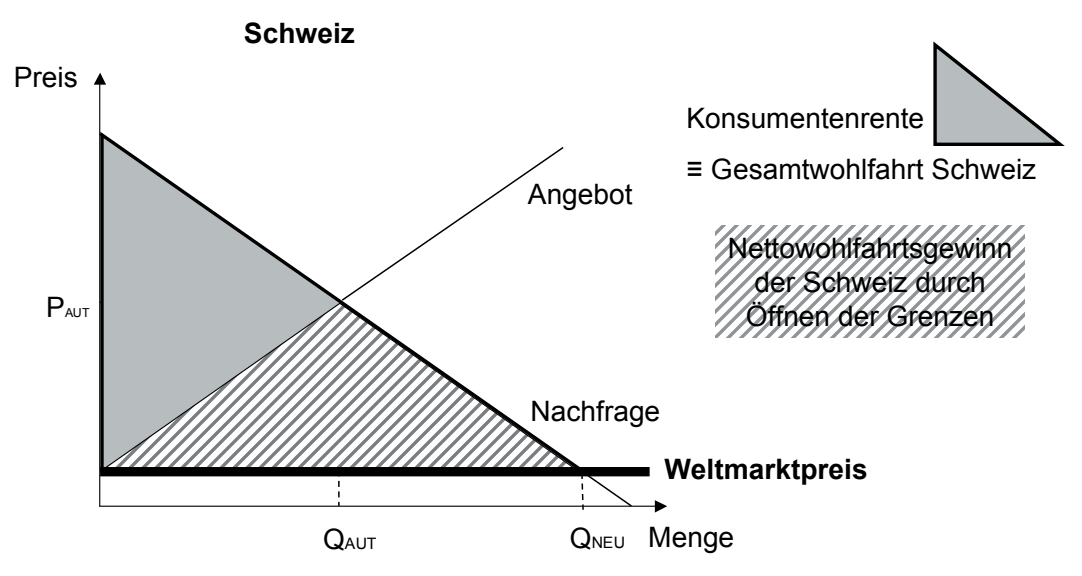

Abbildung 2

Lassen Sie mich die Frage nach der Veränderung die jetzt hier stattgefunden hat, mittels des Konzepts der Gesamtwohlfahrt beantworten. - Wie klar zu sehen ist, sind zu diesem neuen tieferen Preis die Konsumenten der Schweiz bereit, mehr Käse zu kaufen, nämlich $Q_{N E U}$. Andererseits sind die Konsumenten, die zuvor schon Käse gekauft haben erfreut über diesen tieferen Preis und gewinnen dazu. Kurz die Konsumenten gewinnen klar durch eine Öffnung der Grenzen. Wenn Sie sich an das Konzept der Konsumentenrente erinnern, sehen Sie auch, dass das hellgraue Dreieck in Abbildung 2 nun weit grösser ist als in Abbildung 1. 
Tja, und was ist mit den Produzenten? Nachdem kein einziger Schweizer Käseproduzent der ausländischen Konkurrenz Parole bieten kann, gibt es auch keine Produzentenrente. Folglich entspricht die Konsumentenrente der Schweizerischen Gesamtwohlfahrt aus diesem Markt. - Diese Gesamtwohlfahrt ist wie Sie sehen, klar grösser als in der Autarkie. Das grosse hellgraue Dreieck deckt nicht nur die alte Konsumenten- und Produzentenrente ab, es deckt auch noch eine neue, graugestreifte Fläche ab. Das heisst das Öffnen der Grenzen schafft Wohlfahrtsrente die im Autarkiezustand gar nicht möglich gewesen wäre, eben dieses graugestreifte Dreieck. Das heisst, die Schweiz als Ganzes gewinnt ganz klar von einem Öffnen der Grenzen. Selbst wenn sich nun die Schweizer Konsumenten bereit erklärten, die Verluste der verlierenden und vertriebenen heimischen Produzenten vollkommen zu entschädigen, - die Schweiz stünde als Ganzes immer noch besser dar, als in der Autarkie.

Soweit der Käsemarkt. Er führt ohne Preisregulierung, ohne Monopol und ohne Handelsschranken von selbst zum Wohlfahrtsoptimum.

\section{Der Pharmamarkt - Annahmen}

Im zweiten Teil meines Referates will ich ähnliche Überlegungen für den Pharmamarkt anstellen. Dabei muss ich mit einigen Annahmen beginnen, die es mir erlauben diesen Pharmamarkt auch zu modellieren:

Erstens, ich werde sowohl den Pharmamarkt der Schweiz, als auch den Pharmamarkt des Auslands abbilden. Wichtig ist mir dabei, dass das Ausland, zu dem ich später die Grenzen öffnen werde, der Schweiz nicht unähnlich ist, wie zum Beispiel die ehemaligen EU15 Mitgliedstaaten.

Mit den nächsten beiden Annahmen komme ich bereits zu den Wesensmerkmalen des Pharmamarktes. Einerseits wird dem Pharmaproduzent durch den Patentschutz eine Monopolstellung verliehen, die es dem Produzenten grundsätzlich erlaubt selbst den Preis für sein Medikament festzulegen. Andererseits unterliegt er aber auch in den meisten Ländern einer staatlichen Höchstpreisregulierung, sodass es inm nicht möglich ist, seinen Preis $x$-beliebig hoch zu setzen. - Zudem nehme ich noch an, dass es sich bei unserem Pharmaproduzenten, der das In- und Ausland beliefert, um einen Schweizer Unternehmer handelt - also zum Beispiel Roche oder Novartis.

Noch drei weitere Annahmen bevor wir starten. Zur Vereinfachung nehme ich an, dass jedes Medikament in der Erzeugung nichts kostet, die Grenzkosten also null sind. Das heisst, eine weitere Packung Aspirin kostet einen Hersteller nichts. - Aber dem Produzenten erwachsen, wie wir wissen, hohe komplexe und unsichere Forschungs- und Entwicklungskosten, weshalb konsequenterweise Medikamente auch in unserem Modell nicht kostenlos abgegeben werden können. Herr Cueni von der Interpharma wird in seinen Ausführungen bestimmt noch näher auf diese Forschungs- und Entwicklungsausgaben eingehen. - Zum Schluss nehmen wir noch lineare Nachfragekurven an.

Wenn Sie jetzt diese Annahmen oder Gegebenheiten so vor sich sehen, so sind es im Prinzip genau drei die den Pharmamarkt so speziell machen: Der monopolistische Produzent, die Höchstpreisregulierung und die komplexe Fixkostenstruktur. Doch wenn wir es genau nehmen, lassen sich diese drei Eigenheiten auf eine Eigenheit zurückführen, nämlich auf die komplexen und ungewissen Forschungs- und Entwicklungskosten. - Mehr zu diesem Punkt gerne in der Diskussion.

\section{Szenario geschlossene Grenzen}

Lassen Sie uns mit einem Szenario am Pharmamarkt beginnen, das dem heutigen entspricht, nämlich einer nach aussen hin abgeschotteten Schweiz - sprich geschlossene Grenzen - bedingt durch die nationale Erschöpfung im Patentrecht.

Ich verwende wiederum eine Grafik zur einfachen Darstellung (Abbildung 3). Links sehen Sie ein Diagramm, das die Nachfragekurve nach pharmazeutischen Produkten in der Schweiz darstellt, rechts eines für das Ausland. Je nachdem für welche Überlegungen Sie dieses Modell 
verwenden wollen, können Sie an der Nachfragekurve des Auslandes etwas schrauben. - Stossen Sie sich bitte nicht daran, dass Sie jetzt im Gegensatz zum Käsemarkt keine Angebotskurve vorfinden, das liegt an den Annahmen. Die beiden dicken horizontalen Linien in $A b$ bildung 3 stehen für Preisplafonds und somit für die aktuellen Preise im In- und Ausland. - Soweit das Setting. - Wie schon am Käsemarkt will ich Konsumenten- und Produzentenrente ermitteln. Sie erinnern sich, die Konsumentenrente ist die Fläche zwischen Preis und Nachfragekurve und kann durch die beiden hellgrauen Dreiecke für jedes Land eingezeichnet werden. Die Produzentenrente zum anderen, war nichts anderes als der Erlös. Dieser lässt sich aufgrund unserer Annahmen als zwei schwarze Rechtecke darstellen. - Wir betonen nochmals, der Schweizer Pharmaproduzent erzielt sowohl im Inland als auch im Ausland Erlöse.

Wichtig ist, dass der Pharmaproduzent über diese Erlöse, schwarzen Rechtecke, seine Forschungs- und Entwicklungskosten decken muss. - Uns stellt sich damit bereits die Kernfrage, nämlich: Kann er das? Werden die komplexen Forschungs- und Entwicklungskosten durch die Erlöse aus dem In- und Ausland, die ja beide reguliert sind, gedeckt? - So einfach und schnell diese Frage gestellt ist, so schwierig ihre Beantwortung und ich bin wirklich sehr gespannt auf die Ausführungen der Pharmaindustrie und der beiden Preisregulatoren, die sich tagtäglich mit dieser Frage auseinandersetzen müssen.

\section{Zwei - Länder - Patent - Höchstpreisregulierung} geschlossene Grenzen / nationale Erschöpfung

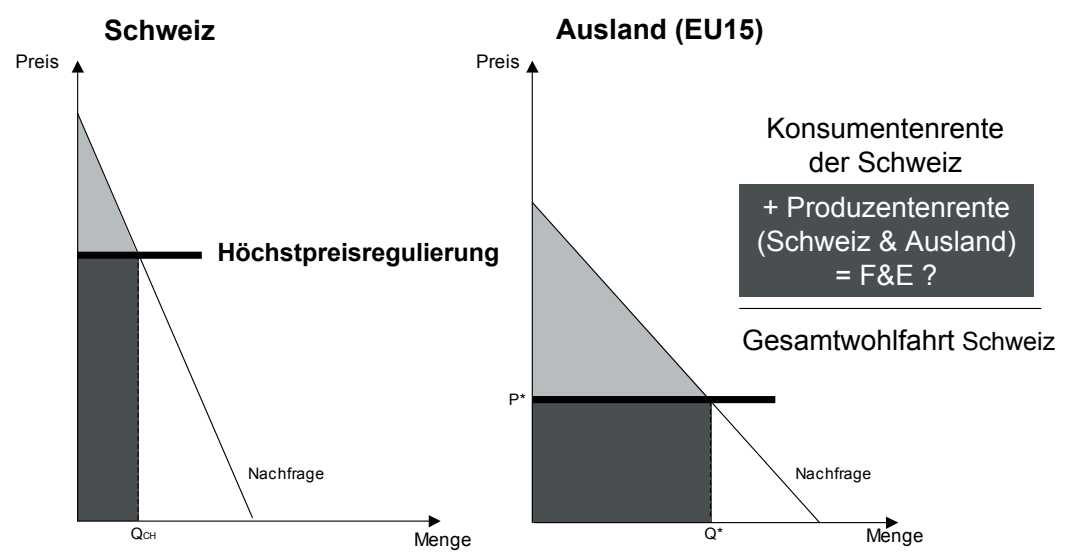

Abbildung 3

Wir wollen wieder die Grösse der Schweizer Gesamtwohlfahrt aus diesem Markt ansehen. Diese ergibt sich durch zusammenzählen der Schweizer Konsumentenrente und der Produzentenrente aus beiden Ländern. Also das hellgraue Dreieck der linken Abbildung plus die zwei schwarzen Rechtecke. Das ist faktisch die Gesamtwohlfahrt der Schweiz zum heutigen Zeitpunkt - Status quo.

\section{Szenario offene Grenzen}

Soweit so gut, im nächsten Schritt will ich Ihnen zeigen, was voraussichtlich passiert, wenn die Schweiz ihre Grenzen zur ehemaligen EU15 öffnet. Viele Szenarien sind denk- und diskutierbar, eines möchte ich 
speziell herausgreifen. - Lassen Sie uns davon ausgehen, dass ein Öffnen der Grenzen dazu führt, dass der Preis in der Schweiz auf das ausländische Preisniveau sinkt. Im Ausland sich aber durch ein Öffnen der Grenzen nichts tut. Sei es weil das Ausland eben sehr gross ist oder weil der Preisregulator im Ausland sich weiterhin durchsetzen kann. Sie sehen jetzt in Abbildung 4 die dicke ausländische Preislinie bis in die Schweiz verlängert. Zu diesem günstigeren Preis werden in der Schweiz mehr Medikamente gekauft, $Q_{c{ }^{\circ}}^{0}$ Im Ausland ändert sich wie gesagt durch ein Öffnen der Grenzen nichts. - Was passiert nun in der Schweiz durch den tieferen Preis?

Einerseits steigt die Konsumentenrente, das heisst die Konsumenten gewinnen. Das hellgraue Dreieck in der Schweiz wird grösser. Es überdeckt jetzt einen Teil der vormaligen Produzentenrente und sogar noch etwas mehr. Aber auch die Produzentenrente verändert sich. So werden die Erlöse des Produzenten in der Schweiz kleiner. Er kann zwar einen Teil seiner Verluste durch Mehrverkäufe in der Schweiz etwas abfedern, doch in Summe bedeutet ein Öffnen der Grenzen in diesem Szenario immer einen Verlust an Produzentenrente. Denn wäre dem nicht so, dann hätte der Produzent bestimmt schon vorher den tieferen Preis gesetzt um seine Gewinne zu maximieren.

Was passiert mit der Schweizerischen Gesamtwohlfahrt, sprich dem vormaligen hellgrauen Dreieck in der Schweiz plus, den beiden vormalig schwarzen Rechtecken? In der Schweiz ist die Konsumentenrente beachtlich gestiegen, wie Sie sehen, und die Produzentenrente etwas gesunken. Die ausländische Produzentenrente hat sich nicht verändert. Sie sehen, das hellgraue Dreieck und das schwarze Rechteck der Schweiz bedecken mehr Fläche als bei geschlossenen Grenzen - ich habe die neuen, zusätzlichen Flächen gestreift markiert. Folglich muss die Schweiz als Ganzes von einem Öffnen der Grenzen profitiert haben.

Wie am Käsemarkt finden wir also eine gestreifte Fläche, die den Nettowohlfahrtsgewinn der Schweiz angibt. Mein Nachredner hat eine ähnlich gestreifte Fläche vor zwei Jahren empirisch geschätzt und dem Bundesrat vorgelegt. Sie erinnern sich an die 0 bis 0.1 Prozent die das Schweizerische Bruttoinlandsprodukt durch ein Öffnen der Grenzen anwachsen würde.

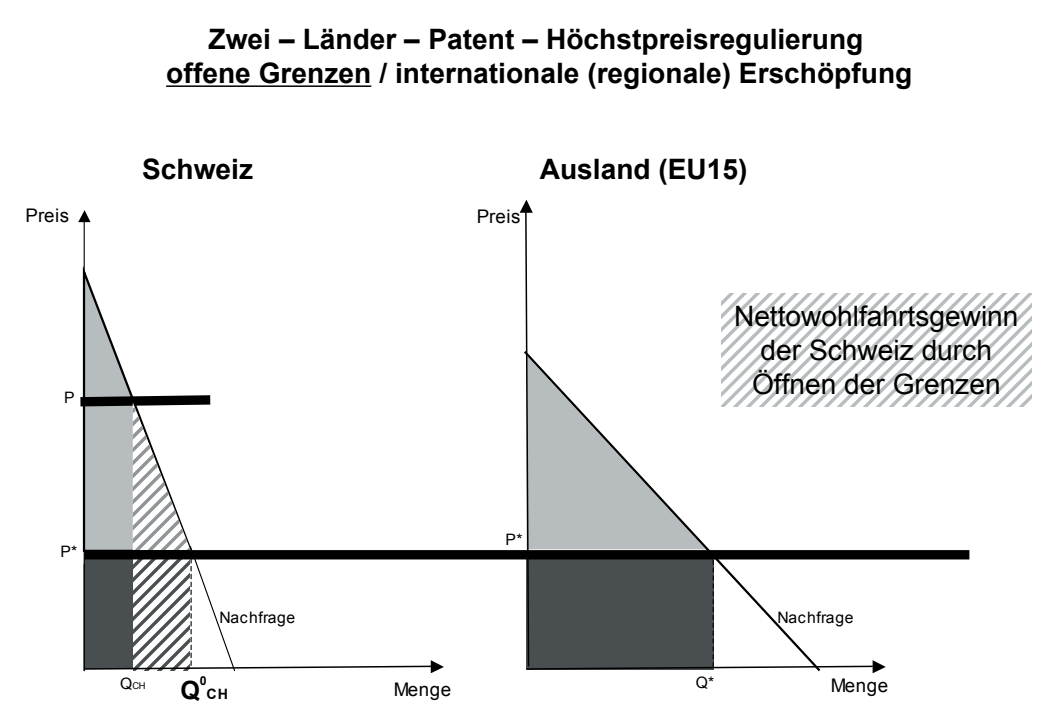

Abbildung 4

\section{Folgerungen, Fragen und Diskussion}

Sehr geehrte Damen und Herren, gleiches Resultat wie am Käsemarkt, warum dann die ganze Diskussion und was soll der Hokuspokus? Eben nicht ganz gleiches Resultat. Am Käsemarkt war es den Schweizern als auch der Welt relativ egal, ob Schweizer Käseproduzenten zu den tieferen Preisen nicht mehr produzierten, denn im Ausland gab es noch 
genügend andere Produzenten, die genauso guten Käse effizienter und somit günstiger herstellten. Am Pharmamarkt ist das etwas anders. Sollte die Öffnung dem Produzenten so viele Mittel entziehen, dass nicht mehr genug Geld für gute F\&E da ist, so verliert nicht nur die Schweiz in der nächsten Runde, sondern mit ihr die gesamte Welt. Denn pharmazeutische Produkte werden nicht für einzelne Märkte entwickelt sondern für die gesamte Welt. - Im abgeschotteten Ausland gibt es grundsätzlich auch keine produktiveren Produzenten.

Darum reduziert sich die wesentliche Frage, ob nach einer Öffnung der Grenzen noch immer genügend Erlöse erzielt werden, um effiziente Forschung und Entwicklung zu finanzieren. Sprich ob die beiden schwarzen Rechtecke nach dem Öffnen der Grenzen gross genug sind. Sind sie das nämlich nicht, dann schädigt ein Öffnen der Grenzen die Gesamtwohlfahrt.

Also doch nicht öffnen? Die schwarzen Rechtecke werden nämlich bestimmt kleiner. Hierzu müssen Sie mich allerdings vier Einschränkungen machen lassen:

Erstens, die Schweiz könnte die verlierenden Produzenten entschädigen und trotzdem mittels offener Grenzen weit besser dastehen als zuvor. - Zweitens, darf nicht vergessen werden, dass die Schweizer Produzenten $90 \%$ ihrer Erlöse im Ausland erzielen und somit die Verluste im Inland sehr bescheiden ausfallen werden, denn im Ausland verliert der Produzent ja nichts. Doch dieses typische Trittbrettfahrerargument kleiner Länder möchte ich auf keinen Fall überbetont wissen. - Drittens, ist es bereits bei geschlossenen Grenzen mit einer Preisregulierung unklar, wie ich Ihnen gezeigt habe, ob genügend Rente oder zuviel Rente für effiziente F\&E generiert wird. - Und es gibt noch einen vierten Punkt: Das Model basiert natürlich auf gewissen Annahmen und je nachdem wie Sie das Ausland modellieren kann ich Ihnen auch ganz klar ein Szenario zeigen, in welchem der Schweizer Pharmaproduzent durch eine Öffnung klar gewinnt.

Ich komme zum Schluss, überfliege nochmals kurz meine Ausführun- gen und möchte mit einigen absichtlich provokativ gestellten Fragen zur Diskussion anregen. - Ich ging konzeptionell an die Frage, Parallelimporte Ja oder Nein, heran. Ich tat dies am gewöhnlichen Markt, als auch auf dem Pharmamarkt und konnte die bedeutendsten Unterschiede aufzeigen. Zudem konnte ich die Bedeutung der einzelnen Akteure herausstreichen und ich freue mich, dass wir für diese Tagung auch alle angesprochenen Akteure in Person gewinnen konnten. Unter den gewählten Annahmen konnte ich Ihnen zeigen, dass die Wohlfahrt der Schweiz und so auch der Zwei-Länder-Welt durch eine Liberalisierung steigt. Wichtige Annahme dabei war, dass die Länder ähnlicher Natur sind. Klar ist ebenfalls, dass die Schweizer Höchstpreisregulierung im Fall von offenen Grenzen hinfällig wird. Unklar bleibt weiterhin, ob die Rente die der Produzent bei offenen Grenzen erzielt für effiziente F\&E ausreicht. Ich habe diese Befürchtungen allerdings auch relativiert.

Mit vier Fragen für die Diskussion möchte ich mein Referat beenden

Ersten, wie passen Patent - und was man heute immer öfter hört: Patentverlängerungen - und Preisregulierung zusammen? Zweitens, ist die F\&E des Pharmaproduzenten unter den heutigen Regulierungen optimal? Drittens, wie steht es mit der detaillierten Überregulierung der einzelnen Akteure im Gesundheitswesen? - Ich meine damit Krankenkassen, Ärzte, Apotheker, Patienten, Produzenten, Parallelimporteure, Zulassungsstellen, Generika, etc.

Und viertens, ein allerletztes Gedankenexperiment: Wo befänden wir uns, wenn sämtliche Preisregulierungen am Pharmamarkt abgeschafft würden, Parallelimporte zwischen ähnlichen Ländern zugelassen würden, jedoch zwischen wirtschaftlich verschiedenen Ländern verboten bleiben, die optimale Patentdauer variiert wird und nach Ablauf des Patentschutzes nur mehr Generika verkauft würden? 


\section{PARALLELIMPORTE IN DIE SCHWEIZ - EMPIRISCHE RESULTATE}

Dr. Stephan Vaterlaus, Mitbegründer und Leiter Plaut Economics, Regensdorf

Eigentlich könnte ich es mir sehr einfach machen und Sie rechtzeitig für das Mittagessen entlassen. Die Ergebnisse unserer Studie wurden ja schon verschiedentlich angesprochen. Trotzdem möchte ich Ihnen in den nächsten 20 Minuten noch etwas detaillierter aufzeigen, wieso wir zu diesen Ergebnissen gekommen sind.

\section{Ausgangslage}

Erlauben Sie mir, dass ich zuerst ganz kurz auf die Ausgangslage eingehe. Grundlage für unsere Studie war der Bericht des Bundesrats aus dem Jahre 2000. Basierend darauf wurden drei verschiedene Gutachten in Auftrag gegeben: ein juristisches Gutachten, einen Preisvergleich von Medikamenten und schliesslich ein volkswirtschaftliches Gutachten, das wir zusammen mit Frontier Economics und unter Nutzung der ökonometrischen Modelle der BAK Basel Economics in den Jahren 2001 und 2002 erstellt haben. All jene, welche sich für die detaillierten Analysen und Berechnungen interessieren, können den gesamten Bericht auf der Homepage des Eidgenössischen Volkswirtschaftdepartements unter dem Dossier Parallelimporte beziehen.

Ich werde im Laufe des Referates kurz auf eine Aktualisierung dieser Studie eingehen. Dabei handelt es sich um die Beantwortung der Frage, wie sich die Ergebnisse der Studie ändern würden, wenn anstelle eines Wechsels von der nationalen zur internationalen Erschöpfung im Patentrecht ein Wechsel zur regionalen Erschöpfung unterstellt würde. 


\section{Die volkswirtschaftliche Studie}

Um Ihnen das Projekt etwas näher zu bringen, werde ich zu Beginn auf die eigentliche Aufgabenstellung eingehen. Anschliessend werde ich aufzeigen, wie wir die Fragen theoretisch umgesetzt haben und welche internationalen Erkenntnisse aus ähnlichen Untersuchungen für die Schweiz gewonnen werden können. Der Kern der Ausführungen konzentriert sich auf den dritten Teil des Vortrages. Darin geht es im Prinzip um die Kernfrage, wie die von Herrn Barsuglia aufgezeigten Wohlfahrtsdreiecke quantifiziert werden. Dazu untersuchten wir im Rahmen einer spieltheoretischen Analyse das Verhalten der verschiedenen Akteure. Abschliessen werde ich meinen Vortrag mit dem bereits erwähnten Ausblick über die Aktualisierung der Studie.

Die Ausgangslage für die Untersuchung ist die nationale Erschöpfung im Patentrecht. In diesem Zusammenhang ist zu betonen, dass es somit in der Untersuchung nur um Produkte gegangen ist, die einen Patentschutz aufweisen. Güter für die andere Schutzrechte wie beispielsweise der Markenschutz Gültigkeit haben, können bereits heute parallel importiert werden und wurden folglich in der Untersuchung nicht berücksichtigt.

Um das von einem Regimewechsel im Patentrecht maximal betroffene Arbitragepotential zu ermitteln, haben wir in einem ersten Schritt in den Branchen, bei welchen der Patentschutz von Bedeutung ist, das Gütervolumen ermittelt, welches für Parallelimporte in Frage kommt. Dabei mussten drei Bedingungen erfüllt sein:

- Erstens muss ein Patentschutz vorliegen.

- Zweitens muss das Gut handelbar sein.

- Drittens müssen die Preise in der Schweiz für diese Güter im internationalen Vergleich höher liegen.

Im Rahmen einer spieltheoretischen Analyse haben wir sodann das Verhalten der verschiedenen involvierten Akteure (Patentinhaber, Pa- rallelimporteure, offizielle Importeure, Kunden, etc.) modelliert. Das Ergebnis ergab das effektiv mögliche Arbitragepotential für patentgeschützte Güter. Mit anderen Worten wurde untersucht, wie viel vom ermittelten maximalen Arbitragepotential aufgrund Transaktionskosten, Markteintrittsbarrieren, etc. nicht ausgeschöpft wird. Diese sektorspezifischen Ergebnisse flossen schliesslich in die ökonometrischen Branchen- und gesamtwirtschaftlichen Modelle ein, woraus sich die gesamtwirtschaftlichen Effekte eines Systemwechsels im Patentrecht errechnen liessen.

Welche theoretischen Reaktionsmechanismen liegen hinter der gesamten Analyse? Ausgegangen wird von einem höheren Preisniveau in der Schweiz. Unterstellt wird, dass in der Schweiz das Preisniveau durch Parallelimporte sinkt. Dadurch steigt die Konsumentenrente und die Produzentenrente sinkt. Die Wirkung ist somit wohlfahrtsökonomisch zumindest kurzfristig positiv. Die Frage, die sich stellt ist, welche sogenannte „second-round“-Effekte über das Investitionsverhalten bezüglich Forschung/Entwicklung zu verzeichnen sind und wie langfristig der Gesamteffekt ausfällt. Des Weiteren spielt es eine Rolle, ob der Systemwechsel nur in der Schweiz erfolgt, oder ob diese Entwicklung auch in anderen Ländern zu beobachten ist. Je nachdem sind natürlich die Effekte insbesondere auf Forschung/Entwicklung anders zu beurteilen.

\section{Das Verhalten der Akteure}

Ein wichtiger Punkt der Analyse war die Modellierung des Verhaltens der verschiedenen Akteure. Es ist zu erwarten, dass ein solcher Systemwechsel bei den betroffenen Akteuren Reaktionen auslösen wird. So versuchen die Hersteller beispielsweise ihre Marktanteile zu sichern, indem sie die Produkte zwischen den Ländern differenzieren, kurzfristige Preissenkungen im Inland oder mittelfristige Preisanhebungen in den billigen Ländern vornehmen oder Produkte bündeln, indem sie beispielsweise die Produkte an gewisse Serviceleistungen koppeln. 
Aber auch der Staat reagiert. Er hat Einfluss auf das Ausmass von Parallelimporten, indem er beispielsweise die Zulassungsbedingungen ändert und somit einen direkten Einfluss auf die Höhe der Transaktionskosten der Parallelimporteure ausübt. Die Transaktionskosten wiederum sind entscheidend für den Parallelimporteur, wie gross die Preisdifferenz sein muss, damit es sich noch rechnet, Produkte in die Schweiz parallel zu importieren.

Und schliesslich reagieren natürlich auch die Parallelimporteure. Diese sind selbstverständlich nicht zwingend an der Versorgung der Schweiz an billigen Gütern interessiert, sondern sie wollen mit Parallelimporten Geld verdienen. Das heisst, sie versuchen den Kostenvorteil so weit wie möglich - im Sinne von Arbitrage - auszureizen. Je nachdem, wie die regulatorischen Rahmenbedingungen sind respektive sich ändern reagieren Hersteller, Staat und Parallelimporteure unterschiedlich. Dies wiederum hat Einfluss auf das Potential das parallel importiert werden kann sowie auf die für die Schweizer Konsumenten verbleibende Preisdifferenz.

\section{Blick auf ausländische Studien zu dieser Thematik}

Wenn wir kurz den Blick über die Grenzen der Schweiz schweifen lassen, dann gab es schon verschiedene Studien, die sich mit der Thematik „Parallelimporte“ auseinander gesetzt haben. Da die Studien mit unterschiedlichen Methoden arbeiten, andere Ländervergleiche und Zeiträume berücksichtigen, sind die Ergebnisse nicht direkt vergleichbar. Trotzdem möchte ich Ihnen einen Überblick über zwei eher ältere und zwei eher aktuellere Studien geben.

In Dänemark war das Industrieministerium die Frage der Parallelimporte angegangen und auf Basis von Zeitungsartikeln und Publikationen der Wettbewerbsbehörde versucht herauszufinden, wie hoch der Anteil an marken- und patentgeschützten Produkten in Dänemark ist ${ }^{2}$, wobei keine Preiseffekte geschätzt wurden. Als wichtiges Ergebnis resultierte, dass $70 \%$ der untersuchten oder erfassten parallel impor- tierten Produkte Pharmazeutika waren. Der Marktanteil dieser parallel importierten Güter am gesamten Pharmamarkt lag bei etwa $11 \%$.

In Schweden wurde konkret ein Systemwechsel untersucht. Dabei stand die Frage im Zentrum, welche Auswirkungen der Übergang von der nationalen zur internationalen Erschöpfung hat. ${ }^{3}$ Im Rahmen dieser Studie wurden auch Preiseffekte geschätzt. Das Ergebnis der Studie war, dass vier Jahre nach dem Systemwechsel der Marktanteil der parallel importierten Güter etwa bei 6\% lag. Der Preiseffekt betrug rund $4 \%$. Da bedeutet konkret, dass die Preissteigerung der parallel importierten Produkte $4 \%$ weniger stark ausgefallen ist, als die Preissteigerungen der Produkte, für welche keine solche Konkurrenz vorhanden war.

Bei den beiden jüngeren Studien ging es vor allem um die Frage, wer von solchen Ersparnissen aufgrund der Parallelimporte profitiert. Ich möchte Ihnen zwei solcher Studien präsentieren, die zu sehr unterschiedlichen Ergebnissen kamen. Bei der Studie der York University kam man für verschiedene Länder der EU für das Jahr 2002 zu einer Ersparnis von 630 Millionen Euro ${ }^{4}$. Die Studie der London School of Economics ${ }^{5}$ dagegen folgerte, dass die Hauptprofiteure von Parallelimporten die Parallelimporteure selber und die Apotheken sind. Es konnte keine Intensivierung des Preiswettbewerbs festgestellt und dementsprechend auch kein Preiseffekt im Inland registriert werden.

\section{Dimensionen des Parallelimports}

In unserer Studie waren die Produkte der Chemie- und vor allem der Pharmabranche sehr wichtig. Daneben spielt das Patentrecht auch bei ausgewählten Konsumgütern eine zentrale Rolle, weshalb dieser Bereich ebenfalls hinsichtlich der Auswirkungen eines Regimewechsels untersucht wurde. In der Textilindustrie dagegen liegen die Preise in der Schweiz im internationalen Vergleich nicht höher und bei der Investitionsgüterindustrie sind die Produkte zu wenig standardisiert und oft mit Serviceleistungen verbunden, was sich negativ auf die 
Möglichkeiten, Parallelimporte durchzuführen, auswirkt.

Wie eingangs erwähnt, wurde in einem ersten Schritt für die von einem Regimewechsel im Patentrecht betroffenen Produktgruppen das maximale Arbitragepotential bestimmt. Dieses Volumen entspricht im Prinzip dem Produktvolumen, das überhaupt von einem Systemwechsel betroffen wäre. Betrachtet wurde zuerst das Handelsvolumen auf der Ebene der Grosshandelspreise. Dies deshalb, weil auf dieser Ebene die Parallelimporteure aktiv werden. Wie Abbildung 1 zeigt, kann bei den Medikamenten von einem maximal betroffenen Handelsvolumen von CHF 1.8 Milliarden ausgegangen werden.

Der Preisunterschied zwischen der Schweiz und den untersuchten Vergleichsländern bezüglich dieser Medikamente auf der Grosshandelsstufe beträgt etwa $40 \%$. Dieser Preisunterschied wurde im Rahmen der Studie ermittelt, indem wir für die 30 umsatzstärksten Medikamente einen internationalen Preisvergleich auf Wirkstoffbasis durchführten. Einbezogen wurden einerseits die billigsten EU-Länder. Andererseits haben wir auch europäische und dazumal noch nicht EU-Mitgliedsländer wie Polen oder Bulgarien als Vergleichsländer berücksichtigt. Schliesslich wurden Länder wie Brasilien, Indien oder Südafrika als klassische Billigpreisländer mit in den Vergleich aufgenommen. Der ermittelte Preisunterschied von $40 \%$ berücksichtigt dabei die Verfügbarkeit der Medikamente in den untersuchten Ländern. Würde der Preisvergleich nur für die EU durchgeführt, so resultierte eine Preisdifferenz zwischen der Schweiz und den berücksichtigten EU-Ländern von 25\%.

Ebenfalls aus der Tabelle ersehen Sie, dass vom gesamten Medikamentenmarkt in der Schweiz rund 60\% der Medikamente einen Patentschutz haben. Berücksichtigt man diese Tatsache, resultiert das angesprochene maximal von einem Regimewechsel betroffene Arbitragepotential.

\section{Maximal betroffenes Handelsvolumen}

\begin{tabular}{|c|c|c|}
\hline \multicolumn{3}{|l|}{ Daten für das Jahr 2000} \\
\hline & Medikamente & Konsumgüter \\
\hline $\begin{array}{l}\text { Umsatz mit patentintensiven Produktgruppen } \\
\text { (zu Konsumentenpreisen), Mio. CHF }\end{array}$ & 54456 & $33 \times 000$ \\
\hline Verhältnis Grosshandels- zu Konsumentenpreis & $57.2 \%$ & $50 \%$ \\
\hline $\begin{array}{l}\text { Gesamtmarkt Schweiz } \\
\text { (zu Grosshandelspreisen), Mio. CHF }\end{array}$ & $3 \cdot 100$ & $16 ‘ 500$ \\
\hline $\begin{array}{l}\text { davon patentgeschützt } \\
\text { [Sensitivität] }\end{array}$ & $\begin{array}{l}59.4 \% \\
{[\text { keine] }}\end{array}$ & $\begin{array}{c}33.3 \% \\
{[20 \% / 50 \%]}\end{array}$ \\
\hline $\begin{array}{l}\text { Maximal betroffenes Handelsvolumen } \\
\text { (zu Grosshandelspreisen), Mio. CHF } \\
\text { [Sensitivität] }\end{array}$ & $\begin{array}{c}1 \text { '854 } \\
\text { [keine] }\end{array}$ & $\begin{array}{c}5^{\prime} 495 \\
{\left[3^{\prime} 300 / 8^{\prime} 250\right]}\end{array}$ \\
\hline Preisunterschied auf Grosshandelss & $-40 \%$ & $-30 \%$ \\
\hline
\end{tabular}

Abbildung 1: Auswirkungen eines Wechsels zur internationalen Erschöpfung im Patentrecht

Ist das Arbitragepotential bestimmt, stellt sich als nächstes die Frage, wie viel davon effektiv über Parallelimporte abgeschöpft wird. In diesem Zusammenhang ist das Verhalten der Akteure besonders wichtig. Eine erste Einschränkung hinsichtlich der Durchführung von Parallelimporten stellen Markteintrittsbarrieren dar. Diese können einerseits ökonomischer Art sein, indem beispielsweise vertikale Vertriebssysteme anders organisiert werden und so der Parallelimporteur zusätzliche Risiken bei der Beschaffung der Produkte eingehen muss. Andererseits können auch staatliche Eintrittsbarrieren beispielsweise aufgrund der Zulassungsbestimmungen eine Rolle spielen. Neben den Eintrittsbarrieren stellen Transaktionskosten eine weitere Hürde für Parallelimporte dar. Gemeint sind vor allem Transportkosten, die aber bei den Medikamenten nicht von Bedeutung sind. Dies war in der Untersuchung bei Konsumgütern wichtig. Weitere Transaktionskosten sind beispielsweise Umpackkosten, die wiederum das Potential reduzieren.

Zudem stellt sich bezüglich der Schätzung, wieviel vom Arbitragepotential ausgeschöpft wird, auch die Frage, ob bei den betrachteten Gütern zwei parallele Märkte nebeneinander existieren können. Ein 
Phänomen, welches Sie sicherlich vom Parfummarkt her kennen: Dort finden sich parallel importierte Parfums und original Parfums in den genau gleichen Parfumflaschen, aber zu ganz unterschiedlichen Preisen. Die beiden Segmente existieren nebeneinander und werden zum Teil auch vom gleichen Hersteller beliefert, damit die unterschiedlichen Kundengruppen angesprochen werden können.

Schliesslich gilt es noch den letzten Punkt zu betrachten: den Nachfrageeffekt. Wenn die Preise aufgrund von Parallelimporten sinken, müsste gemäss der ökonomischen Theorie auch mehr von diesen Gütern nachgefragt werden. Selbstverständlich handelt es sich bei den Medikamenten um Güter mit einer tiefen Preiselastizität.

Werden all die erwähnten Faktoren berücksichtigt, lässt sich ermitteln, wieviel vom maximal möglichen Arbitragepotential überhaupt als effektive Parallelimporte in Frage kommen. Bei Pharmaprodukten beträgt das Volumen rund eine Milliarde Schweizer Franken, bei einem Preissekungspotential von 14 bis $32 \%$. Wenn dieses ganze Arbitragepotential realisiert würde, hätte dies eine Einsparung bei den Medikamentenausgaben von zwischen 420 und 130 Millionen CHF zur Folge. Pro Kopf und Monat entspricht dies zwischen CHF 4.70.- oder 1.50.-. Im Vergleich mit den eingangs vorgestellten internationalen Studien - insbesondere der Studie der York University - liegen diese Effekte für die Schweiz höher. Dies liegt natürlich auch daran, dass es sich bei der Schweiz um ein Land mit höheren Preisen handelt, als die Länder, die bei der York University Studie untersucht wurden.

\section{Aktualisierung}

Die präsentierten Ergebnisse untersuchten den Fall eines Wechsels von der nationalen zur internationalen Erschöpfung im Patentrecht. Wir haben heute schon vielfach gehört, dass die regionale Erschöpfung zunehmend zum diskutierten Thema in der Schweiz wird. Im Auftrag des Staatssekretariats für Wirtschaft (seco) haben wir deshalb die gesamtwirtschaftlichen Auswirkungen eines solchen Wechsels im Er- schöpfungsregime des Patentrechts ermittelt. Dabei sind zwei Aspekte zu berücksichtigen: Zum einen wurde seit den ersten Berechnungen das Kartellgesetz revidiert. Insbesondere die angestrebte präventive Wirkung im Bereich der vertikalen Vertriebssysteme gilt es zu berücksichtigen. Zum anderen spielen im Gegensatz zur internationalen Erschöpfung bei der regionalen Erschöpfung die aktuellen Handelsverflechtungen sowie die möglichen Veränderungen der Handelsströme nach einem Regimewechsel eine wichtige Rolle. Dies deshalb, weil bei einer regionalen Erschöpfung Parallelimporte lediglich von europäischen Ländern möglich sind.

Die Kartellgesetzrevision dürfte bezüglich der Parallelimporte von Pharmaprodukten keinen Einfluss haben. Das verdeutlichen auch die Erfahrungen der Wettbewerbskommission (WEKO) mit der sogenannten Bekanntmachung. Keiner der bisher untersuchten Fälle betraf den Bereich der Pharmaprodukte.

Die Abbildung 2 illustriert noch einmal die Vorgehensweise. In einem ersten Schritt wurden die Ergebnisse einer Änderung des Erschöpfungsregimes zur internationalen Erschöpfung um die Auswirkungen der Revision des Kartellgesetzes bereinigt. Anschliessend galt es, die Unterschiede zwischen der internationalen und regionalen $\mathrm{Er}$ schöpfung zu berechnen. Dabei wurden insbesondere die heutige Handelsverflechtung sowie die erwarteten Veränderungen der Handelsströme berücksichtigt. Die Ergebnisse zeigen, dass bei einem Regimewechsel zur regionalen Erschöpfung im Vergleich zur internationalen Erschöpfung sowohl das parallel importierte Volumen als auch die möglichen Preisreduktionen für die Schweiz kleiner ausfallen. Dies war insofern zu erwarten, da bei der regionalen Erschöpfung ein eingeschränkter Handelsraum als mögliche Quellen für Parallelimporte in Frage kommt. 
Vorgehen und Ergebnisse für Pharmaprodukte:

\begin{tabular}{|c|c|c|c|}
\hline & Kartellgesetz "alt" & & Kartellgesetz "neu" \\
\hline Nationale Erschöpfung & 1. & & $\begin{array}{l}\text { Auswirkungen } \\
\text { Kartellgesetzrevision }\end{array}$ \\
\hline Internationale Erschöpfung & $\begin{array}{c}\text { A } \\
\text { "Systemwechsel" }\end{array}$ & 2. & $\begin{array}{l}\text { Auswirkungen } \\
\text { internationale } \\
\text { Erschöpfung }\end{array}$ \\
\hline Regionale Erschöpfung & & & $\begin{array}{l}\text { Differenzzwischen } \\
\text { regionaler und internationaler } \\
\text { Erschöpfung }\end{array}$ \\
\hline
\end{tabular}

\begin{tabular}{|l|c|c|}
\hline \multicolumn{2}{|l|}{ Parallelimportvolumen und Preissenkungspotenzial auf Grosshandelsstufe } \\
\hline & $\begin{array}{c}\text { Parallelimport } \\
\text { Volumen }\end{array}$ & Preissenkungspotenzial \\
\hline Regionale Erschöpfung & $\mathbf{0 . 6 5 - 1 . 1 ~ M r d . ~ C H F ~}$ & $\mathbf{9 \% - 2 0 \%}$ \\
\hline Internationale Erschöpfung & $0.9-1.3$ Mrd. CHF & $14 \%-32 \%$ \\
\hline
\end{tabular}

Abbildung 2: Auswirkungen eines Wechsels zur regionalen Erschöpfung im Patentrecht

\section{Gesamtwirtschaftliche Effekte}

Schliesslich haben wir aufgrund des ermittelten Volumens an Parallelimporten und den erwarteten Preisreduktionen die gesamtwirtschaftlichen Effekte berechnet. Erreicht haben wir dies, indem wir die diskutierten Ergebnisse der Sektoranalyse in die ökonometrischen gesamtwirtschaftlichen Modelle eingebaut haben. Das Ergebnis waren die heute bereits vielfach zitierten 0.0 bis $0.1 \%$ des Bruttoinlandprodukts (BIP). Die wichtigsten Mechanismen, die zu diesem Ergebnis geführt haben sind: Die tieferen Importpreise führen dazu, dass die realen Einkommen steigen. Dies führt zu einer gesteigerten Nachfrage, von denen alle Branchen profitieren. Auch nach 6 Jahren liegt das Bruttoinlandprodukt nach dem Regimewechsel immer noch zwischen 140 bis knapp 500 Millionen CHF über dem Niveau ohne Regimewechsel und beim realen Einkommen liegt die Differenz bei zwischen 30 und 90 CHF pro Kopf und Jahr. Bei der Interpretation der Ergebnisse ist zu berücksichtigen, dass es sich hier aber um die gesamtwirtschaftlichen Berechnungen mit allen von einem Regimewechsel betroffenen Produkten handelt. Neben den Pharmaprodukten sind somit bei den gesamtwirtschaftlichen Effekten auch die parallel importierten Konsumgüter berücksichtigt.

\section{Schlussfolgerungen}

Die Untersuchung hat gezeigt, dass das Potential für Parallelimporte relativ klein ist, dass aber trotzdem ein bescheidener positiver Einfluss auf die gesamtwirtschaftliche Entwicklung von einem Regimewechsel zu erwarten ist. Wenn das Potential für Parallelimporte möglichst ausgeschöpft werden sollte, sind insbesondere Markteintrittsbarrieren für Parallelimporte abzubauen. Das heisst, dass Anreize geschaffen werden müssen, damit Parallelimporteure im Wettbewerb zu einander stehen. Schliesslich sind auf allen Ebenen die Zulassungs- und Bewilligungsverfahren so auszugestalten, dass damit möglichst keine Eintrittshürden verbunden sind.

Lassen Sie mich nach der Präsentation der Ergebnisse unserer Studien zum Schluss noch auf zwei grundsätzliche Aspekte eingehen: Bei der Einführung der internationalen Erschöpfung im Patentrecht spielt es eine Rolle, ob die Schweiz die internationale Erschöpfung alleine einführt. In diesem Fall besteht die Gefahr, dass bei staatlich regulierten Märkten nicht billigere Medikamente in die Schweiz importiert werden, sondern ein Import von Regulierungssystemen stattfindet. Ein weiterer Punkt, der zu klären ist, sind die Auswirkungen der Parallelimporte auf den Forschungsstandort. In diesem Zusammenhang ist festzuhalten, dass die Möglichkeit von Parallelimporten kein zentraler Standortfaktor für den Forschungsstandort darstellt. Für die Forschung sind Faktoren wie beispielsweise die Verfügbarkeit von hochqualifizierten Forschern 
bedeutender. Trotzdem kann die Möglichkeit von Parallelimporten natürlich als ein negatives Signal für den Forschungsstandort interpretiert werden und dadurch Forschungsentscheidungen beeinflussen - gerade wenn die Forschungsbedingungen ansonsten international vergleichbar sind.

\section{Fussnoten:}

1 Frontier Economics / Plaut Economics (2003), «Erschöpfung von Eigentumsrechten: Auswirkungen eines Systemwechsels auf die Schweizerische Volkswirtschaft», Studie im Auftrag des Bundesrates, Bern. ${ }^{2}$ The Danisch Ministry of Trade and Industry (1999), «Financial Consequences of Parallel Imports», Memorandum.

${ }^{3}$ Ganslandt M., Maskus K. (2001), «Parallel Imports of Phamraceuticals in the European Union» Research Institute of Industrial Economics, Working Paper No. 546/2001, Stockholm.

${ }^{4}$ York Health Economics Consortium (2003), «Benefits to Payers and Patients From Parallel Trade», York Universitiy, York.

${ }^{5}$ London School of Economics, LSE (2004), «The Economic Impact of Pharmaceutical Parallel Trade in Europe Union Member States: AStakeholder Analysis», LSE Health and Social Care, London. 


\section{DIE POSITION DER FORSCHENDEN PHARMA- INDUSTRIE SCHWEIZ}

Thomas Cueni, Generalsekretär der Interpharma, Basel

In der Diskussion über Parallelimporte in der Schweiz staune ich immer wieder, wie selbst renommierte Ökonomen an der Komplexität des Problems scheitern. So halte ich es für absolut unzulässig, wenn man Für und Wider von Parallelimporten an einem rein statischen Modell darlegt. Ebenso unzulässig ist es, wenn man aus Einfachheitsgründen annimmt, dass der Preisunterschied zwischen In- und Ausland voll oder weitgehend dem Konsumenten zugute kommt oder beiseite schiebt, dass entgangene Einnahmenausfälle Auswirkungen auf Investitionsverhalten oder Standortentscheide der Pharmaindustrie haben. Nach dem Motto „Die Wirklichkeit ist zu kompliziert für mein Modell“ ignoriert beispielsweise der Preisüberwacher über 20 Jahre Felderfahrung in der EU und erzählt von Einsparungen, die auf rein theoretisch-hypothetischen Modellrechnungen basieren, die aber mit der Realität, wie man sie in der EU beobachten kann, nichts zu tun haben.

Wenn man von Parallelimporten spricht, geht es letztlich stets um Ressourcentransfer. Der bekannte amerikanische Gesundheitsökonom, Uwe Reinhardt, hat mir einmal erklärt, dass "managed care» der grösste Ressourcentransfer in der Geschichte der Menschheit sei, nämlich von den Ärzten weg zu den Ökonomen; die Ökonomen unter uns freut's, ob's den Patienten gut bekommt, ist eine andere Frage. Ein Ressourcentransfer findet ohne jeden Zweifel auch bei Parallelimporten statt. Wie ich Ihnen zeigen werde, geht dieser im Wesentlichen von der forschenden Pharmaindustrie weg, hin zu den Parallelimporteuren. Inwieweit dies volkswirtschaftlich sinnvoll oder sinnlos ist, werden wir auch in die Diskussion aufnehmen. 


\section{Die Schweizer Pharmaindustrie}

Einleitend möchte ich Ihnen ein paar Zahlen und Fakten präsentieren, welche die Schweizer Pharmaindustrie und ihre Bedeutung für den Forschungsstandort Schweiz aufzeigen. Anschliessend werde ich auf den Nutzen von Medikamenten eingehen. Dies scheint mir umso wichtiger, als im Allgemeinen die gesundheitspolitische Diskussion in unserem Land bei den Kosten und dem Kostenanstieg bei den Medikamentenausgaben stehen bleibt. Und dann werde ich auf die ökonomische Wirkung von Parallelimporten und der regionalen Erschöpfung als mögliche Alternative eingehen.

Die Diskussion um Parallelimporte ist in diesem Land untrennbar mit der Diskussion über die volkswirtschaftliche Bedeutung der Pharmaindustrie verbunden. Anfang der 90er Jahre war stets die Rede vom Exodus der Pharmaindustrie, namentlich in die USA. In der Schweiz hat diese Entwicklung aber schlicht nicht stattgefunden, im Gegenteil: Die Pharmaexporte sind seit 1990 von rund CHF 8 Milliarden auf über 30 Milliarden angestiegen, und allein seit 1995 sind in der Pharmaindustrie in der Schweiz rund 10`000 neue Arbeitsplätze entstanden. Wird zudem berücksichtigt, dass allein Novartis in den nächsten Jahren in Basel etwa 30 neue Büro- und Laborgebäude errichtet, können Sie sich ausrechnen, wie sich diese Investitionen allein für die Bauindustrie auswirken. Ähnliches gilt auch für Roche, die erst vor 18 Monaten inr neues Forschungsgebäude eröffnet hat und jetzt eine neue Produktionsanlage für die Biotechnologie baut. Oder die Serono, welche in Genf ein neues Headquarter im ehemaligen Areal der Sécherons beziehen wird. Mit diesen Investitionen hat die Pharmaindustrie ein klares Bekenntnis zum Standort Schweiz abgelegt.

Die Pharmaindustrie ist für die Volkswirtschaft der Schweiz und insbesondere der Nordwestschweiz von überdurchschnittlicher Bedeutung. Die Pharmaindustrie ist denn auch die einzige namhafte Branche, welche zum Wirtschaftswachstum beiträgt. Die Schweizer Pharmafirmen haben sich im internationalen Wettbewerb gut behauptet und in den vergangenen Jahren ihren Weltmarktanteil erhöhen können. Neben den beiden grossen Pharmafirmen - Novartis und Roche - zeugen neue Unternehmen wie Serono, Vifor und Actelion von der Stärke des Pharmastandorts.

(Index 1990=100)

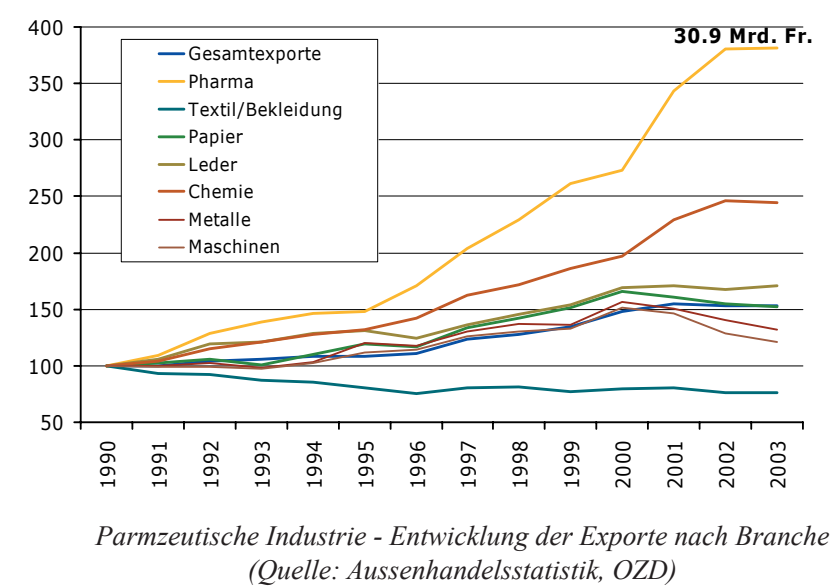

Die Schweizer Pharmaindustrie gibt überdurchschnittlich viel für Forschung und Entwicklung aus. Die Interpharma Firmen investieren in diesen Bereich rund $17 \%$ ihres Umsatzes. Dieser hohe Anteil an Forschungsausgaben ist ein Indiz dafür, wie bedeutend der Fixkostenanteil in dieser Industrie ist. Im Vergleich dazu sind die reinen Produktionskosten - abgesehen von der Herstellung biotechnologischer Produkte, welche im Allgemeinen teuer ist - niedrig. Entsprechend sind Preisdifferenzierungen wohlfahrtsökonomisch sinnvoll. D.h. berücksichtigt man die Kaufkraft, ist es nicht sinnvoll, in Griechenland den gleichen Preis zu haben wie in Deutschland. Parallelimporte stellen diese Differenzierung in Frage.

Pharmaunternehmen sind auch in einer anderen Beziehung speziell. Die Investitionen in Forschung und Entwicklung beinhalten ein hohes Risiko. Dies hat uns die jüngste Vergangenheit am Fall Vioxx 
und der Cox-2-Klasse demonstriert. Ein hohes Risiko bedeutet auch entsprechende Zinserwartungen der Anleger. Vor ein paar Monaten haben Sie vielleicht in der Sonntagspresse gelesen, dass neue Untersuchungen darauf hindeuteten, dass die Forschung und Entwicklung eines neuen Medikaments gar nicht so teuer ist, wie von der Industrie stets behauptet werde. Dieser Vorwurf ist falsch. Zwar sind in der Tat in den oft zitierten 800 Millionen Dollar für die Entwicklung eines neuen Medikaments neben direkten F+E-Kosten auch Opportunitätskosten enthalten. Nicht berücksichtigt sind hingegen die R\&D-Misserfolge, d.h. all die Projekte, an welchen über Jahren geforscht wird, die es aber nie auf den Markt schaffen, weil sie die Erwartungen nicht erfüllen. Der Anspruch an neue Medikamente ist hoch. Sie müssen nicht nur sicher und wirksam sein, sondern in der Regel auch über eine relative Wirksamkeit verfügen, die höher ist als bereits bekannte Medikamente.

\section{Forschungsausgaben}

Die Interpharma-Firmen geben heute für Forschung und Entwicklung rund 10 Milliarden Franken weltweit aus, davon wird ein hoher Anteil, nämlich rund $40 \%$, in der Schweiz investiert. Die Schweiz ist für unsere Mitglieder nach wie vor das wichtigste Zentrum sowohl für die Forschung, als auch für die Preisfestsetzung. Wichtig ist beispielsweise auch ein eigenständiges Zulassungssystem, denn mit der Zulassung durch Swissmedic kann die Zulassung in 70 weiteren Ländern beantragt werden.

Bei der Preisfestsetzung stellen sich namentlich folgende Fragen: Welchen Nutzen bringt ein Medikament im Vergleich zu den Risiken? Wie ist seine Wirtschaftlichkeit gegenüber anderen Medikamenten, und wie hoch ist sein Preis im internationalen Vergleich? Dass neue Medikamente tatsächlich mehr Nutzen bringen, lässt sich leicht am Erfolg in der Behandlung verschiedener Krankheiten aufzeigen. Die Sterblichkeit bei Säuglingskrankheiten, rheumatischem Fieber, Arteriosklerose, Hypertonie, um nur einige Beispiele zu nennen, ist in den vergangenen Jahren stark zurückgegangen.

Schliesslich ist die steigende Lebenserwartung ein weiterer Indikator für den anhaltenden Fortschritt in der Medizin. Alle 10 Jahre verlängert sich unsere Lebenserwartung um 2-3 Jahre. Wäre ich 1900 geboren worden, dann dürfte es mich eigentlich schon nicht mehr geben, weil ich meine Lebenserwartung von 45 Jahren bereits überschritten hätte. Heute, bei einer Lebenserwartung von knapp 78 Jahren, kann ich aber davon ausgehen, dass ich noch etwa 30 muntere Jahre vor mir habe. Wir werden aber nicht nur immer älter, sondern wir werden in aller Regel auch gesünder älter.

Die Frage in unserem Gesundheitswesen ist demnach nicht einfach, „wie kann ich die Kosten senken?", sondern „welchen Nutzen erhalte ich?". Nehmen wir das Beispiel Aids: Dank moderner Medikamente kann die Krankheit zwar nicht geheilt, doch während vieler Jahre kontrolliert werden. Die Betroffenen überleben während Jahren und sind dabei noch arbeitsfähig. Entsprechend ist die Sterblichkeit bei HIV-Aids um über $90 \%$ zurückgegangen. Dieser Erfolg lässt sich etwa mit der Einführung von Penicillin in den 40er / 50er Jahren vergleichen.

\section{Parallelimporte}

Die Pharmaindustrie leistet einen wesentlichen Beitrag zur Qualität des Gesundheitswesens und zum Wirtschaftswachstum. Ganz anders steht es mit Parallelimporten. Ich sage es ganz hart. Parallelimporteure sind Trittbrettfahrer, die keinen volkswirtschaftlichen Mehrwert schaffen. Die Erfahrung in der EU zeigt, dass Parallelimporte zu keiner Preisangleichung führen. In diesem Zusammenhang verstehe ich auch die schweizerischen Diskussionen über theoretische Modelle nicht ganz. Die Feldstudie EU gibt genügend Aufschluss darüber, welche Auswirkungen Parallelimporte in der Realität haben, namentlich: Der Verbraucher profitiert fast nichts, die Pharmaindustrie hat Mindereinnahmen, Forschungsinvestitionen in Europa werden reduziert, die Forschung wandert zum Teil in die USA ab. 
Schliesslich sind die volkswirtschaftlichen Zusammenhänge zu berücksichtigen: Wird weniger Geld verdient, dann sinken die Steuereinnahmen, und wenn wesentlich weniger verdient wird, dann sinken die Steuereinnahmen gar deutlich stärker, als mittels Parallelimporten bei den Krankenkassen eingespart wird. Zudem gehen qualifizierte Arbeitsplätze verloren. Selbst die WHO hat letzte Woche auf die Problematik der Parallelimporte hingewiesen. Sie bringen wenig und untergraben die Innovation.

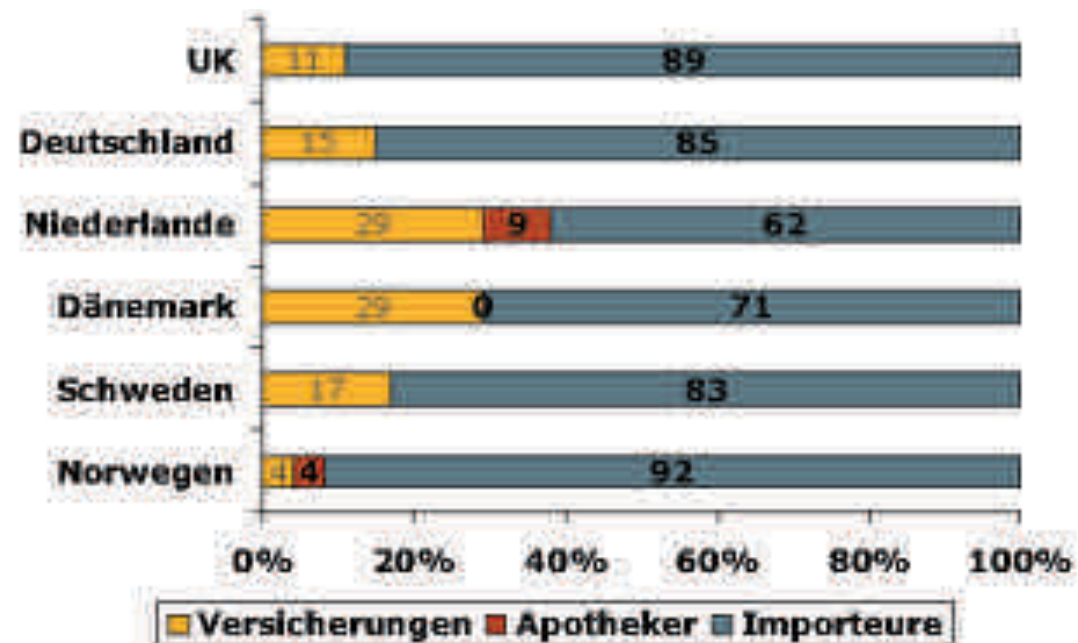

Prozentuale Verteilung der Gewinne aus Parallelimporten nach Stakeholdern (Quelle: Panos Kanvos, London School of Economics, 2004)

Importeure sind Trittbrettfahrer, weil sie von den Preisdifferenzen profitieren und nur einen geringen Teil ihres Arbitrageprofits an die Konsumenten weitergeben. In einer Studie zeigt Panos Kanavos ${ }^{1}$, Professor an der London School of Economics, am Beispiel verschiedener Länder auf, welcher Anteil der Preisdifferenz an die Versicherungen und damit an den Patienten weitergeben wird. In England sind es etwa $11 \%$, in Holland mit 29\% deutlich mehr, in Norwegen sind es nur $4 \%$.
Vor diesem Hintergrund sind die hypothetischen Einsparungen in der Schweiz kritisch zu hinterfragen.

\section{Geringer Preisvorteil bei Parallelimporten}

Das statische Modell, welches beispielsweise von Herrn Barsuglia vorgestellt wurde, ignoriert die Dynamik des Marktes. Es ist völlig selbstverständlich, dass jeder Parallelimporteur bei seinem Markteintritt relativ tiefe Preise festsetzt. Nur so kann er Marktanteile gewinnen und sich auf dem Markt etablieren. Ist diese Eintrittsphase vorüber, wird der Parallelimporteur die Preise rasch nach oben anpassen, um sie nur unwesentlich unter dem handelsüblichen Preis zu fixieren. Dieses Verhalten konnte in der Praxis an verschiedenen Beispielen aus Skandinavien nachgewiesen werden.

Die Konsequenz ist, dass Parallelimporteure zwar weiterhin billig einkaufen, den Gewinn aber selber abschöpfen. Der Patient geht dabei praktisch leer aus. Sie können diesen Effekt im Übrigen auch in Deutschland beobachten, wo in den letzten Monaten mit der Einführung der staatlichen Zwangsrabatte von 16\% die Parallelimporte um etwa die Hälfte eingebrochen sind.

Diese Ausführungen möchte ich noch mittels einer von der NERA ${ }^{2}$ durchgeführten Studie untermauern. In dieser hat die NERA nachgewiesen, dass in Ländern wie Dänemark und Holland, die einen regen Parallelimport kennen, rund $10 \%$ des Medikamentenmarktes über Parallelimporte abgedeckt werden und dass der durchschnittliche Preisvorteil zwischen $30 \%$ und $40 \%$ beträgt. Davon schöpfen der Parallelhändler rund $70 \%$ und der Zwischenhandel rund $27 \%$ ab. Dem Patienten bzw. der Krankenkasse verbleiben somit rund 3\% der Preisdifferenz. Wird davon ausgegangen, dass die Schweiz mit Holland und Dänemark vergleichbar ist und deshalb ähnliches Verhalten zum Tragen kommt, ergeben sich für die Schweiz folgende Einsparungen:

Bei einem Gesamtumsatz von 3,3 Mrd. Franken würden rund 330 Millionen durch Parallelimporte gedeckt. Bei einer Preisdifferenz von 
rund $30 \%$ bis $40 \%$ wäre somit ein potenzielles Einsparungspotenzial von zwischen 100 und 130 Millionen möglich. Davon schöpfen aber die Parallelhändler rund $70 \%$ (d.h. CHF 70 bis 90 Mio.) und der Zwischenhandel rund $27 \%$ (d.h. CHF 27 bis 35 Mio.) ab. Für den Patienten bzw. die Krankenkassen verbleiben somit zwischen $\mathrm{CHF} 3$ und 4 Millionen.

Aus Sicht des Parallelimporteurs sind die Anteile durchaus gerechtfertigt. Für inn fallen Transaktions- und Beschaffungs- sowie Transportkosten an. Häufig müssen die Produkte umgepackt und zwischengelagert werden, ferner müssen die Apotheker und selbstdispensierenden Ärzte als Abnehmer gewonnen werden. Und zu guter Letzt soll noch ein angemessener Gewinn erzielt werden. Vor diesem Hintergrund ist es nicht weiter erstaunlich, dass die Preisdifferenz wegschmilzt.

Was heisst dies für die theoretischen Einsparmodelle in der Schweiz? Im Wesentlichen bedeutet es, dass sie reine Modellrechnungen sind, ohne grossen Realitätsbezug. Dies gilt selbst für die Modellrechnungen, welche Plaut Economics für den Bundesrat erstellt haben, und in dem sie zum Schluss gekommen sind, dass der Wachstumseffekt durch Parallelimporte volkswirtschaftlich vernachlässigbar ist, maximal $0.1 \%$. Aber selbst dieser Wachstumseffekt basiert auf hypothetischen Einsparungen von 56 Franken pro Jahr und Kopf der Bevölkerung. Dass diese Annahme unrealistisch ist, zeigen die realen Zahlen aus den Niederlanden: Dort werden die Einsparungen pro Jahr und Kopf mit drei Franken angeben, d.h. 25 Rappen (!) pro Monat, ein nicht eben grosser volkswirtschaftlicher Betrag, namentlich unter Berücksichtigung der möglichen negativen Auswirkungen.

Mittel- und langfristig sind noch weitere Wirkungen zu berücksichtigen. Marktteilnehmer passen bekanntlich ihr Verhalten an. So kann es durchaus vorkommen, dass im Exportland das Angebot reduziert wird und es zu einem Mangel kommt. Denn die Unternehmen werden dem Markttreiben nicht tatenlos zuschauen, sondern nach Möglichkeiten suchen, den Parallelexport zu begrenzen.
Im Importland hingegen, und die Erfahrung in der EU bestätigt es, bleiben die Preise nahezu unverändert hoch. Lediglich das Angebot variiert in Abhängigkeit der Produkte, denn Parallelimporteure sind Rosinenpicker. Sie werden nur in Produktemärkten aktiv sein, die auch entsprechende Margen versprechen. Deshalb kann auch nicht generell von einem Parallelimportmarkt gesprochen werden. In England beispielsweise werden von den 2000 Medikamenten auf dem Markt nur knapp 100 parallel importiert. Die übrigen Produkte sind für die Parallelimporteure wirtschaftlich uninteressant. Während die Kassen und die Patienten kaum etwas vom Parallelimport spüren, schadet er den Arzneimittelherstellern. Die volkswirtschaftlichen Wirkungen von Parallelimporten dürfen deshalb nicht unterschätzt werden.

\section{Regionale Erschöpfung - der dritte Weg?}

Die europäische Industrie verlagert einen immer grösseren Teil ihrer Forschung in die USA. Denn die USA ist ein attraktiver Markt. Zwar haben auch hier in der jüngsten Vergangenheit die Preisdiskussionen an Bedeutung gewonnen, weil arme Menschen, die sich keine Versicherung leisten können, die höchsten Preise bezahlen müssen. Insgesamt ist aber die Stimmung nach wie vor positiv.

In der Schweiz, wo es zu keinem Abbau der Forschungsinvestitionen gekommen ist, wird vermehrt die regionale Erschöpfung, sozusagen als goldener Mittelweg, propagiert - ein typisch schweizerischer Kompromiss. Mit einer solchen Lösung können wir aber auch gleich der EU beitreten. Wir können hier in Basel nicht auf die Dauer mit Schweizer Kosten- und Lohnniveau forschen und den volkswirtschaftlichen Mehrwert erwarten, aber letztlich von polnischen oder griechischen Preisen profitieren wollen.

Vor diesem Hintergrund verstehe ich auch nicht, weshalb die Linke - wie Herr Strahm - so sehr an diesem Thema festhält. Den Gewerkschaften beispielsweise ist sehr viel stärker bewusst, dass es auch um Arbeitsplätze geht. 
Darüber hinaus müsste bei der regionalen Erschöpfung die Schweiz auch eine Gegenleistung bei den übrigen Immaterialgüterrechten, namentlich bei Marken und Urheberrechten anbieten. Gemäss Silhouette Urteil sind in der EU nämlich nur Parallelimporte innerhalb der EU erlaubt, während sämtliche Importe von immaterialgüterrechtlich geschützten Produkten aus Drittstaaten verboten sind, d.h. Markenartikel wie Sonnenbrillen können in der EU nicht von ausserhalb importiert werden. Damit müsste die Schweiz im Marken- und Urheberrecht das liberale System der internationalen Erschöpfung, welches Parallelimporte unbeschränkt erlaubt, zugunsten der weniger liberalen regionalen Erschöpfung der EU aufgeben.

Zudem muss berücksichtigt werden, dass es für Medikamente gar keinen echten Markt gibt; die Medikamentenpreise sind staatlich reguliert. Unter diesen Umständen kann Arbitrage nicht unterstützt werden, weil die Ursache der Preisdifferenz die staatlichen Eingriffe sind.

Ferner würde ein bilaterales Abkommen mit der EU über die Einführung der regionalen Erschöpfung zu einer Preisgabe von Souveränität führen. Denn die Schweiz müsste auch die zukünftige Rechtsentwicklung sowie die Entscheide des Europäischen Gerichtshofes übernehmen. Es ist nicht davon auszugehen, dass die Pharmaindustrie eine solche Entwicklung untätig hinnimmt. Es ärgert denn auch, wenn aufgrund von Parallelimporten innerhalb der EU Werte vernichtet werden und aufgrund der Zollunion nichts dagegen unternommen werden kann.

In der EU findet jetzt ein Umdenken statt. Wie Herr Addor bereits erwähnt hat, wurde im „Bayer-Adalat»-Fall vom Europäischen Gerichtshof klar festgehalten, dass Unternehmen einseitige Massnahmen ergreifen können, indem sie zum Beispiel die Nachfrage nicht mehr vollständig befriedigen, um den Export zu unterbinden. In einem zweiten Fall (GlaxoSmithKline gegen Syfait - Griechenland) hat der Generalanwalt deutlich dargelegt, dass die unternehmerische Freiheit gewahrt werden muss. Das Unternehmen kann deshalb Lieferungen beschränken, selbst wenn es im fraglichen Produktmarkt eine dominante Marktmacht hat. Mit anderen Worten: Einschränkungen von Parallelimporten sind auch innerhalb der EU nicht per se eine Verletzung des freien Warenverkehrs.

Nachdem die EU ihre Erfahrungen mit Parallelimporten gemacht hat und teilweise Einschränkungen wieder zulässt, ist es fraglich, ob es sich lohnt, bei uns die regionale Erschöpfung einzuführen, zumal eine Alternative, nämlich Preiskontrollen, zur Verfügung steht. Wir haben uns vor einigen Jahren mit Frau Dreifuss für diese Lösung entschieden. Dies beinhaltet, dass unrealistisch hohe Preise vermieden werden sollen und sich die Schweiz dafür mit im Pharmabereich vergleichbaren Ländern wie Deutschland, Holland, Grossbritannien und Dänemark vergleichen soll. Länder wie Portugal, Spanien, Griechenland oder Polen sind aus dem Vergleich ausgeschlossen, weil sie andere Interessen in Forschung und Entwicklung haben. Bei diesen Preiskontrollen profitieren alle Konsumenten bzw. Patienten direkt, weil der Preisvergleich unmittelbare Auswirkungen auf die Spezialitätenliste und damit auf die Vergütung durch die Krankenkassen hat.

Schliesslich ist zu berücksichtigen, dass der Schweizer Preis einen direkten Einfluss auf die Preisbildung in vielen anderen Ländern hat. Dänemark beispielsweise vergleicht seine Preise mit allen Ländern Europas mit Ausnahme von Liechtenstein, Luxemburg, Portugal, Spanien und Griechenland. Holland hingegen berücksichtigt Belgien, Frankreich, England und Deutschland. Diese Vernetzung führt dazu, dass im Schweizer Preisvergleich alle Preise Europas direkt oder indirekt einfliessen. Im Weiteren wird der Preis im Heimmarkt Schweiz im Ausland häufig als Referenzpreis benutzt. Er hat damit direkte Auswirkungen auf den Schweizer Export von Pharmaprodukten.

Schweizer Preise haben sich dem Ausland angenähert

Seit Einführung der Preiskontrollen haben sich unsere Preise weitgehend dem Niveau im Ausland angenähert. Berücksichtigt man noch 
die Mehrwertsteuer, sind die Preise bei neuen Produkten gerade gegenüber Deutschland praktisch gleich oder gar billiger. Die grössten Preisunterschiede gibt es nach wie vor bei älteren Medikamenten, deren Patent bereits abgelaufen ist. Dort sind Parallelimporte indessen zulässig.

Ein Aspekt darf bei der Diskussion nicht vergessen werden: Die Schweizer Pharmaindustrie realisiert hierzulande lediglich einen Umsatz von rund 580 Millionen Franken. Gleichzeitig investiert sie hier rund 3,5 Mrd. Franken in Forschung und Entwicklung und exportiert Produkte im Wert von mehr als 30 Milliarden Franken. Angesichts dieser Gegebenheiten muss eingehend geprüft werden, welcher Tauschhandel sich volkswirtschaftlich tatsächlich lohnt.

Ich möchte schliessen mit dem mongolischen Sprichwort: „Ist man krank, denkt man an die Behandlung, ist man wieder gesund, denkt man wieder ans Geld."

\section{Fussnoten:}

1 Pavos Kanavos, The Economic Impact of Pharmaceutical Parallel Trade: A Stakeholder Analysis, LSE, 2004.

${ }^{2}$ Die folgenden Zahlen stützen sich auf eine Studie von NERA Economic Consulting, http://www.nera.com 


\section{Position des Schweizer Preisregulators - Die Spezialitätenliste}

Dr. Reinhard Kämpf, Sektionschef, Sektion Medikamente, Bundesamt für Gesundheit, Bern

Ich spreche im Folgenden zu Ihnen im Zusammenhang mit der Spezialitätenliste, kurz SL genannt.

\section{Die Spezialitätenliste (SL)}

Was ist die SL? Das ist eine Sammlung von pharmazeutischen Spezialitäten, welche durch die obligatorische Krankenpflegeversicherung (OKP) übernommen werden müssen. Die SL umfasst etwa 2'400 Präparate, das ist bezogen auf die gesamthaft durch Swissmedic zugelassenen Medikamente für den Humanbereich etwa $1 / 4$. Nur damit Sie eine Grössenordnung haben, wovon wir im Rahmen der SL sprechen.

Wir haben den Rx- Bereich (Medikamente nur gegen ärztliches Rezept, d.h. die Abgabekategorien A und B). Der macht zahlenmässig etwa $80 \%$ aus, die Abgabekategorie C etwa $15 \%$ und diejenige von D noch etwa $5 \%$. Ich möchte nicht darauf eintreten, inwiefern allenfalls diese beiden Kategorien nicht mehr Gegenstand für die soziale Krankenversicherung bilden könnten.

\section{Aufnahme der Medikamente in die SL}

Ich habe meine Ausführung in zwei Themen gegliedert. Zuerst die Aufnahmen von Medikamenten in die SL, und dann, was Sie speziell interessiert, die Festlegung des Höchstpreises.

Nun zur Aufnahme der Medikamente in die SL: Wie Sie wissen, wird unser Amt in der Aufnahme der Medikamente durch die Eidgenössische Arzneimittellkommission (EAK) beraten. Das ist eine ausserparlamentarische Kommission, welche vom Gesamtbundesrat gewählt worden ist. Sie sehen, wir haben zwei Hauptausschüsse in der EAK, 
den schulmedizinischen Ausschuss - die Hauptarbeit wird durch inn geleistet - und den komplementärmedizinischen Ausschuss. Diese zwei Ausschüsse tagen getrennt voneinander.

Es existieren verschiedene Aufnahmegesuchsarten. Wir haben die Neuaufnahmen (NA), das sind Gesuche welche erstmals dem Amt unterbreitet werden, dann Gesuche für andere Packungen und Dosierungen (APD), das heisst, wenn eine zusätzliche Dosierung angewendet wird, dann die sogenannten Neuüberprüfungsgesuche (NUG), Wiedererwägungsgesuche (WG) - das ist ein juristischer Unterschied: NUG sind solche Fälle welche noch keine Verfügung erhalten haben vom unserem Amt, also sie kommen nochmals vor die EAK. WEG sind solche, welche bereits eine ablehnende Verfügung erhalten haben, das heisst diese Verfügung ist bereits in der Rechtskraft erwachsen. Das Gesuch kann jedoch selbstverständlich nochmals vor die Kommission gebracht werden. Dann haben wir eine neue Kategorie eingeführt: Die Gesuche um Änderung der Limitation, die so genannten GÄL.

Wie sie wissen, haben wir Möglichkeiten, Präparate in der SL zu limitieren. Es bestehen zwei Varianten. Die Mengenmässige, ich nehme als Beispiel die Abführmittel (Laxantien), hier kann man innerhalb von drei Monaten - das entspricht der Dauer des Apothekerscheines - lediglich zwei Kleinpackungen oder eine Grosspackung verschreiben. Oder dann die Indikationsbezogene, das heisst, wenn wir der Meinung sind, dass von den durch Swissmedic zugelassenen Anwendungsmöglichkeiten/Indikationen, nur gewisse im Rahmen der obligatorischen Krankenpflegeversicherung (OKP) zu übernehmen sind. Das sind die beiden Möglichkeiten, die wir von Gesetzes wegen für eine Limitation (L) haben.

In den meisten Fällen geht es um eine Erweiterung der (L), d.h. es soll eine weitere Indikation hinzukommen. Es kann aber auch vorkommen, dass man zur Ansicht gelangt, dass die (L) als solches ganz aufzuheben wäre. Dann, last but not least, Preiserhöhungsgesuche (PEG), die sind natürlich auch möglich, aber in letzter Zeit in Anbetracht der geringen Teuerung relativ selten.

Anträge an die Eidg.

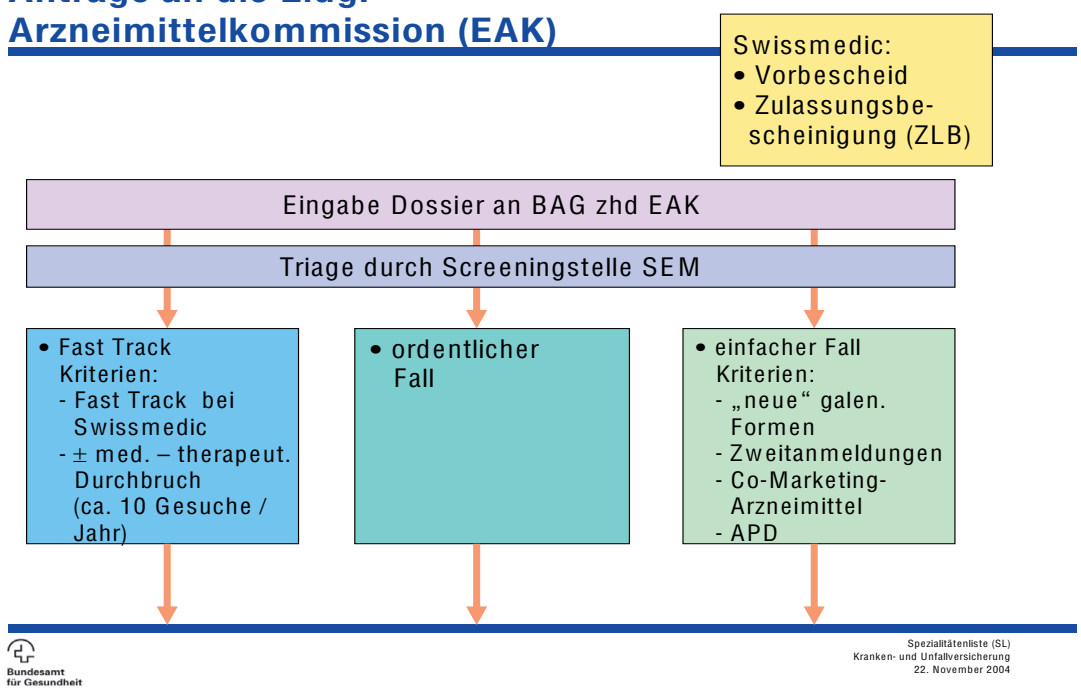

Die pharmazeutischen Firmen kommen zu unserem Amt auf freiwilliger Basis, was wichtig zu wissen ist. Wir fordern Firmen praktisch nie, oder nur in ganz seltenen Fällen auf, dass sie ein Gesuch einreichen. Also, sie kommen zu uns: Eingabe des Dossiers, zuhanden des Amtes, respektive der beratenden EAK. Wichtig ist das Kästchen oben rechts, wo Sie die Vorbedingung sehen: die Firma verfügt im Idealfall über eine gültige Swissmedic-Zulassungsbescheinigung, es kann aber auch bereits der Vorbescheid sein. Das heisst, es ist effektiv der Vorbescheid, der hier auch reicht. Wenn es dann zur Aufnahme kommt, muss natürlich die Zulassungsverfügung und die Zulassungsbescheinigung vorliegen, sonst können wir die Aufnahme nicht verfügen. Das sind die Präliminarien.

Kommt das Dossier zu uns, wird innerhalb der Sektion Medikamente 
eine Triage durchgeführt. Diese „Screeningstelle“ muss sich aufgrund unseres sehr engen Zeitrahmens praktisch auf die Kontrolle der Vollständigkeit der Gesuchsunterlagen beschränken. Es existieren drei verschiedene Verfahren. Ganz links sehen sie den so genannten "Fast Track", das ist auch der Begriff von Swissmedic. Wir haben immer betont, was bei Swissmedic „fast" ist, wird auch im Amt „fast" behandelt. Voraussetzung ist auch hier der Vorbescheid von Swissmedic. Grössenordnungsmässig sind es bislang nicht mehr als 10 „Fast Track"-Gesuche pro Jahr, die wir zu behandeln haben. Es sind dies weitgehend Medikamente, welche mit einen medizinisch-therapeutischen Durchbruch verbunden sind. Dann kommt der ordentliche Fall, und rechts sehen Sie die Definition des einfachen Falls, das heisst, diese Fälle kommen praktisch nicht vor die EAK. Sie sehen: „neue“ galenische Formen, Zweitanmeldungen, Co-Marketing-Arzneimittel und APDs (andere Packungen und Dosierungen).

\section{Anforderungen an die Dokumentation der Firmen}

Was ist die Anforderung an die Dokumentation seitens der Firmen? Der Vorbescheid und die Fachinformation sind natürlich sehr wichtig für uns. Wir wollen ja wissen, wie dieses Präparat effektiv angewendet wird, d.h. welche Tagestherapiekosten es verursacht. Dann nach Möglichkeit die drei wichtigsten klinischen Arbeiten, idealerweise in bereits publizierter Form. Dann der therapeutische Quervergleich, allenfalls die Begründung eines Innovationszuschlages, wenn ein solcher beantragt wird. Last but not least, auch die therapeutische Begründung der Packungsgrösse, und der Auslandpreisvergleich. Pharmaökonomische Studien sind je länger je interessanter und wichtiger, und auch epidemiologische Daten sind für uns natürlich von Bedeutung. Sehr wichtig für die EAK sind die „Key Facts“, das ist eine Kurz-Zusammenfassung der wichtigsten Fakten. Vor allem geht es ja darum, dass ein Präparat während der gesamten Dauer des SL-Eintrages die Kriterien der Wirksamkeit, Zweckmässigkeit und Wirtschaftlichkeit (WZW) erfüllt.
Die beiden ersten Kriterien, die Wirksamkeit und die Zweckmässigkeit werden mehr oder weniger durch die Zulassungsbehörde Swissmedic abgedeckt. Für uns ist natürlich die Wirtschaftlichkeit von grosser Bedeutung für die Preisfestsetzung.

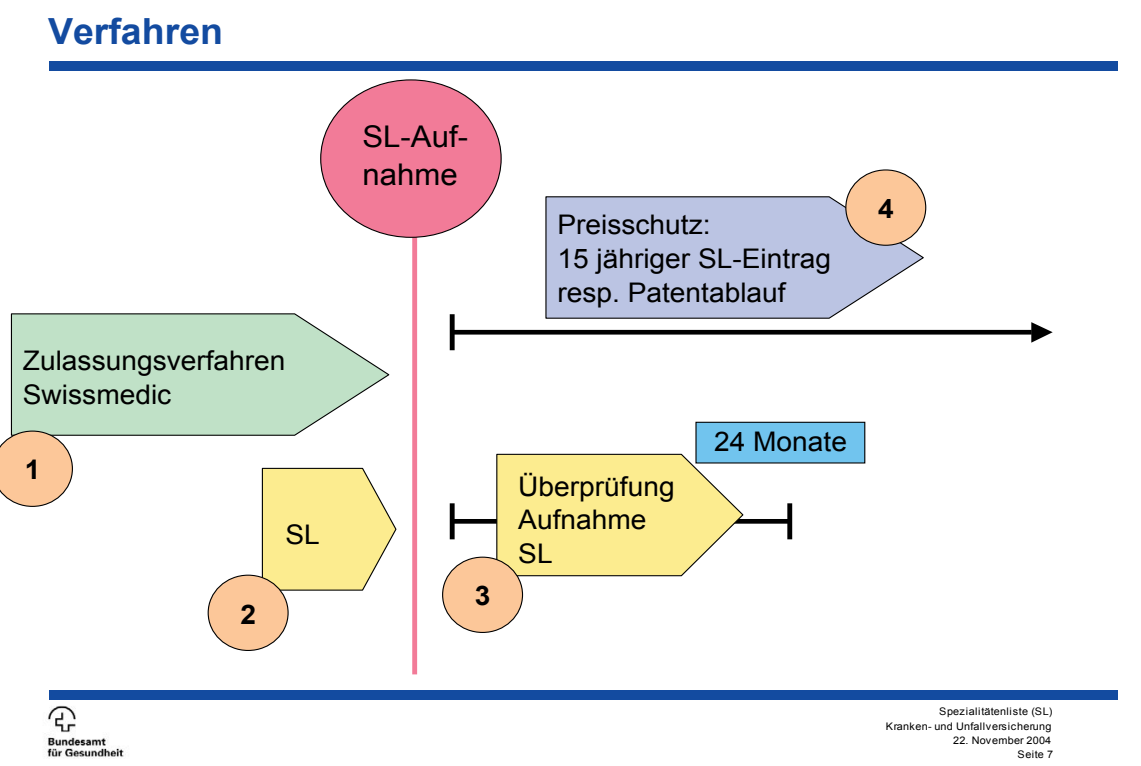

\section{Das Verfahren}

Sie sehen den Punkt oben: die SL-Aufnahme. Vorgängig läuft wie gesagt - teilweise parallel - das Zulassungsverfahren bei Swissmedic, das ist der Pfeil 1. Mit dem Vorbescheid kommt die Gesuchstellerin dann parallel dazu zum BAG mit dem Aufnahmegesuch für die SL. Die Aufnahme in die SL kann dann erst beim Vorliegen der gültigen Zulassungsbescheinigung erfolgen. Was passiert nach der SL-Aufnahme? Sie sehen, nach 24 Monaten muss die Firma nochmals bei uns vorbeikommen bezüglich des Auslandvergleiches, das heisst nach 18 
Monaten muss sie die Preise im Ausland bekannt geben. Dann kommt ein weiterer Fixpunkt hinzu: Bisher wurde das Präparat nach 15-jährigem SL-Eintrag nochmals überprüft. Neu ist, dass dies bereits nach Ablauf des Patentschutzes beim Originalpräparat erfolgt.

Das sind die drei Phasen wo wir die Preise beurteilen: Aufnahme in die SL, 18 rsp. 24 Monate später, und dann nach 15 Jahren oder nach Ablauf vom Patent.

Zum Verfahren. Wie gesagt muss die WZW während der ganzen Dauer des SL-Eintrages kumulativ erfüllt sein. Kurz zur Wiederholung: die EAK berät unser Amt, d.h. gibt eine Empfehlung ab, das Bundesamt für Gesundheit (BAG) verfügt, was wichtig zu wissen ist. Im Falle, wo wir eine Aufnahmen noch nicht verfügen können, erfolgt aufgrund der EAK- Sitzung, eine Mitteilung an die Antrag stellende Firma. Wenn alle Vorbehalte ausgeräumt werden können, kann die Aufnahmeverfügung erstellt werden, d.h. die Gutheissung durchs BAG. Wir sind dann verpflichtet die Aufnahmen im Bulletin des BAG zu publizieren, damit die Leistungserbringer und Kostenträger orientiert sind, was neu zu Lasten der OKP vergütet wird.

Wenn es zur Ablehnung kommt, gibt es wie gesagt die Möglichkeit der Einreichung eines Neuüberprüfungsgesuches, oder allenfalls, wenn grundsätzliche Fragen damit verbunden sind, kann die Firma beim BAG auch eine ablehnende Verfügung verlangen. Diese Verfügung erlaubt bei der Eidgenössischen Rekurskommission für die Spezialitätenliste (RKSL) in Lausanne eine Beschwerde einzureichen. Falls die RKSL die ablehnende Haltung des BAG mit Urteil stützt, kann die Firma beim Eidgenössische Versicherungsgericht (EVG) in Luzern, welches in letzter Instanz urteilt, Verwaltungsgerichtsbeschwerde erheben. Die Erfahrung hat gezeigt, dass ein solches Verfahren gut zwei bis zweieinhalb Jahre dauern kann. In dieser Zeit ist die Kassenzulässigkeit des Präparates nicht gegeben.

\section{Festlegung der Medikamentenpreise}

Zum Thema Festlegung der Medikamentenpreise. Sie haben bereits bei den Ausführungen von Herr Cueni gesehen, dass zwei Länderkörbe existieren. Der Hauptkorb beinhaltet Länder mit wirtschaftlich vergleichbaren Strukturen im Pharmabereich: Deutschland, Dänemark und die Niederlande, kürzlich ist noch England hinzugekommen. Subsidiär werden Frankreich, Italien und Österreich in den Vergleich miteinbezogen.

Wie wird dieser Auslandpreisvergleich bewerkstelligt? In der Regel ist es das arithmetische Mittel vom Hauptländerkorb. Es gibt natürlich die verschiedensten Spielvarianten, wenn kein Preis im Hauptländerkorb oder im Subsidiären vorliegt, oder wenn „Ausreisser“-Preise bestehen. Ich will hier nicht ins Detail gehen, da die verschiedensten Möglichkeiten denkbar sind, aber im Prinzip ist das arithmetische Mittel des Hauptländerkorbes massgebend.

Es geht jetzt also um die Wirtschaftlichkeit. Wir haben zwei Vergleiche: Den Länder- und den Quervergleich resp. den therapeutischen Vergleich. Zuerst wird geklärt, ob in der SL bereits ein Präparat eingetragen ist, welches gleiche oder ähnliche Indikationen besitzt. Mit diesem wird verglichen. Es wird dann auch auf eine therapeutische Äquivalenz abgestellt, sofern eine solche aufgrund von wissenschaftlichen klinischen Studien angegeben werden kann. Wichtig ist zu beachten, dass die Preisfestsetzung aufgrund des Fabrikabgabepreises (FAP) ohne Mehrwertsteuer erfolgt. Das ist die Basis. Dann wird der Preis aufgrund der Tagestherapie- oder der Kurkosten festgelegt: Tagestherapie- bei Langzeitmedikamenten, Kurkosten z.B. bei einer Antibiotikumtherapie, die beispielsweise eine Woche dauert.

In der SL sind Höchstpreise aufgeführt, die unterschritten werden können. Der Höchstpreis besteht aus dem Niveau des Fabrikabgabepreises, hinzu kommt der Vertriebsanteil. Sie sehen, dies im Art. $67^{1}$ der Verordnung über die Krankenversicherung (KVV) vom 27.6.1995. Der FAP gilt die Leistungen der Hersteller- resp. Vertriebsfirma bis und 
mit Ausgabe ab Lager. Hinzu kommt der Vertriebsanteil, welcher die logistischen Leistungen umfasst. Am Schluss kommt noch die Mehrwertsteuer hinzu, der reduzierte Satz von $2,4 \%$, das ergibt dann den Höchstpreis in der SL.

Unsere Verfügung basiert auf den mit der Firma „ausgehandelten“ Fabrikabgabepreisen. Wir verfügen lediglich den Publikumspreis (PP), nicht jedoch den FAP. Für die Festlegung des PP, ist jedoch der FAP die Basis.

Noch kurz zum therapeutischen Quervergleich. Hier werden Medikamente miteinbezogen mit vergleichbarem Wirkstoff, vergleichbaren Indikationen, Tagestherapiekosten-, Kurkosten oder therapeutischer Äquivalenz, und letztlich der Innovationszuschlag (IZ). Der IZ muss von der Firma beantragt werden, sie hat darzulegen, aufgrund von welcher Basis und mit welchem Präparat verglichen wird. Die maximale Erhöhung für einen IZ beträgt gemäss ständiger Praxis 10 bis $20 \%$.

\section{Vergütung des off label-use}

Ich komme noch zu einem kurzen Exkurs: Vergütung des off label-use, usw. Wir haben im Handbuch betreffend die SL, welche am 1. Januar 2004 neu rausgekommen ist, das Kapitel 8 neu aufgeführt. Es geht um folgende Kategorien: orphan drugs, orphan indications und um den off label-use.

Von orphan drugs spricht man, wenn das Präparat in der Schweiz nicht zugelassen ist. Für die Zulassung von orphan drugs gibt es seitens der Zulassungsbehörden gewisse Erleichterungen. Orphan indications: Gemäss EU-Verordnung handelt es sich um eine Krankheit, welche nicht mehr als 5 von $10^{\circ} 000$ Personen betrifft. Orphan indications und orphan drugs sind durch die soziale Krankenversicherung zu übernehmen, wobei die folgenden Voraussetzungen erfüllt sein müssen: wissenschaftliche Nachweis, medizinisch unbestritten und die vertrauensärztliche Zustimmung.

Jetzt zum off label-use. Kürzlich ist ein EVG-Urteil vom 14. Septem- ber $2004^{2}$ ergangen, das ganz klar zum Ausdruck gebracht hat, dass effektiv der off label-use - es ist in Französisch abgefasst - " En règle générale, un médicament figurant sur la liste des spécialités n'est à charge de l'assurance-maladie sociale que lorsqu'il a été prescrit pour des indications médicales conformes à celles approuvées par Swissmedic». Hier wird eine klare Sprache gesprochen. Im konkreten Fall wird eine Ausnahme gemacht. Wenn es Sie interessiert, können Sie dieses Urteil aus dem Internet runterladen, unter der Adresse www. bundesgericht.ch, dann gehen Sie auf die Rechtsprechung, dann Urteile ab 2000, weil es effektiv am 14.09.2004 erlassen wurde und dann geben sie das Kürzel K103/03 ein. Somit haben Sie Zugang zum ganzen.

\section{Immer aktuell}

Noch in eigener Sache. Die SL kommt einmal im Jahr in gedruckter Form heraus, am 1. Juli, aber sie ist jederrzeit über diese relativ lange Adresse abrufbar (www.bag.admin.ch/kv/gesetze/s//d/index.html), Wir mutieren sämtliche Daten bei uns im Amt. Sie haben also immer den neusten Stand und auch die neusten Preise.

\section{Parallelimporte}

Das Thema der Parallelimporte wird Sie noch interessieren. Bis heute sind wir noch nicht mit einem Aufnahmegesuch für ein parallel importiertes Präparat konfrontiert worden. Deshalb besteht hierzu auch keine Praxis seitens der EAK. Wie Sie wissen, ist gemäss Heilmittelgesetz der Parallelimport derzeit nur nach Ablauf vom Patent des Originalpräparates möglich. Hierzu ist wichtig zu wissen, dass nach Ablauf vom Patent der Preis des Originialpräparates mit denjenigen im Ausland geprüft wird, wobei jährliche Preissenkungen per 1. September erfolgen, was einzigartig ist in ganz Europa. Die betroffenen Pharmafirmen akzeptieren diese Senkungen und es werden keine Rechtsmittel eingelegt. 
Seit dem 1. Januar 2004 muss ein Generikum neu vom Publikumspreisniveau des Originalpräparates ausgehend mindestens 30\% billiger sein, sonst hat es gar keine Möglichkeit in die SL aufgenommen zu werden.

Interessanterweise findet auf dem Generikamarkt ein relativ grosser Wettbewerb statt. Das BAG publiziert relativ häufig freiwillig beantragte Senkungen für Generika, was teilweise ein extremes Preisgefälle zur Folge hat.

\section{Fussnoten:}

\section{${ }^{1}$ Art. $67 \mathrm{KVV}$}

Abs. 1 „Die Spezialitätenliste enthält die bei Abgabe durch Apothekerinnen und Apotheker, Ärztinnen und Ärzte sowie Spitäler und Pflegeheime massgebenden Höchstpreise

Abs. 1bis Der Höchstpreis besteht aus dem Fabrikabgabepreis und dem Vertreibsanteil

Abs. 1ter Der Fabrikabgabepreis gilt die Leistung, Abgaben inbegriffen, der Herstellungs- und der Vertriebsfirma bis zur Abgabe ab Lager in der Schweiz ab.

Abs. 1quater Der Bertiebsanteil gilt die logistischen Leistungen ab, insbesondere die mit dem Transport, der Lagerhaltung der Abgabe und dem Inkasso verbundenen Betriebs und Investitionskosten."(...)

${ }^{2}$ EVG-Urteil vom 14.09.2004 (K 103/03) 


\section{DER PARALLELIMPORTEUR - ERFAHRUNGEN AUS DEUTSCHLAND}

Jörg Geller, Mitglied der Geschäftsleitung kohlpharma euro-arzneimittel $\mathrm{GmbH}$ und Vorstandsmitglied des Verbandes der Arzneimittel-Importeure Deutschlands

Ich freue mich über die Möglichkeit, Sie über den deutschen Markt für Parallelimporte zu informieren.

\section{Die römischen Verträge}

Was ist eigentlich Arzneimittelimport? Am 25. März 1957 entsteht mit den römischen Verträgen die europäische Wirtschaftsgemeinschaft. Die Gründerstaaten beabsichtigen durch den Abschluss dieser Verträge und einer gemeinsamen Wirtschaftspolitik einen freien Markt ohne Handelshemnisse zu schaffen und damit - das ist ganz bedeutend - zur Angleichung der Lebensverhältnisse in der Europäischen Union beizutragen.

Was heisst Angleichung der Lebensverhältnisse? Es heisst zunächst, dass die Mitgliedstaaten in denen die Lebensverhältnisse schlechter sind als in anderen in ihren Lebensverhältnissen angehoben werden. Und das heisst sicherlich umgekehrt auch - das ist das Wesen einer jeden Nivellierung - dass die Lebensverhältnisse möglicherweise in einigen Ländern, in denen sie besonders hoch sind, zur gleichen Zeit etwas absinken. Wir erleben das zur Zeit in Deutschland in der Diskussion um die Frage, ob Arbeitsplätze in Deutschland möglicherweise zu teuer sind. Das heisst, Unternehmen überlegen sich mit ihren Arbeitsplätzen aus Deutschland zum Beispiel nach Polen abzuwandern. Sie nutzen damit ein Preisgefälle für Arbeit in der Europäischen Union, um ihre Produkte in der EU billiger herstellen zu können. Das heisst nicht, dass sie diese Produkte in Deutschland auch billiger vertreiben wollen, ist aber bedingt durch die absinkende Kaufkraft auf lange Sicht 
die zwingende Folge.

Polen ist übrigens, zur Information, ein Hochpreismarkt für Arzneimittel, es ist kein Niedrigpreismarkt wie vorhin behauptet wurde. Wir können kein einziges Produkt aus Polen importieren, im Gegenteil es finden Exporte nach Polen statt. Es gibt also Firmen, die sich darauf spezialisiert haben, Arzneimittel aus der Europäischen Union nach Polen zu importieren.

Wesentlich sind die Art. 28 und 30 EGV, sowie 81 und 82 EGV. Das ist das Verbot mengenmässiger Einfuhrbeschränkungen mit den entsprechenden Ausnahmeregelungen einerseits, die Verbote wettbewerbsbeschränkender Vereinbarungen und Verhaltensweisen und des Missbrauchs einer marktbeherrschenden Stellung andererseits. Eine Begrenzung erhält der freie Warenverkehr allerdings dann, wenn einschränkende Massnahmen zum Schutze der Gesundheit von Menschen oder des gewerblichen und kommerziellen Eigentums gerechtfertigt sind, soweit diese Massnahmen kein Mittel zur willkürlichen Diskriminierung oder eine verschleierte Beschränkung des Handels zwischen den Mitgliedstaaten darstellen.

\section{Der „Adalat“ Fall}

Der Veranstalter hatte in den Vorgesprächen gewünscht, dass ich hier auch kurz auf den „Adalat" Fall eingehen soll, von dem Sie ja schon gehört haben. Vielleicht daher nur ein ganz kurzes Zitat aus der Entscheidung des EuGH (Europäischer Gerichtshof), nämlich die Randnummer 42 ${ }^{1}$. In der Tat hat hier der EuGH in zweiter Instanz geprüft, ob es verbotene Absprache zwischen Bayer und den Grosshändlern in Frankreich und Spanien gegeben hat, und natürlich gab es keine solche Absprachen. Deswegen konnte das Vorhandensein solcher Absprachen auch durch die Kommission nicht nachgewiesen werden. Die Grosshändler hatten gerade ein grosses Interesse daran, Arzneimittel, die sie bei Bayer eingekauft hatten, an Importeure zu verkaufen, sie hatten keine Absprache mit Bayer getroffen das zu unterlassen. Des- wegen konnte auch kein diesbezüglicher Nachweis geführt werden. Insofern hat die Kommission in ihrer Klage die falschen Rechtsnormen angewendet so, dass der EuGH sehr konsequent dann schreibt:

«Vor einer Prüfung der Rechtsmittelgründe ist hervorzuheben, dass sich die Kommission in der streitigen Entscheidung strikt auf die Prüfung eines einzelnen Beschwerdepunktes beschränkt hat, nämlich des Vorliegens einer Vereinbarung im Sinne von Art. 85 Abs. 1 des Vertrages zwischen Bayer und ihren Grosshändlern und zwar im Rahmen eines durch Bezugnahme auf die wichtigsten therapeutischen Indikationen des erfragten Erzeugnisses, Adalat, bestimmten Marktes. Es geht somit im vorliegenden Verfahren weder um die eventuellen Anwendungen anderer Tatbestände des Art. 85 oder 86 EGV, noch um andere mögliche Abgrenzungen des massgebenden Marktes.»

Das bedeutet, und die Europäische Kommission hat dies auch unmittelbar nach Urteilsverkündung verlautbart, dass Verstösse nach Art. 81 und 82 EGV unter allen denkbaren Möglichkeiten von der Europäischen Kommission untersucht werden und Massnahmen zur Begrenzung des freien Warenverkehrs auch weiterhin von der Europäischen Kommission verfolgt werden.

Der EuGH-Entscheid vom 06.01.2004 stellt also keinen Freibrief zur Reduzierung ausgelieferten Mengen dar, denn der EuGH hat den erstinstanzlichen Entscheid nur deshalb bestätigt, weil es nach seiner Auffassung der Europäischen Kommission nicht gelungen war, verbotene Vereinbarungen zwischen Bayer und seinen Abnehmer nachzuweisen. 


\section{Spannungsfeld zwischen freiem Warenverkehr und Marken- recht}

Die rechtliche Grundlage unseres Geschäfts steht im Spannungsfeld zwischen freiem Warenverkehr einerseits und Arzneimittel- und Markenrecht andererseits. Wie sie wissen, müssen die in Deutschland vertriebenen Arzneimittel zugelassen sein. Das bedeutet, dass auch die von den Importeuren vertriebenen Arzneimitteln in Deutschland zugelassen sein müssen. Allerdings erhalten die Importeure - das haben wir vorhin schon gehört - die Zulassung in einem vereinfachten Zulassungsverfahren durch das Bundesinstitut für Arzneimittel und Medizinprodukte (BfArM). Würden die Importeure eine Vollzulassung in einem Zulassungsverfahren benötigen, so wie es die Originalhersteller durchlaufen müssen, würde dies eine Massnahme zur Beschränkung des freien Warenverkehrs darstellen. Das hat der Europäische Gerichtshof in einer grundlegenden Entscheidung im Jahre 1976 festgelegt, die dann in den 80er Jahre zu einer entsprechenden Bekanntmachung geführt hat, die vom BfArM umgesetzt wurde.

Juristische Probleme sind in der Vergangenheit jedoch dann aufgetaucht, wenn der Importeur eine solche Zulassung im vereinfachten Verfahren erhalten hat und der Originalhersteller, der das Bezugsarzneimittel im Einfuhrstaat ebenfalls vertrieben hat, später auf diese Zulassung verzichtet. Dasselbe gilt im übrigen auch für die zentral von der EMEA (European Medicines Agency) in London zugelassenen Arzneimittel, denn diese Arzneimittel sind abschliessend geprüft und nach der Zulassung in der gesamten EU verkehrsfähig, ohne dass es einer zusätzlichen Zulassung des Importeurs bedarf.

Das zweite Spannungsverhältnis, das beim Import von Arzneimittel berücksichtigt werden muss, ergibt sich aus dem Verhältnis des Importeurs zum Originalhersteller des Arzneimittels, der in der Regel neben der notwendigen Zulassung auch über die jeweiligen Markenrechte an der Bezeichnung des jeweiligen Arzneimittels verfügt. Das deutsche Markengesetz, mit der die europäische Markenrichtlinie umgesetzt worden ist, geht davon aus, dass der Inhaber einer Marke nicht das Recht hat, einem Dritten zu untersagen, diese Marke für Waren zu benutzen, die unter dieser Marke von ihm oder mit seiner Zustimmung in einem der Mitgliedstaaten der Europäischen Union in den Verkehr gebracht worden sind. Das heisst, die Rechte eines Markeninhabers innerhalb der Europäischen Union sind insoweit erschöpft. Wir haben schon gehört welche Grundlagen bestehen, um diese Erschöpfung letzten Endes dann umzusetzen.

Für Importe aus den neuen Mitgliedstaaten der Europäischen Union in Osteuropa gibt es eine Sonderregelung, die „spezifischer Mechanismus" genannt wird. Das heisst, hier muss geprüft werden, bevor man importieren kann, ob die Patentrechte erschöpft sind.

Zusammenfassend ist also festzustellen, dass die Importarzneimittel in Deutschland nicht nur unproblematisch verordnet, abgegeben und eingenommen werden können, sondern darüber hinaus auch heute noch unter dem besonderen Schutz der Europäischen Union stehen. Denn der Grundsatz des Schutzes des freien Warenverkehrs gilt von Anbeginn der Europäischen Union an und ist trotz Kenntnis der Entscheidungsträgers über Unterschiede in einzelnen nationalen Systemen immer wieder in der eben beschriebenen Form bestätigt und aufrecht erhalten worden.

Auch 47 Jahre nach Abschluss der wegweisenden römischen Verträge ist einen wirkliche Tendenz zur Angleichung der Gesundheitsmärkte der Mitgliedstaaten der Europäischen Union nicht erkennbar. Vielmehr sehen die nationalen Regierungen bislang gerade in diesem Markt die Notwendigkeit durch Fortschreibung und Weiterentwicklung der nationalen Gesetzgebung zum Schutze der Patienten und zur Erhaltung der Finanzierbarkeit der Gesundheitssysteme einzugreifen. Naturgemäss versuchen die Anbieter in den jeweiligen Märkten jeweils den höchsten durchsetzbaren Preis für ihre Leistungen und Waren zu erzielen. Das ist völlig normal und völlig legitim. In der Folge ergeben sich für identische Präparate des gleichen multinationalen Anbieters 
zum Teil erhebliche Preisunterschiede auf den europäischen Märkten, die Parallelhandel erst ermöglichen. Parallelhandel ist deswegen kein grauer Markt - Importeure sind auch keine Trittbrettfahrer, wie eben gesagt wurde - sondern genau das, was sich die Väter der römischen Verträge gewünscht hatten: Sie wollten freien Warenverkehr.

Natürlich ist nicht in jedem Markt der gleiche Preis durchsetzbar. In keinem Europäischen Land gibt es Preisdiktate. Kein Unternehmen ist verpflichtet, in jedem Land präsent zu sein, oder seine Präparate sogar mit Verlust zu verkaufen, und tut es sicherlich auch nicht. Kein Unternehmen ist verpflichtet, in Europa mit unterschiedlichen Preisen zu operieren, tut dies aber, weil die sonst notwendigen Preissenkungen in den Hochpreisländern schmerzlicher wären, als die vergleichsweise geringeren Margenverluste durch Importe.

\section{Unterschied zwischen Parallelimport und Reimport}

In der allgemeinen Diskussion werden die Begriffe Parallelimport und Reimport oft synonym verwendet. Sie sprechen hier von Parallelimport. Es gibt jedoch einen grundlegenden Unterschied, der vielleicht gerade für die Schweiz eine Bedeutung hat. Beim sogenannten Parallelimport wird das, in unserem Fall, für den deutschen Markt bestimmte Produkt des Originalherstellers nicht in Deutschland, sondern im Ausland produziert. Deswegen heisst dieser Vorgang Parallelimport. Sowohl der Originator wie der Parallelimporteur bringen dieses Produkt aus dem Ausland nach Deutschland. Der deutsche Originalhersteller fungiert insoweit, wenn sie so wollen, mittlerweile auch rechtlich als Grosshändler - er ist nicht Hersteller in Deutschland. Folglich wird auch kein Arbeiter in Hoechst, Darmstadt oder woanders in Deutschland beschäftigt, um diese Präparate herzustellen. Die Lohnkosten fallen ausschliesslich im Ausland an.

Die deutsche Vertriebsgesellschaft des multinationalen Konzerns kauft das Präparat bei der zum Konzern gehörenden ausländischen Herstellerfirma zu Konzernverrechnungspreisen. Der Konzern hat inso- fern auch die Möglichkeit, Gewinne dort anfallen zu lassen, wo es aus steuerlichen Überlegungen am sinnvollsten erscheint. In Deutschland finden dann ausschliesslich Vertriebsaktivitäten statt.

Auch der Importeur kauft auf einem Auslandmarkt ein und importiert parallel nach Deutschland. Ein Beispiel sind die Clexane Fertigspritzen 20 mg, die Aventis für den deutschen Mark auch in Frankreich herstellt. Mehr als $90 \%$ der in Deutschland getätigten Umsätze der Importeure werden mit sogenannten Parallelimporten getätigt. Das zeigt, meine sehr verehrten Damen und Herren, auch die Bedeutung der deutschen Pharmaindustrie, die einmal die Apotheke der Welt war. 90\% der patentgeschützten Arzneimittel werden für den deutschen Markt im Ausland - zum Beispiel in der Schweiz - produziert. Das bedeutet, Deutschland hat hier offensichtlich als Herstellerland keine Bedeutung mehr, und zwar aus Gründen, die mit Parallelimporten nichts zu tun haben.

Reimporte dagegen sind Präparate, die auch für den ausländischen Einkaufsmarkt der Importeure - in unserem Fall in Deutschland - hergestellt werden. Auch hier hat das Vorhandensein der Importe keinerlei Beschäftigungseffekte bei den entsprechenden Originalherstellern. Zwar sind die vom deutschen Originalhersteller in Deutschland vertriebenen Mengen rückläufig, dafür steigt aber die Auslandnachfrage beim deutschen Hersteller mindestens im gleichen Masse. Einige Konzerne haben ausserdem bereits mit Überraschung festgestellt, dass - was Sie heute Morgen schon gehört haben - tatsächlich gilt, dass es nämlich einen Zusammenhang zwischen Preis und Menge gibt. Das heisst, das Vorhandensein eines preiswerten Imports kann dazu führen, dass der Gesamtabsatz einer Marke gesteigert wird. Das haben wir an vielen Beispielen in Deutschland feststellen können. Auch einige Hersteller haben das festgestellt und waren darüber gar nicht so unglücklich, bietet sich doch die Möglichkeit, quasi eine Zweipreisstrategie durchzuführen und sich trotzdem gleichzeitig von dem zweiten Preis zu distanzieren. Insofern hat der zweite Preis auch keinen Einfluss auf eventuelle Referenzpreissysteme gehabt, wie sie vorhin beschrieben 
wurden. Bei Referenzpreissystemen ist der Preis von Emra Med oder Kohlpharma oder Eurim Pharm nicht der relevante Preis, sondern der Preis des Originalherstellers. Das heisst, man kann im deutschen Markt letzten Endes einen günstigeren Preis anbieten, aber selbst ist man für diesen Preis nicht verantwortlich und der Preis spielt auch keine Rolle bei der Berechnung eines Referenzpreises.

\section{Preisdifferenz}

Weniger als $10 \%$ der Umsätze der Importeure werden als Reimport getätigt. Der Einkauf der Importeure verfolgt ständig die Neueinführungen und die Preispolitik der multinationalen Konzerne auf den europäischen Märkten. Dabei wird geprüft, ob es Präparate gibt, die eine hinreichende Preisdifferenz zu dem in Deutschland vertriebenen Präparat des Originalherstellers bei gleichzeitiger hinreichender Marktbedeutung aufweisen.

Bis 2002 musste die Preisdifferenz ausreichen, um die Handlingskosten und Gewinnerwartungen des Importeurs und den Preisabstand zum deutschen Original zu finanzieren, der direkt den Versicherten und Krankenkassen zugute kam. Der Preisabstand war nicht gesetzlich fixiert, lag aber für die meisten Importeure zwischen 33\%, im gewichteten Mittel bei etwa 10\%. 10\% Preisdifferenz kamen also direkt den Patienten, den Versicherten und den Krankenkassen zugute. Preisvorteile tragen unabhängig von ihrer prozentualen Höhe zur Verbesserung der Finanzierung des Gesundheitssystems bei. Ausserdem dürfte unbestreitbar sein, dass Wettbewerb generell zum Absinken des Preisniveaus führt, das heisst, dass alleine schon das Vorhandensein einer Importalternative zu verminderten und erschwerten Preiserhöhungen der betroffenen deutschen Originale führt.

Seit 2003 musste die Preisdifferenz in europäischen Märkten zusätzlich einen Herstellerrabatt von 6\% tragen. Damit gingen dem Import nicht nur Präparate verloren, die diese Preisspreizung nicht tragen können, sondern auch, wie wir intern sagen, sogenannte „Zukaufsländer“. die grosse Nachfrage nach Importarzneimittel hat dazu geführt, dass Importeure in Deutschland ihren Bedarf längst nicht mehr in dem preisgünstigsten Land befriedigen können, sondern vielmehr in weiteren teureren Ländern einkaufen müssen. Das heisst, der Importeur kauft dieses Präparat zum Teil in bis zu acht verschieden Ländern ein.

In 2004 hat sich die Situation in Deutschland weiter verschärft. Der Herstellerrabatt hat sich auf 16\% erhöht, den auch die Importeure bezahlen müssen, da sie formaljuristisch als Hersteller gelten. Die Lobbyarbeit des VFA (Verband der forschenden Arzneimittelhersteller) - ich nehme an, die InterPharma hier in der Schweiz ist ein vergleichbarer Verband - hat ausserdem zur Festlegung eines Preisabstands von $15 \%$ oder 15 Euro zum deutschen Original geführt, den Importeure einhalten müssen, wenn sie wollen, dass ihre Präparate von den Abgabeverpflichtungen der Apotheker begünstigt werden sollen.

Beide Neuregelungen erschweren den Import und haben auch dazu geführt, dass das Volumen des Imports im letzten Jahr deutlich zurückgegangen ist. Aber gerade die Preisabstandsregelung ist im Kontext eines Gesetzgebungsverfahrens, das sich zum Ziel gesetzt hatte, Beitragssenkungen bei den gesetzlichen Krankenkassen zu bewirken - was bisher nicht erfolgreich war - äusserst kontraproduktiv. Konnten die Krankenkassen sowohl in 2002 wie in 2003 noch jeweils etwa 200 Million Euro direkte Einsparungen realisieren, werden die Einsparungen in 2004 deutlich sinken und nur etwa 100 Millionen Euro betragen.

Das Vorhandensein von Importarzneimitteln hat neben staatlichen Interventionen zu einer moderaten Preissetzung von Arzneimittel in Europa beigetragen. In den USA sind die Preise, wie Sie wissen, weit höher und dort haben wir einen abgeschotteten Markt, der letzten Endes für Importe nicht zugänglich ist. 


\section{Branchenvergleich}

\begin{tabular}{|c|c|c|c|}
\hline Worte fn Mio. Euro & Umsat= & Erg. n. st. & vom Umsat= \\
\hline VEA (37 Unternehmen) & $324.634,9$ & $56.040,4$ & 17,268 \\
\hline $\begin{array}{l}\text { Grofhandel Fealtheare } \\
\text { (E grusten) }\end{array}$ & $171.524,3$ & $2.067,8$ & 1,218 \\
\hline Banken ( $€ 2$ gzositen) & 1.285 .416 & $52.757,4$ & 4,108 \\
\hline Chnmi= 16 grobtani & $121.152,2$ & 1. 680,0 & 1,398 \\
\hline Eingelfandel (12 grosten & $449,983,5$ & $11.439,1$ & 2,548 \\
\hline $\begin{array}{l}\text { EDV Hard us. Software } \\
\text { (1) grobten }\end{array}$ & $315.680,9$ & $13,174,8$ & 4,178 \\
\hline Elektro (1.8 grobten) & $542,423,5$ & $-3.740,9$ & $-0,698$ \\
\hline Eniergie 100 grobten] & $167.124,3$ & $-2.580,9$ & $-1,548$ \\
\hline Versicherungen 119 growbet & a) $468.787,0$ & $9.557,4$ & $2,04 \%$ \\
\hline Fahrzeugbau 132 grobten] & $1.212 .180,9$ & $24.979,1$ & 2,068 \\
\hline Q1 (25 graeten) & $1.109 .771,3$ & $52.406,1$ & 4,72 용 \\
\hline
\end{tabular}

kohlpharma

\section{Branchenvergleich}

Wir haben heute auch etwas über Kosten von Forschung gehört. Der Vorredner hat zwar gesagt, welchen Prozentsatz des Umsatzes in Forschung investiert wird, aber er hat verschwiegen, wie die Umsatzrendite der forschenden Hersteller aussieht. Wir sehen das hier. 17,26\% Umsatzrendite haben die forschenden Firmen (37 Unternehmen in Deutschland) vor Steuern erreicht. Im Branchenvergleich ist das ganz stattlich, sowohl absolut wie auch relativ. Auf den nächsten Plätzen folgen die Banken mit nur 4,1\%. 17,26\% ist wirklich der absolute Spitzenplatz. Der Fahrzeugbau ist auch eine innovative Industrie und muss sich mit einer Umsatzrendite von nur 2,06\% begnügen. Also, da war sicherlich genug Geld vorhanden, um auch die eine oder andere Forschung zu finanzieren.

\section{Die Studie der London School of Economics}

Sie haben auch einiges über diverse Studien gehört. Da war zum Beispiel die Rede von einer Studie in London. Die Studie ist insoweit sehr interessant, als ich dort erstmalig erfuhr, welche tollen Renditen wir in Deutschland erzielen. Gleichzeitig partizipieren die Apotheker ausweislich dieser Studie von diesen Importen überhaupt nicht. Dabei sagt man in Deutschland, dass man den Apothekern zu hohe Rabatte einräumen würde, um sie damit zu motivieren, letzten Endes Importe abzugeben. Irgendwas an dieser Studie scheint nicht zu stimmen. Erstaunlicherweise wurden dort auch nur eine Handvoll Präparate einbezogen, aus denen dann die Ersparnisse der Krankenkassen berechnet wurden. Eine Handvoll Präparate, wir alleine vertreiben in Deutschland 1.400 verschiedene Handelsformeln. Es waren aber weniger als 20, die Eingang in diese Studie gefunden haben, und der Autor dieser Studie hat sich nicht einmal die Mühe gemacht, die dann errechneten Einsparungen - die er auf sehr fragliche Weise ermittelte - auf den gesamten Importmarkt hochzurechnen. Er wäre dann zu ähnlichen Einsparungen gekommen, wie sie die York Studie richtigerweise berechnet hat.

Diese Zahlen, 60 Millionen Euro Einsparungen zum damaligen Zeitpunkt, waren ein realistischer Wert. Wir haben 200 Millionen erreicht, das Potential war damals ca. 300 Millionen. Auch die Londoner Studie wäre zum gleichen Wert gekommen, hätte sie einfach den Marktanteil der betrachteten Präparate mit den Umsätzen der tatsächlich importierten Präparate gewichtet. Man darf sich über die Ergebnisse aber nicht wundern, wenn eine solche Studie einen Finanzier wie Johnson \& Johnson hat, der ein eindeutiges Interesse verfolgt.

Fussnote:

${ }^{1}$ C-2/01P und C-3/01 P, Grur Int \&/04, 508ff 


\section{Österreichische Kleinstaat-Erfahrungen mit Parallel- importen}

Gernot Spanninger, Österreichisches Bundesministerium für Gesundheit und Frauen, Abteilungsleiter Pharmaökonomie und Geschäftsstelle unabhängige Heilmittelkommission, Wien

Ich danke dafür, dass der Bogen für mich etwas weiter gespannt wurde, denn zu dem Thema Parallelimporte könnten wir in Österreich relativ rasch zu einem Ende gelangen. Ich darf Ihnen berichten, wir haben in Österreich jetzt seit eineinhalb Jahren die Gesundheitsreformsdiskussion, und wir sind jetzt dabei, diese ganzen Diskussionen in Gesetzesmassnamen zu giessen und im Jahr 2004 abzuschliessen. Aber in diesen eineinhalb Jahren ist das Thema Parallelimporte nicht im Mittelpunkt gestanden, weil es für Österreich gesamtwirtschaftlich, beziehungsweise volkswirtschaftlich, nicht die Bedeutung gehabt hat, dass wir es im Ranking in die Diskussion genommen hätten.

\section{Parallelimportfragen für Österreich kein Thema}

Wir haben das Thema Parallelimporte in den letzten eineinhalb Jahren nicht in die Diskussion zum Thema Gesundheitsreform hinein genommen, weil es aus österreichischer Sicht im Ranking nicht so bedeutend war. Wir sind dabei etwas anders gelagert als die Schweiz; ich gebe den Referenten recht, die gesagt haben: «Wenn man exportorientiert ist, muss man sich die Dinge anders überlegen.» Die österreichische Pharmaindustrie ist nicht so ausgeprägt exportorientiert und hat nicht auf diese Parameter so Rücksicht zu nehmen, wie dies in der Schweiz der Fall ist.

Zum Punkt zwei. Wie wir gehört haben, hat sich die EU bereits dieses Themas angenommen; in diesem Zusammenhang wären zwei Aspekte zu nennen. Der erste Aspekt: es hat ein EUGH-Urteil gegeben, die EU hat darauf gesagt, Parallelimporte sind möglich. Dies ist 
in einem Schreiben der Kommission an alle Staaten der EU hinausgegeben. Der zweite Aspekt: Vielleicht gibt es Vertreter unter uns, die dabei waren, als Italien im zweiten Halbjahr 2004 den EU-Vorsitz in Rom übernommen hat. Damals hat es ein Meeting gegeben, in dem bekanntgegeben wurde, dass die Kommission beschlossen hat, ihre Empfehlungen über Arzneimittel und die forschende pharmazeutische Industrie an den Rat weiterzuleiten.

Im Zuge dieser Gespräche haben die Firmen vorgetragen und gemeint, Parallelimporte seien betriebswirtschaftlich schädlich und beeinträchtigen die Forschung und Entwicklung. Wie aus der $\mathrm{Zu}-$ sammenfassung der Tagung ersichtlich, ist zu akzeptieren, dass $\mathrm{Pa}$ rallelimporte eine Folgeerscheinung im Wirtschaftsleben sind. So ist es im Rahmen der EU-Gremien besprochen worden.

Wenn also eine differenzierte Preispolitik in den einzelnen Ländern der EU vorliegt, die von den Firmen gemacht wird, müssen wir als Folge zur Kenntnis nehmen, dass es als Begleiterscheinung diese Parallelimporte gibt, wenn der freie Warenverkehr gewahrt bleiben soll. Das heisst, diese Stellungnahme der EU ist in Österreich akzeptiert.

\section{Österreich unterscheidet sich von der Schweiz}

Ich werde nun kurz aufzeigen, warum in Österreich das Thema Parallelimporte meiner Meinung nach nicht mehr ein so wichtiges Thema ist. Wir unterscheiden uns in Österreich in drei, vier Punkten ganz wesentlich von der Schweiz.

Sie haben in der Schweiz ein Versicherungssystem, das sich sicherlich ganz abhebt von dem in Österreich; das heisst Sie haben andere Finanziers und andere Finanzströme wie wir. In Österreich unterscheiden wir zwei wirklich getrennte Gesundheitsmärkte.

Das eine ist der stationäre Bereich, der föderalistisch ausgerichtet ist, das heisst, sich im Kompetenzbereich der Länder befindet. Finanziers in diesem stationären Bereich sind drei Hauptkomponenten:
Pflichtversicherungen, private Zusatzversicherungen und als dritte Komponente die jeweiligen Landesbudgets. In Österreich ist Pflichtversicherung gegeben. Fest steht, dass das Sagen im stationären Bereich die Länder haben.

Ausdruck dieses Umstandes im Krankenhaus ist die Anstaltsapotheke. Die Anstaltsapotheke kauft die Arzneimittel nach den Empfehlungen der jeweiligen Ärzte. Preisgestaltung und Sortimentsgestaltung liegt in den Händen der Anstaltsapotheken. Beliefert werden die Anstaltsapotheken von den Firmen direkt, das heisst Grosshandel und Apotheken sind ausgeschaltet. Wenn ein Anstaltsapotheker die Chance hat, oder es inm angeboten wird, parallel importierte Produkte zu kaufen, dann wird er diese Chance wahrnehmen, wenn sich dadurch Vorteile für das Krankenhaus ergeben. Es soll uns wirklich nicht stören, wenn eine Firma ein Angebot macht, wo die Einsparung direkt an den Träger geht. Aber ich darf innen versichern, es kommt nicht so oft vor; die Vertreter der Schweizer Firmen werden Ihnen bestätigen, dass die Märkte in Österreich insofern unterschiedlich behandelt werden, dass im Krankenhausbereich ein Rabattsystem umfassend ausgeschöpft wird. Das heisst, hier wird die Belieferung nicht ausschliesslich über die Preiskomponente getätigt, sondern über die sogenannte Spirale der Naturalrabatte. Wenn es darum geht, ein Konkurrenzprodukt vielleicht vom Markt fern zu halten, gibt man eben mehr Naturalrabatte.

Dieses System wird in Österreich exzessiv gehandhabt und wir sind durchaus der Meinung, dass, wenn die Marktkriterien ihren Eingang gefunden haben - und dabei keine Rechtsbestimmungen verletzt werden - nicht zwanghaft eingegriffen werden soll. Also bezieht sich unsere Schau des Themas Parallelimporte vorwiegend auf den Rest des Marktes - das heisst, die ca. $20 \%$ Marktanteil des Spitalssektors werden ausgeklammert - auf den niedergelassenen Bereich, das sind ca. $80 \%$ des gesamten Pharmamarktes in Österreich. Jeder Marketingexperte weiss, dass state of the art in der Medizin im Krankenhaus gebildet wird und nicht im niedergelassenen Bereich. Diese Botschaft 
wollte ich noch vermitteln, damit man nicht glaubt, dass Bundesbehörden sich dieser Tatsachen nicht bewusst sind.

\section{Sozialpartnerschaft}

Wenn man jetzt die restlichen $80 \%$, die eine Folgeerscheinung vorgelagerter betriebswirtschaftlicher Aktionen sind, näher beleuchten, dann müssen wir sagen, dass dieser Bereich bei uns wirklich sehr stark reguliert ist. Dabei ergibt sich die Situation, und dabei haben wir gelegentlich unter der Tradition gelitten, die besagt, dass wir gerne regulieren und Konflikte lösen, bevor wir Gesetze beschliessen. Das nennt sich bei uns Sozialpartnerschaft. Ich glaube dieses Modell ist in die Welt hinausgedrungen. Es führt bei unserem Thema dazu, dass wir im Arzneimittelmarkt - wo wir im niedergelassenen Bereich diesen Stufenbau vor uns haben - auf Herstellersebene, auf Grosshandelsebene und auf Apothekenebene jeweils Beratungsorgane haben, wo die Anbieterseite und die Nachfragerseite jeweils eingebunden ist.

Ziel ist es, und das kann ich sagen, einstimmige Beschlüsse zu fassen. Dies hat den Vorteil, dass der Konflikt vorgelagert ist und wir wenige Klagen beim obersten Gericht haben. Es hat aber den Nachteil, dass manche Entscheidungen, die diesbezüglich gefällt sind, mit dem EU-Recht vielleicht in Konflikt kommen können. Da mussten wir erst lernen, wie das Verhältnis Österreichs mit der EU sich gestaltet. Heute können wir sagen, dass dies staatlicherseits relativ gut gelungen ist. Da haben wir der Grossindustrie entsprechend in Österreich in den letzten 10 Jahren sehr brav agiert, haben mit Akzeptanz der Wirtschaft die Distribution neu geordnet und im Grosshandelsbereich vier mal die Grosshandelsspanne gesenkt, die inzwischen auf 9\% zurückgegangen ist. Sie ist wirklich dramatisch reduziert worden, vier mal ein Senkungsprogramm. Ausserdem wurden bei den Apotheken genauso Senkungsprogramme hinsichtlich Spanne durchgeführt, weil wir in Österreich fleissig EU Querschnitte verglichen haben.

Bei diesen EU Querschnitten wurden die skandinavischen Länder herausgenommen, weil wir der Meinung sind, dass Einkanalsysteme nicht vergleichbar sind mit anderen Distributionsformen. Aber selbst bei dieser Herausnahme im Rahmen der EU-Vergleiche sind wir zur Kenntnis gekommen, Grosshandel- und Apothekenspanne sind zu senken. Diese Spannen sind im Grosshandel vier mal, bei den Apotheken drei mal gesenkt. Das heisst, wir können über die letzten 10 Jahre sagen - und bitte von der Seite der Industrie durchaus als Datum mitnehmen - dass wir in Österreich hohe Wachstumsraten im Arzneimittelbereich gehabt haben, Ausgabenwachstum im pharmazeutischen Bereich bei gleichzeitiger Kürzung der Distribution in beiden Stufen.

Ich glaube das kennzeichnet die Entwicklung, die wir durch den Beitritt zur EU mitgemacht haben. Nachdem wir eine Pflichtversicherung haben, bei der jeder versichert sein muss, ist es klar, dass der niedergelassene Bereich hinsichtlich ärztlicher Leistungen und des pharmazeutischen Bereichs dadurch abgedeckt wird. Der Versicherung kommt damit als Verhandlungspartner der pharmazeutischen Industrie eine nicht unwesentliche Position zu. Dies findet den Ausdruck darin, dass in Österreich ein sogenanntes Heilmittelverzeichnis aufgelegt wird und jede Firma versucht, ihr Produkt in dieses Heilmittelverzeichnis zu plazieren, weil damit die Anwendung im niedergelassenen Bereich einen gewissen Verstärkungseffekt aufweist.

Als wir zur EU gekommen sind haben die Sozialpartner, die auch in der Sozialversicherung kollegial vertreten sind, gemeint, dass das ein wirksames Instrumentarium ist. Die EU hat uns in einem Verfahren vor dem EuGH erklärt, dass diese Massnahmen nicht rechtens sind. Nicht rechtens deswegen, weil es keinen rechtlichen Stufenbau gibt. Das heisst, die Festlegung oder die Einstufung, die Aufnahme in das Heilmittelverzeichnis ja oder nein, war eine endgültige. Damit hat es keine Einspruchsmöglichkeit gegeben. Die Entscheidung des EuGH besagte, dass der Stufenbau der Rechtsordnung in Österreich gewahrt werden muss.

Aufgrund dieses Erkenntnisses haben wir unsere Gesetze umgebaut. 
Es ist das Heilmittelverzeichnis geblieben, wird nunmehr mit 1.1.2005 in den Erstattungskodex übergeführt. Als zweite Stufe gibt es jetzt die unabhängige Heilmittelskommission. Dies ist eine Kommission - wo vor allem fachliche Vertreter aus den verschiedenen Organisationen entsendet sind - mit richterlichem Einschlag, der Vorsitzende ist vom Obersten Gerichtshof. Die zweite Instanz prüft, ob in der ersten Instanz alles rechtmässig abgewickelt wurde. Als dritte Instanz gibt es den Verfassungsgerichtshof, der eine Entscheidung auf verfassungsrechtliche Bedenken prüft.

\section{Parallelimport}

Hier sind wir nunmehr beim Problem Parallelimporte gelandet, wo derzeit mehrere Fälle beim Verwaltungsgerichtshof anhängig sind; sie haben also die erste und die zweite Instanz absolviert, sind nun also in der dritten Instanz. Es könnte sein, dass sie in der dritten Instanz enden, könnte aber auch sein, dass sie beim EuGH landen; das wissen wir noch nicht. Deshalb bin ich sehr zurückhaltend mit meinen Ausführungen.

Ich kann nur eines dazu sagen: Wir haben in der Preiskommission ein offenes Verfahren mit dem Parallelimporteuren, weil wir im $\S 6$ Preisgesetz ausgeführt haben, dass der Bundesminister von Amtswegen Preise festlegen kann, wenn dazu eine volkswirtschaftliche Notwendigkeit gegeben ist.

Das Problem ist somit bei uns aufgezeigt, und wir haben diesbezüglich ein Vorprüfungsverfahren vor zwei Jahren eingeleitet. Dies deshalb, weil eine Firma aufgefordert wurde, uns zu sagen, wo neben dem firmenspezifischen betriebswirtschaftlichen Nutzen ein volkswirtschaftlicher Nutzen des Konsumenten durch Parallelimporte gegeben ist. Dass der betriebswirtschaftliche Nutzen seitens des Anbieters gegeben ist, von dieser Annahme gehen wir in der Preiskommission aus, sonst würde er das Produkt nicht am Markt anbieten und verkaufen. Wir wollten zusätzlich wissen, wo der volkswirtschaftliche Nutzen des
Nachfragers, bzw. des Konsumenten/der Versicherung gegeben ist. Diese Frage ist noch nicht beantwortet. Es gilt abzuwarten, wie die rechtlichen Entscheidungen fallen. Der Standpunkt der parallelimportierenden Firmen ist, dass sie keine Neuregistrierung sind, sondern eine Zusatzregistrierung eines Arzneimittels ausweisen. Wenn sie eine Zusatzregistrierung sind, würden sie somit keine Preisfestsetzung benötigen. Das heisst, sie können eigentlich zum Preis des Originalprodukts verkaufen.

Wir werden abwarten, inwieweit diese Meinung beim Verfassungsgerichtshof Niederschlag findet oder nicht. Wenn sie nicht findet, ob der EuGH angerufen wird. Fest steht für uns, dass es im Moment nur eine geringe Zahl von Arzneimitteln gibt, die in Österreich parallelimportiert werden. Das Umsatzvolumen ist so gering, dass wir im Moment die Situation genau beobachten und uns keine Sorgen machen. Sollte die Rechtsprechung Ihre Urteile getroffen haben und uns dahingehend informiert haben, werden wir als Ökonomen die erforderlichen Schlüsse aufgrund dieser rechtlichen Rahmenbedingungen zu ziehen haben. Und dabei gibt es unterschiedliche Möglichkeiten. Wenn die Firma, die das parallelimportierte Arzneimittel verkauft, bereit ist, einen Nachlass zu geben, wie es die Sozialversicherung verlangt - diese meint, diese Produkte müssen um $10 \%$ billiger sein als der Originalhersteller - dann sollte uns das recht sein. Eine solche Vereinbarung, die mit der Sozialversicherung zu treffen ist, obliegt der jeweiligen Firma.

Sollte dies nicht der Fall sein, wird man eine Bewertung im Sinne des Preisgesetzes prüfen. Es muss ja auch auf Nachfragerseite jemanden geben, der durch Parallelimporte Vorteile hat. Wenn solche Firmen diese Vorteile nur an den Handel weitergeben, indem sie sagen: da haben vielleicht die Apotheker oder die Hausapotheker die Möglichkeit, in den Genuss von Rabatten zu kommen, die der Behörde nicht bekannt sind, könnten wir diese Vorgehensweise aufgreifen und diskutieren, ob diese Rabatte, die einzelne Betriebsergebnisse fördern, in die Überlegungen volkswirtschaftlicher Natur einfliessen und zu einer anderen Regelung 
führen sollten. Das steht alles noch offen; da müssen zuerst die Juristen durch ihre Rechtsprechung sagen, wie sie dieses Rechtsproblem sehen. Erst dann werden die Ökonomen die Entscheidung treffen, damit sowohl die Anbieter als auch die Nachfrager von parallelimportierten Arzneimitteln im Sinne der EU ihre Vorteile ziehen können.

\section{BASLER SCHRIFTEN ZUR EUROPÄISCHEN INTEGRATION}

O Wir bestellen die Schriftenreihe im Jahresabonnement zu CHF 120.-. Das Abonnement verlängert sich automatisch um ein Jahr, wenn es nicht drei Monate vor Ablauf schriftlich gekündigt wird.

O Wir bestellen folgende Nummern zum Preis von CHF 20.- (Doppelnr 30.)

O Wir sind an einem Publikationsaustausch interessiert.

O Wir sind an Weiterbildungs-Unterlagen (Nachdiplomkurs) interessiert.

* vergriffen

O Nr. 1 Subsidiarität - Schlagwort oder Kurskorrektur (mit Beiträgen von Flavio Cotti, Jean-Paul Heider, Jakob Kellenberger und Erwin Teufel) (Doppelnummer)*

ONr. 2 Ein schweizerisches Börsengesetz im europäischen Kontext (Tagungsband/Doppelnummer)*

O Nr. 3 Martin Holland, The European Union's Common Foreign and Security Policy: The Joint Action Toward South Africa*

O Nr. 4 Brigid Gavin, The Implications of the Uruguay Round for the Common Agricultural Policy

ONr. 6 Urs Saxer, Die Zukunft des Nationalstaates

ONr. 7 Frank Emmert, Lange Stange im Nebel oder neue Strategie? Die aktuelle Rechtsprechung des EuGH zur Warenverkehrsfreiheit

ONr. 8 Stephan Kux, Subsidiarity and the Environment: Implementing International Agreements

O Nr. 9 Arbeitslosigkeit (mit Beiträgen von Christopher Boyd, Wolfgang Franz und Jean-Luc Nordmann)

O Nr.10 Peter Schmidt, Die aussenpolitische Rolle Deutschlands im neuen Europa

O Nr.11 Hans Baumann, Möglichkeiten und Grenzen der Sozialen Dimension nach Maastricht: Das Beispiel der Bauwirtschaft *

O Nr.12 Georg Kreis, Das schweizerische Staatsvertragsreferendum: Wechselspiel zwischen indirekter und direkter Demokratie 
ONr.13 Markus Lusser, Die europäische Währungsintegration und die Schweiz

O Nr.14 Claus Leggewie, Ist kulturelle Koexistenz lernbar?

O Nr.15 Rolf Lüpke, Die Durchsetzung strengerer einzelstaatlicher Umweltschutznormen im Gemeinschaftsrecht (Doppelnummer)

ONr.16 Stephan Kux, Ursachen und Lösungsansätze des Balkankonflikts: Folgerungen für das Abkommen von Dayton

O Nr.17 Jan Dietze/Dominik Schnichels, Die aktuelle Rechtssprechung des Europäischen Gerichtshofes zum Europäischen Gerichtsstands- und Vollstreckungsübereinkommen (EuGVÜ)

O Nr.18 Basler Thesen für die künftige Verfassung Europas (2. Aufl.)

O Nr.19 Christian Garbe, Subsidiarity and European Environmental Policy: An Economic Perspective

O Nr.20 Claudia Weiss, Die Schweiz und die Europäische Menschenrechtskonvention: Die Haltung des Parlaments 1969-1995

ONr.21 Gunther Teubner, Globale Bukowina: Zur Emergenz eines transnationalen Rechtspluralismus

O Nr.22 Jürgen Mittelstrass, Stichwort Interdisziplinarität (mit einem anschliessenden Werkstattgespräch)

O Nr.23 William James Adams, The Political Economy of French Agriculture

O Nr.24 Aktuelle Fragen der Wirtschafts- und Währungsunion (mit Beiträgen von Gunter Baer, Peter Bofinger, Renate Ohr und Georg Rich) (Tagungsband/Doppelnummer)

O Nr.25 Franz Blankart, Handel und Menschenrechte

O Nr.26 Manfred Dammeyer/Christoph Koellreuter, Die Globalisierung der Wirtschaft als Herausforderung an die Regionen Europas

O Nr.27 Beat Sitter-Liver, Von Macht und Verantwortung in der Wissenschaft

O Nr.28 Hartwig Isernhagen, Interdisziplinarität und die gesellschaftliche Rolle der Geistes- und Kulturwissenschaften

O Nr.29 Muriel Peneveyre, La réglementation prudentielle des banques dans I'Union Européenne

O Nr.30 Giuseppe Callovi/Roland Schärer/Georg Kreis, Citoyenneté et na- turalisations en Europe

O Nr.31 Peter Häberle, Gemeineuropäisches Verfassungsrecht

O Nr.32 Jacques Pelkmans, Europe's Rediscovery of Asia. Political, economic and institutional aspectsO Nr.34 Valéry Giscard d'Estaing, L'Union Européenne: Elargissement ou approfondissement?

O Nr.33 Maya Krell, Euro-mediterrane Partnerschaft. Die Chancen des Stabilitätstransfers

ONr.34 Valéry Giscard d'Estaing, L'Union Européenne: Elargissement ou approfondissement?

O Nr.35 Martin Holland, Do Acronyms Matter? The Future of ACP-EU Relations and the Developing World

O Nr.36 Andreas Guski, Westeuropa - Osteuropa: Aspekte einer problematischen Nachbarschaft

O Nr.37 Matthias Amgwerd, Autonomer Nachvollzug von EU-Recht durch die Schweiz - unter spezieller Berücksichtigung des Kartellrechts (Doppelnr.)

O Nr.38 Manfred Rist, Infotainment oder Sachinformation? Die Europäische Union als journalistische Herausforderung (Doppelnummer)

O Nr.39 Lothar Kettenacker/Hansgerd Schulte/Christoph Weckerle, Kulturpräsenz im Ausland. Deutschland, Frankreich, Schweiz

O Nr.40 Georg Kreis/Andreas Auer/Christoph Koellreuter, Die Zukunft der Schweiz in Europa? Schweizerische Informationstagung vom 15. April 1999 veranstaltet durch das EUROPA FORUM LUZERN

ONr.41 Charles Liebherr, Regulierung der audiovisuellen Industrie in der Europäischen Union

ONr.42/3 Urs Saxer, Kosovo und das Völkerrecht. Ein Konfliktmanagement im Spannungsfeld von Menschenrechten, kollektiver Sicherheit und Unilateralismus

O Nr.44/5 Gabriela Arnold, sollen Parallelimporte von Arzneimitteln zugelassen werden? Eine Analyse der Situation in der Europäischen Union mit Folgerungen für die Schweiz

ONr.46 Markus Freitag, Die politischen Rahmenbedingungen des Euro: Glaubwürdige Weichenstellungen oder Gefahr möglicher Entgleisungen?

ONr.47/8 Andrew Watt, „What has Become of Employment Policy?“- Explaning 
the Ineffectiveness of Employment Policy in the European Union

O Nr.49 Christian Busse, Österreich contra Europäische Union - Eine rechtliche Beurteilung der Reaktionen der EU und inrer Mitgliedstaaten auf die Regierungsbeteiligung der FPÖ in Österreich

O Nr.50 Thomas Gisselbrecht, Besteuerung von Zinserträgen in der Europäischen Union - Abschied vom Schweizerischen Bankgeheimnis?O Nr.51 Uta Hühn, Die Waffen der Frauen: Der Fall Kreil - erneuter Anlass zum Konflikt zwischen europäischer und deutscher Gerichtsbarkeit? EuGH, Urteil vom 11.1.2000 in der Rs. C-283/98, Tanja Kreil/BRD

ONr.52/3 Thomas Oberer, Die innenpolitische Genehmigung der bilateralen Verträge Schweiz - EU: Wende oder Ausnahme bei aussenpolitischen Vorlagen?

O Nr.54 Georg Kreis, Gibraltar: ein Teil Europas - Imperiale oder nationale Besitzansprüche und evolutive Streiterledigung.

O Nr.55 Beat Kappeler, Europäische Staatlichkeit und das stumme Unbehagen in der Schweiz. Mit Kommentaren von Laurent Goetschel und Rolf Weder.

ONr.56 Gürsel Demirok, How could the relations between Turkey and the European Union be improved?

O Nr.57 Magdalena Bernath, Die Europäische Politische Gemeinschaft. Ein erster Versuch für eine gemeinsame europäische Aussenpolitik

O Nr.58 Lars Knuchel, Mittlerin und manches mehr. Die Rolle der Europäischen Kommission bei den Beitrittsverhandlungen zur Osterweiterung der Europäischen Union. Eine Zwischenbilanz

O Nr.59 Perspektiven auf Europa. Mit Beiträgen von Hartwig Isernhagen und Annemarie Pieper

O Nr.60 Die Bedeutung einer lingua franca für Europa. Mit Beiträgen von Georges Lüdi und Anne Theme

O Nr.61 Felix Dinger, What shall we do with the drunken sailor? EC Competition Law and Maritime Transport

O Nr.62 Georg F. Krayer, Spielraum für Bankegoismen in der EU-Bankenordnung
O Nr.63 Philippe Nell, China's Accession to the WTO: Challenges ahead

O Nr.64 Andreas R. Ziegler, Wechselwirkung zwischen Bilateralismus und Multilateralismus Das Beispiel der Freihandelsabkommen der EFTAStaaten

O Nr.65 Markus M. Haefliger, Die europäische Konfliktintervention im burundischen Bürgerkrieg, („Arusha-Prozess“)von 1996 bis 2002

O Nr.66 Georg Kreis (Hrsg), Orlando Budelacci (Redaktion): Der Beitrag der Wissenschaften zur künftigen Verfassung der EU. Interdisziplinäres Verfassungssymposium anlässlich des 10 Jahre Jubiläums des Europainstituts der Universität Basel.

O Nr.67 Francis Cheneval, Die Europäische Union und das Problem de demokratischen Repräsentation.

O Nr.68 Politik und Religion in Europa. Mit Beiträgen von Orlando Budelacci und Gabriel N. Toggenburg.

O Nr.69 Chantal Delli, Das Wesen der Unionsbürgerschaft, Überlegungen anhand des Falls Rudy Grzelczyk gegen Centre public d'aide sociale d'Ottignies-Louvain-la-Neuve.

O Nr.70 Federica Sanna, La garantie du droit de grève en Suisse et dans la L'Union européenne.

O Nr.71 Elze Matulionyte, Transatlantic GMO Dispute in the WTO: WIII Europe futher abstain from Frankenstein foods?

Europainstitut der Universität Basel, Gellertstrasse 27, CH-4020 Basel, Schweiz, Tel. ++41 (0) 613179767 , FAX ++41 (0) 613179766 E-mail: europa@unibas.ch, Internet: www.europa.unibas.ch

\section{@ Europainstitut der Universität Basel 2005}

Alle Rechte vorbehalten. Nachdruck, auch auszugsweise, sowie die Verbreitung auf elektronischem, photomechanischem oder sonstigem Wege bedürfen einer schriftlichen Genehmigung des Europainstituts. 